\title{
People do not adapt. New analyses of the dynamic effects of own and reference income on life satisfaction
}

\author{
Caspar Kaiser* \\ Department of Social Policy and Intervention, \\ Wellbeing Research Centre \\ and \\ Nuffield College, University of Oxford \\ July 2020 \\ Published in Journal of Economic Behavior \& Organization ${ }^{\dagger}$
}

\begin{abstract}
Do people adapt to changes in income? In contradiction to much of the previous literature, I find no evidence of adaptation to income in GSOEP (1984-2015) and UKHLS (1996-2017) data. Furthermore, I find that people also do not adapt to changes in reference income. Instead, reference income effects may be subject to reinforcement over time. Following the empirical approach of Vendrik (2013), I obtain these findings by estimating life satisfaction equations in which contemporaneous and lagged terms for a respondent's own household income and their estimated reference income are simultaneously entered. Additionally, I instrument for own income and include lags of a large set of controls. What was found to be adaptation to raw household income in previous studies turns out to have been driven by reinforcement of an initially small negative effect of household size that grows large over time. Implications of this result for the estimation of equivalence scales with subjective data are discussed.
\end{abstract}

Keywords: subjective well-being, life satisfaction, adaptation, income comparisons, equivalence scales, GSOEP, BHPS, Understanding Society, UKHLS

JEL codes: D6, I31

\footnotetext{
*Nuffield College, 1 New Road, OX1 1NF, Oxford (UK). Email: caspar.kaiser@nuffield.ox.ac.uk

${ }^{\dagger}$ For the published version, see: https://doi.org/10.1016/j.jebo.2020.06.003. This is the final accepted version of a manuscript previously titled "People do not adapt to income changes: A re-evaluation of the dynamic effects of (reference) income on life satisfaction". All previous versions are available on the Open Science Framework. See: https://doi.org/10.31235/osf.io/qtgbn
} 


\section{Introduction}

When people earn more, they tend to become more satisfied with their lives. However, with time, people may grow accustomed to higher incomes. As a consequence, people's life satisfaction tends to decline. This phenomenon is commonly called adaptation. In the present study, I show that no significant adaptation to income can be observed in two of the data-sets (GSOEP and UKHLS ${ }^{1}$ ) that are most commonly used in the study of happiness.

With this paper I follow a large literature that evaluates whether people adapt to various life events more generally (for studies on adaptation in non-pecuniary domains, see e.g. Angeles, 2010; Clark et al., 2008; Hanglberger and Merz, 2011). There are some previous studies that investigate whether we adapt to income in life satisfaction (e.g. Di Tella et al., 2010; Di Tella and MacCulloch, 2010; Vendrik, 2013; Ferrer-i Carbonell and Van Praag, 2008; Wolbring et al., 2013). However, those studies do not form a consensus. Despite this lack of consensus, a number of authors assume that adaptation to income in life satisfaction has been empirically established (Sen, 1985; Nussbaum, 2000; Qizilbash, 2006; Schokkaert, 2007; Jayawickreme and Pawelski, 2012; Graham and Nikolova, 2015) Furthermore, adaptation has previously been put forward as a possible explanation for the well-known and much debated Easterlin Paradox (Clark et al., 2008; Easterlin, 2016; Clark, 2016). Thus, there is some importance to assessing whether adaptation to income in life satisfaction does in fact occur.

Before doing so, it is useful to clarify my terminology. By adaptation to income I mean that the absolute size of the long-run ${ }^{2}$ effect of income on life satisfaction is significantly smaller than the absolute size of the contemporaneous effect of income on life satisfaction. I further distinguish between partial and full adaptation. Partial adaptation refers to a situation in which the absolute size of the long-run effect is indeed significantly smaller, but where the long-run effect is nevertheless significant and of the same sign. In contrast, full adaptation occurs in situations where the contemporaneous effect is significantly larger than the long-run effect, and where the long-run effect is close to zero and insignificant. Following Vendrik (2013), I call the opposite of adaptation "reinforcement". Reinforcement occurs when long- and short-run effects have the same sign and when the absolute size of the long-run effect of income on life satisfaction is significantly larger than the absolute size of the short-run effect. An illustration of reinforcement, as well as full and partial adaptation is given in figure 1 .

In most studies adaptation to income is exclusively taken to be adaptation to own income. However, this need not be so. Given that we know that the incomes of peers (henceforth, "reference incomes") tend to have negative contemporaneous effects on life satisfaction (e.g. McBride, 2001; Ferrer-i Carbonell, 2005; Vendrik and Woltjer, 2007), it may well be that such reference incomes could also be subject to either adaptation or reinforcement. If so, it is useful to estimate the combined short- and long-run effects of both own and reference income. Such estimates can be obtained by simply taking sums of the effects of own and reference income. Substantively, these effects can be interpreted as the short- and long-run effects of simultaneously increasing (or decreasing) an individual's, as well as her reference group's income by the same amount. Only if this combined long-run effect is positive would an increase in the income of all also increase the happiness of all. Crucially, the oft-debated Easterlin paradox denies that this combined long-run effect is positive.

\footnotetext{
${ }^{1}$ Which is a combination of the older British Household Panel Study (BHPS) and its successor Understanding Society.

${ }^{2}$ I take the long-run to be a situation in which income and life satisfaction are unchanging and in equilibrium with respect to each other.
} 

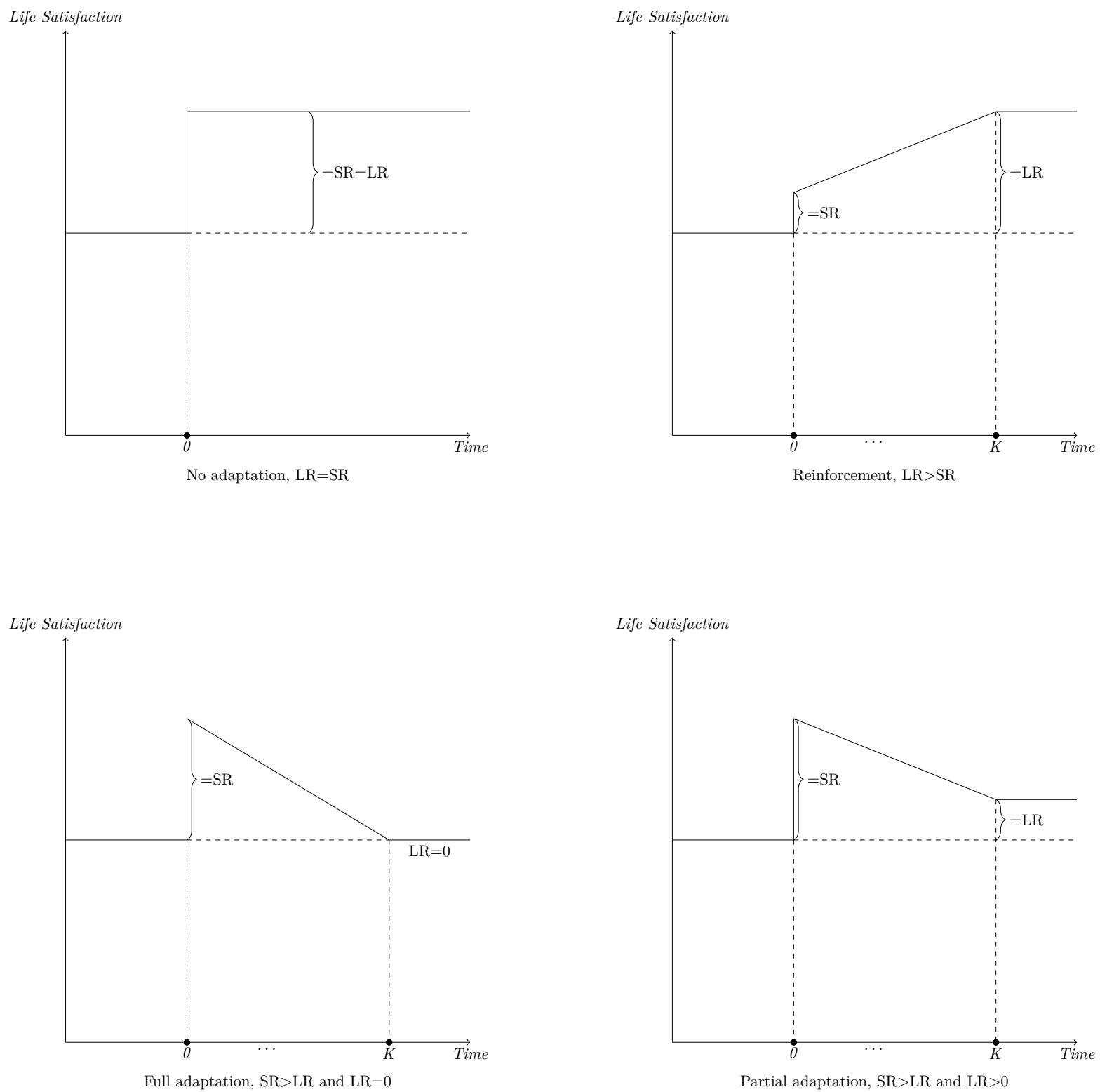

Figure 1: Adaptation types. In all cases a positive and persistent income shock occurs at time zero. I assume that higher incomes have a positive effect on life satisfaction and that the adaptation process ends after $K$ periods. 
The present paper builds on the empirical approach of Vendrik (2013), which seems to be the most robust study on adaptation to income to date. I give a much needed attempt at corroboration of that paper's main ideas with updated GSOEP data (with ten additional waves). This attempt at corroboration is well justified, since the results of Vendrik (2013) appear to suffer from a crucial omitted variable bias, namely the omission of partner employment status. With the addition of this variable, all evidence of adaptation disappears.

Beyond that, as the first in the literature on adaptation to income, I explicitly compare estimates obtained from the two main surveys used in the literature on subjective well-being, i.e. the GSOEP and UKHLS. Given that it often seems in the literature as though results obtained from surveys that are representative of the population of one particular country are generalizable to all industrialized countries, it is especially important to investigate whether this implicit assumption does in fact hold. This is particularly true today, when it has become apparent that many results in psychology and economics are not replicable (Earp and Trafimow, 2015; Chang and Li, 2018), while there is still a lack of attempts at replication (Hamermesh, 2007).

My key substantive findings are summarized as follows: Firstly, no adaptation to income can be observed in any of the preferred specifications. This holds true independently of the country considered and whether an instrument for own income was used or not. Secondly, all previous evidence of adaptation was driven by omitted variable bias; most crucially via the omission of lags of controls for household composition and partner employment status. Thirdly, my estimates of the combined long-run effects are always insignificant, thus corroborating the Easterlin Paradox.

The next section provides a review of the literature. Section 3 outlines my empirical approach and data. In section 4, I present my results. I make some concluding remarks in section 5 .

\section{$2 \quad$ Literature Review}

The study by Di Tella et al. (2010) is the most well known and widely cited ${ }^{3}$ work on adaptation to income in life satisfaction. Because of that I will take their approach as my baseline for the analysis to follow in section 4. Using data from GSOEP (1984-2000; restricted to West Germany), they regress life satisfaction on the contemporaneous level of (the ln of) real post-tax household income, as well as up to 4-year lags of this income measure. To test for adaptation, they perform tests on the significance of the sum of these lags as a well as the sum of lags and the contemporaneous coefficient. They obtain a large positive contemporaneous effect $(=0.23)$, find clear evidence for adaptation $\left(\sum\right.$ lags $\left.=0.15\right)$, and cannot reject the hypothesis of full adaptation. In a follow-up, Di Tella and MacCulloch (2010) replicate these findings with up to 7 rather than 4 year lags. They only find evidence of adaptation for home owners, showing that adaptation to income levels may be moderated by levels of wealth.

Ferrer-i Carbonell and Van Praag (2008) follow a different strategy. Also using GSOEP data (20002004), they use first differences to account for individual fixed effects. They also use post-tax household income as their measure of income and include up to 4-year lags. In total, they run four specifications, one without any controls, one with levels of a standard set of contemporaneous demographic controls, one using the first differences of all controls, and finally one with their lagged first differences. When using no controls they find adaptation of about $60 \%$. However, when using contemporaneous terms of their

\footnotetext{
${ }^{3}$ Google Scholar citation count: 535 (31.10.2019)
} 


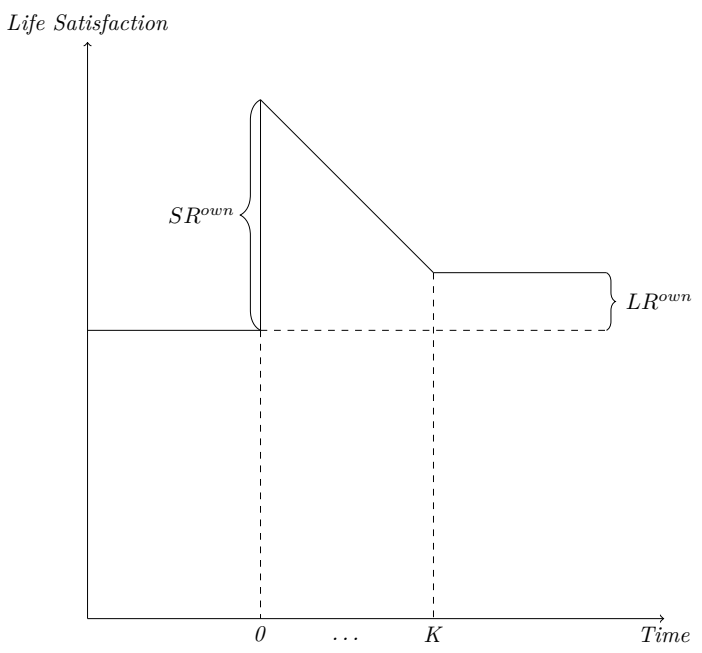

Long- and short-run effects of own income; partial adaptation

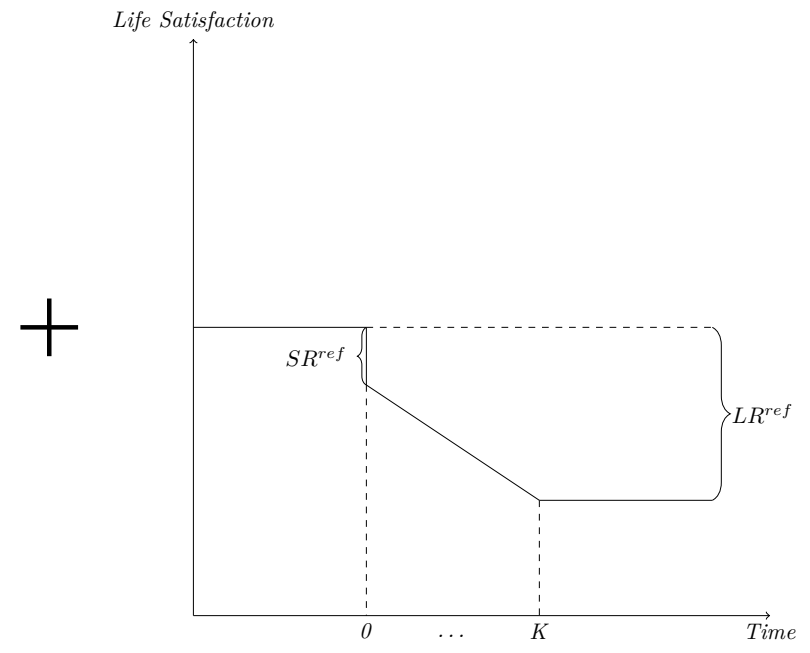

Long- and short-run effects of reference income; reinforcement

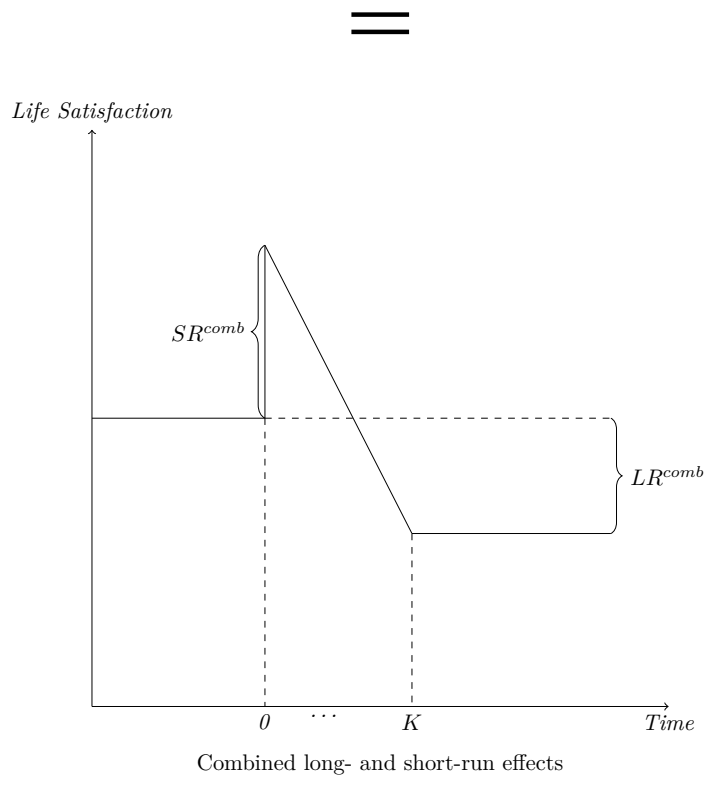

Figure 2: Illustration of how different adaptation/reinforcement patterns in own and reference income may yield a distinct pattern for the combined effects. I assume partial adaptation in own income and reinforcement in reference income. Combining these effects results in a positive short-run and a negative long-run effect. 
controls, they obtain evidence of full adaptation. In contrast, when using all lags of the first differences, observed adaptation is reduced to as little as 40\%. Ferrer-i Carbonell and Van Praag do not offer an explanation for these strange results.

Pfaff (2013) makes use of both GSOEP (1992-2010, separating East- and West- Germany) and BHPS (1996-2008) data. In the main, his estimation strategy is identical to that of Di Tella et al. (2010). He obtains effect sizes that are much larger for Germany than for the UK, but does not comment on this puzzling result. After experimenting with different income measures, it turns out that he only finds evidence of (complete) adaptation when either using labor income or raw real net household income; but not when using equivalized household income. Like Ferrer-i Carbonell and Van Praag in the case of their peculiar results, Pfaff does not give an explanation for this strange result. He simply notes that equivalized incomes are to be preferred for what he views as theoretical reasons (see p.7). Binder and Coad (2010), who use a somewhat different estimation strategy, face the same puzzlement as Pfaff (2013): when using raw household income they obtain evidence of adaptation, but when using equivalized household income they fail to do so. Further studies on adaptation with similarly inconclusive results include those by Van Praag (1971), Clark (1999), Stutzer (2004), Easterlin (2005), Frijters et al. (2011) and Paul and Guilbert (2013).

There is a large literature on reference incomes. However, almost all of them simply focus on the contemporaneous effects of reference incomes. Although there is a small literature that measures reference incomes directly via the subjective assessments of respondents (e.g. Senik, 2009; Mayraz et al., 2009; Goerke and Pannenberg, 2015; Dumludag et al., 2016; Clark et al., 2017 ), most studies compute reference incomes on the basis of cell means in income of a presumed reference group. Such groups may either be defined in spatial terms (e.g. Luttmer, 2005; Kingdon and Knight, 2007; Ifcher et al., 2018), or in terms of similar demographic characteristics, particularly age and education (e.g. McBride, 2001; Ferrer-i Carbonell, 2005; Vendrik and Woltjer, 2007; Vendrik, 2013). However, this choice seems not to generally matter, yielding negative effects for contemporaneous reference incomes that tend to roughly equal the contemporaneous effects of own income. ${ }^{4}$ To my knowledge, only D'Ambrosio and Frick (2012), and Vendrik (2013) study adaptation/reinforcement to reference income. Unfortunately, D'Ambrosio and Frick (2012) only include one-year lags and estimate the effects of reference income in a way that makes it difficult to explicitly recover the dynamics and relative strengths of the (combined) long-run, short-run and adaptation effects of own and reference income.

Vendrik (2013) may be the most robust investigation on both adaptation to own as well as reference income. He also uses GSOEP data (1984-2007; restricted to West Germany). In the main, he combines the approaches of Ferrer-i Carbonell and Van Praag (2008) and Di Tella et al. (2010) and regresses life satisfaction on the current ln of equivalized real net household income and reference income as well as lags of both variables. He also includes lags of all his control variables. Moreover, he includes a term for one-year lagged life satisfaction, yielding an error correction model that implicitly models effects of unincluded lags of income in the further past. In the main analyses he instruments income using the approach of Luechinger (2009) and Luttmer (2005). When simply using observed income, Vendrik is unable to obtain any evidence of adaptation to own income. However, in his (seemingly) more robust regressions where he instruments for own income he does obtain evidence of adaptation. He further finds

\footnotetext{
${ }^{4}$ Especially in volatile economies this negative effect may not hold. It may instead be dominated by a positive "signaling" effect. See Senik (2004, 2008).
} 
a negative long-run effect of reference income that is larger than that of own income.

Four key points may be taken from this literature review. First, whether we observe adaptation to own income depends on whether we use equivalized or raw household income, and whether we instrument for own income. Only in the case of raw household income or instrumented income, do we observe adaptation (e.g. Pfaff (2013) and Binder and Coad (2010)). Second, we observe less adaptation to own income when including lagged terms of controls (Ferrer-i Carbonell and Van Praag, 2008; Vendrik, 2013). Third, with respect to adaptation to reference income and from today's viewpoint, the only (to my knowledge) viable study is the one of Vendrik (2013). Fourth, there seem to be almost no studies doing cross-country comparative work. The working paper of Pfaff (2013) is the only exception, but he does not comment on the comparative aspect. The present study attempts to address each of these points.

\section{$3 \quad$ Empirical strategy and data}

\subsection{Econometric specification}

I start with a distributed lag model very similar to that of Di Tella et al. (2010), with the main difference being my inclusion of reference incomes:

$$
L S_{i, t}=\sum_{k=0}^{K} \beta_{0-k} \ln \left(y_{i, t-k}\right)+\sum_{k=0}^{K} \gamma_{0-k} \ln \left(y_{i, t-k}^{r e f}\right)+\phi X_{i, t}+\mu_{i}+\tau_{t}+\epsilon_{i, t}
$$

Here $L S_{i, t}$ is the (reported) life satisfaction of individual $i$ at time $t, y_{i, t}$ is a measure of own household $(\mathrm{HH})$ income, $y_{i, t}^{r e f}$ is a measure of reference income, $\mu_{i}$ is an individual fixed effect, $\tau_{t}$ is a year fixed effect and $\epsilon_{i, t}$ is assumed to be a normally distributed error term. $X_{i, t}$ is a vector of time-varying controls thought to be correlated with both income and life satisfaction. These include: dummies for numbers of children and adults in the household, employment status of the respondent, employment status of the respondent's partner, dummy for child birth, age, age-squared, marital status, housing tenure, job hours, dummy for illness, region dummies, and a region-specific linear time trend. These controls are similar to those chosen by Di Tella et al. (2010) and Vendrik (2013). A precise description of each of these variables is given in table D.1 of the online appendix.

In this set-up, the contemporaneous, or short-run $(S R)$, effect of own income on life satisfaction is given by the contemporaneous effect:

$$
S R=\beta_{0}
$$

In general, the long-run $(L R)$ effect is given by the contemporaneous effect, plus the sum of all lags of own income:

$$
L R=\sum_{k=0}^{\infty} \beta_{0-k}
$$

However, I assume $\beta_{0-k}=0 \forall k>K$ in the special case of equation (1). Thus in equation (1), the $L R$ effect is given by $\sum_{k=0}^{K} \beta_{0-k}$. The total effect of adaptation, i.e. the degree to which the effect of income 


\section{Life Satisfaction}

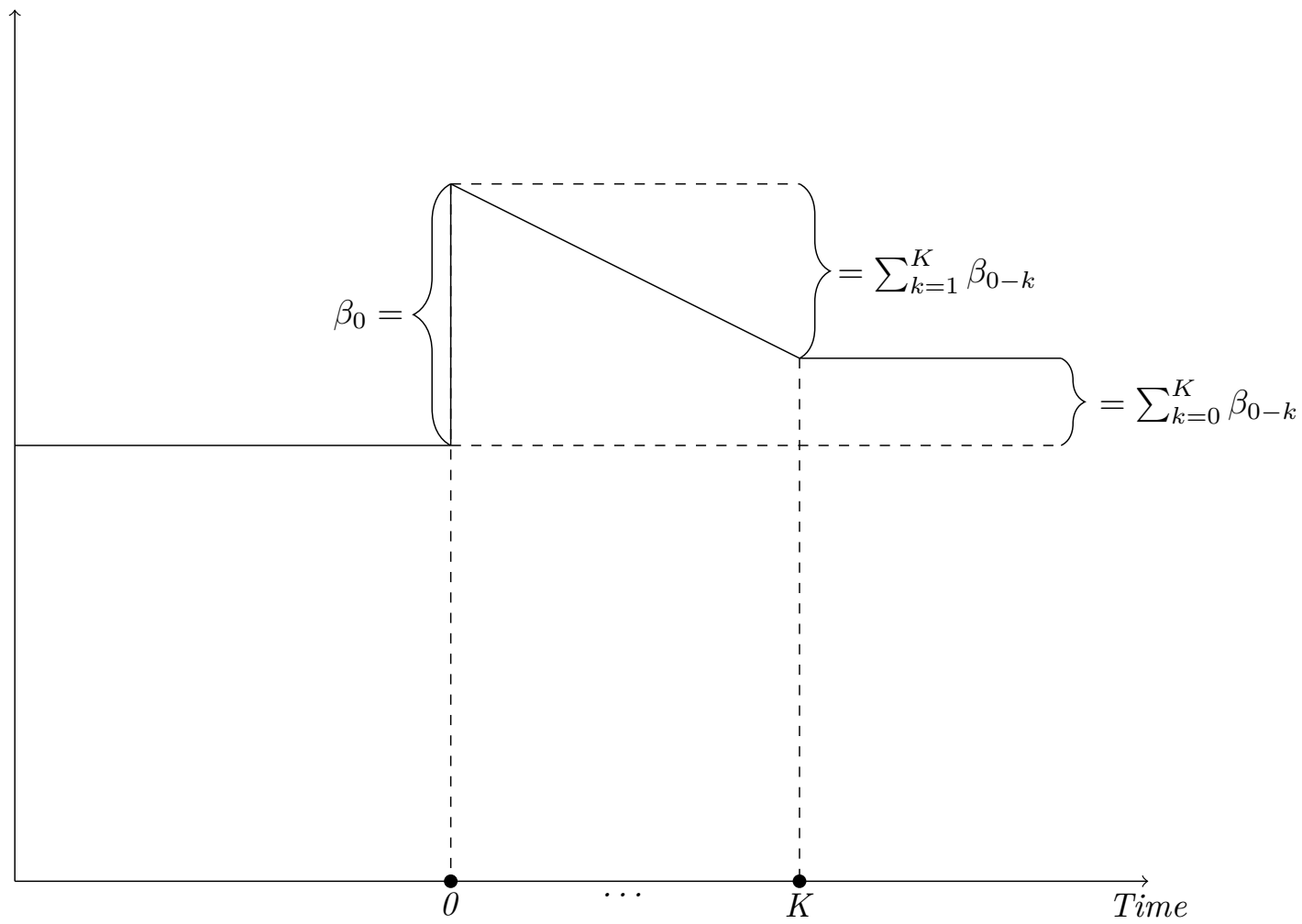

Figure 3: Illustration of the process modeled in (1) and (5). A positive and persistent income shock in own income is experienced at time zero. I assume partial adaptation.

dissipates with time, is given by the sum of all lags of own income: ${ }^{5}$

$$
A D A P=\sum_{k=1}^{\infty} \beta_{0-k}
$$

We may also generally say that adaptation is given by the difference between the long-run and the contemporaneous effect (i.e. $A D A P=L R-S R$ ). All of this is illustrated in figure $3 .{ }^{6}$ The same reasoning applies to the estimates of the $S R, L R$, and adaptation effects of reference incomes. When looking for the respective combined effects, we may simply take the sums of the effects of own and reference income.

The review in section 2 showed that controlling for lagged terms of controls can drastically change results. The reason for this may be as follows: controlling for $X_{i, t}$ stems from the belief that $X_{i, t}$ is

\footnotetext{
${ }^{5}$ Or $\sum_{k=1}^{K} \beta_{0-k}$ in the case of (1))

${ }^{6}$ The study of Wolbring et al. (2013), where they also attempt to study adaptation to income in life satisfaction, pursues an altogether different approach. They exclusively use lagged first differences (up to three) and no term for the level of income, i.e $L S_{i, t}=\gamma_{o} \Delta \ln \left(y_{t}\right)+\gamma_{1} \Delta \ln \left(y_{t-1}\right)+\gamma_{2} \Delta \ln \left(y_{t-2}\right)+\phi X_{i, t}+\mu_{i}+\epsilon_{i, t}$. They state that if the effect of the first differences declines as one moves to higher order lags (i.e. if $\gamma_{0}>\gamma_{1}>\gamma_{2}$ ), there is evidence of adaptation. This is indeed what they find. However, such an interpretation is not warranted. All this would imply is that more recent changes in income have a stronger effect on life satisfaction. In fact, their model presumes that full adaptation will occur. This can be see by rewriting the model as $L S_{i, t}=\gamma_{o} \ln \left(y_{i, t}\right)+\left(\gamma_{1}-\gamma_{0}\right) \ln \left(y_{i, t}\right)+\left(\gamma_{2}-\gamma_{1}\right) \ln \left(y_{i, t-2}\right)+\left(-\gamma_{2}\right) \ln \left(y_{i, t-3}\right)+\ldots$ Applying the formula above gives $L R=0$ (all terms cancel), $S R_{0}=\gamma_{o}$, and $A D A P=-\gamma_{o}$.
} 
correlated with $y_{i, t}^{\text {own }}$ and $L S_{i, t}$. If this is so, we must also also believe that $X_{i, t-k}$ is correlated with $y_{i, t-k}^{\text {own }}$. Given the literature on adaptation to various life events (Angeles, 2010; Clark et al., 2008; Hanglberger and Merz, 2011), we may have further reason to believe that at least some variables in $X_{i, t-k}$ will also be correlated with $L S_{i, t}{ }^{7}$ If this is so, my estimates of the long-run, short-run and adaptation effects would have to be biased. In particular, any observed adaptation to income may be driven by unobserved adaptation to changes in any of the covariates in $X$. Hence I should further extend the model by adding lags of all control variables that are not perfectly collinear with its contemporaneous values. ${ }^{8}$ This is similar to the approach of Ferrer-i Carbonell and Van Praag (2008) and Vendrik (2013). When adding such lags, I always include as many lags as used for the own and reference income terms (indicated by $K)$. The model thus becomes:

$$
L S_{i, t}=\sum_{k=0}^{K} \beta_{0-k} \ln \left(y_{i, t-k}\right)+\sum_{k=0}^{K} \gamma_{0-k} \ln \left(y_{i, t-k}^{r e f}\right)+\sum_{k=0}^{K} \phi_{0-k} X_{i, t-k}+\mu_{i}+\tau_{t}+\epsilon_{i, t}
$$

When attempting to compare effects obtained from UKHLS and GSOEP and to account for the limited coverage of the UKHLS, I restrict the observation window for GSOEP to start in 1996. Moreover, I use the same income concept (at baseline: real net household income) ${ }^{9}$, and use comparable controls (see online appendix table D.1) across both countries.

Furthermore, to make sure that lags are comparable and so that only yearly adaptation dynamics are indeed captured, I exclusively include observations that occur within a time-frame of 10 to 14 months in succession. ${ }^{10}$ Finally, I treat life satisfaction as cardinal. Ferrer-i Carbonell and Frijters (2004), Van Praag and Ferrer-i Carbonell (2008) and Riedl and Geishecker (2014) showed that ratios of coefficients and levels of significance from OLS regressions are not much different from ordered probit regressions.

\subsection{Instrumenting}

There are two main objections to directly using observed own income for estimation. First, income is measured with error. Such error may be driven by individuals not being able to accurately report on their income, the need to impute income in some cases, or inaccuracies in the tax-simulation routines used to arrive at net incomes. Such measurement error may lead to attenuation bias towards zero of the estimated effects. Second, there may unobserved costs to income generation, e.g. stress or increased commuting times, which may present a downward bias.

To alleviate these concerns, I instrument income following the approach first pursued by Luttmer (2005) and later adopted by Luechinger (2009) and Vendrik (2013). This approach goes as follows: For each wave, I predict real individual labor earnings using the respondent's age, age-squared, gender and a large set of occupation and industry dummies. Thus, for each wave, I run a regression of the form:

\footnotetext{
${ }^{7}$ It may further be that elements in an appropriately constructed vector $X_{i, t}^{r e f}$, e.g. levels of unemployment in the reference group, would behave similarly. I omit this complication from the present investigation.

${ }^{8}$ This turns out to make a large difference to my results. The aforementioned studies investigating adaptation to non-monetary life events may therefore also be affected by this problem.

${ }^{9} \mathrm{I}$ choose not to convert Pounds into Euros. Under the assumption that the separate series for inflation used to obtain a household income measure in constant prices in each country are comparable, my use of lns for all income terms in all estimations, as well as my use of year fixed effects, renders such a conversion unnecessary.

${ }^{10} \mathrm{I}$ thank an anonymous reviewer for this point. Unfortunately, enforcing that all observations must strictly occur within 12 months intervals leads to an exceedingly large drop in panel observations and was thus not possible.
} 


$$
y_{i}^{\text {labour }}=\alpha+\beta_{1} M A L E+\beta_{2}, A G E+\beta_{3} A G E^{2}+\delta_{\text {ind }} I N D U S T R Y_{i}+\phi_{o c c} O C C U P A T I O N_{i}+\epsilon_{i}
$$

Here $\delta_{\text {ind }}$ and $\phi_{\text {occ }}$ are industry- and occupation-specific parameters. I use 3-digit ISCO88 codes for occupation, and 2-digit NACE codes for industry. Finally, I sum the predicted earnings of each individual in the household to obtain a measure of predicted household incomes. This constructed measure is then used to instrument for observed household income.

There are two main threats to the exclusion restriction of this instrument. The first concern is that there may be other time-varying effects on life satisfaction of industry or occupation beyond those of timevarying pecuniary returns. For example, it may be that individuals in the same industry/occupation form part of the individual's reference group. Although I control for reference incomes defined over education and age, there may nevertheless be an uncontrolled-for negative effect that would downwardly bias the IV estimate. Alternatively, it may be that some generally better paying industries/occupations have more pleasant work environments than others. This would yield an upward bias. I partially guard against the latter concern by adding contemporaneous and lagged dummies for each industry and occupation to the model. In line with the rest of the empirical approach, the number of lags used is always equal to the number of lags used for the income terms and all other controls. Note that the predicted incomes from which the IV is constructed are estimated separately at each wave. This is why they are not perfectly collinear with the industry/occupation dummies.

The inclusion of these dummies controls for all time-invariant effects of industry and occupation. The aforementioned biases are therefore restricted to occur only via time-varying non-pecuniary effects of industry and occupation. However, work conditions in some industries may for example have gotten better compared to others, while pay has increased too. Such a bias would not be captured by the added dummies.

The second concern is that respondents may choose to select into particular industries or occupations in anticipation of changes in income or other benefits that may impact life satisfaction. Pischke and Schwandt (2012) note that industry choice is indeed correlated with fixed characteristics of individuals. If individuals had no option to switch industries or occupations during the estimation period, such selection would not be a concern (since such differences would be captured by the individual fixed effects). However, clearly some individuals have the option (or are forced) to switch industries/occupations. In about $23 \%$ (Germany) and 28\% (UK) of all observations such switches occur. This may be problematic. As noted above, the addition of (lags of) dummies for industries and occupations capture the effects emanating from time-invariant pecuniary and non-pecuniary differences between industries/occupations. However, these dummies do not capture over-time changes in the differences between industries/occupations. Therefore, if people actively switch industries or occupations in anticipation of changes in industry- or occupation-specific pecuniary or non-pecuniary returns, and when the propensity to switch is correlated with unobservables, my estimates may still be biased. In a robustness test, I therefore exclude observations where a switch of industry/occupation occurred (see table R.9 of the online appendix). However, since failing to switch is also potentially endogenous, this is not a complete test.

Notice that all of these potential biases - and more are discussed in section 4.3 - apply equally to both contemporaneous and lagged own income. Therefore, although the absolute sizes of the short- 
and long-run effects may be biased in an unknown direction, their difference, i.e. the degree of adaptation/reinforcement, is potentially less biased. ${ }^{11}$

\subsection{Determining the number of lags}

A tricky question is what the appropriate number of lags $K$ is. On the one hand, one would wish to include very many lags in order to make the assumptions made for equations (5) as plausible as possible. On the other hand, adding more lags is problematic for two reasons: First the addition of each lag causes the loss of a large number of panel observations. Second, levels of income at $t$ and $t-1$ are highly collinear, thus also leading to a loss in efficiency of the estimates. Vendrik (2013) determines the number of lags by first starting with some large number of lags. He then conducts F- and t-tests of the (joint) significance of the highest lag of own and reference income. If all tests fail to reject the null hypothesis of (joint) equality to zero, he removes all highest order lags and repeats the process until he obtains at least one rejection. At baseline, this leads him to use a maximum lag length of 3 , while when including lagged life satisfaction and instrumenting for income, he finds an appropriate lag length of 1.

When I apply this approach I obtain a lag length of 1 for both the UK and Germany. Given that I have no need to use such a short lag length, I chose a more conservative lag-length of $K=3$ for my baseline estimates. This choice of $K=3$ is much closer to the choice of Di Tella et al. (2010), Pfaff (2013) and Ferrer-i Carbonell and Van Praag (2008) and many others in the literature who use a lag length of four. However, as it turns out these considerations turn out not to be very important, since my IV results on the full samples are largely robust to lag lengths between 1 and 6 for both the UK and Germany (see section 4.3). At higher order lags my instruments become weak.

\subsection{Data}

For Germany I use waves 1 to 32 of the German Socio-Economic Panel (GSOEP), spanning the time 1984-2015. For the UK, I use all available waves of the UKHLS, which combines waves $6-18^{12}$ of the BHPS and waves 1-8 of Understanding Society. This translates to the years 1996-2017. Previous work has indicated that incomes at the very top and the very bottom of the income distribution suffer from large measurement error (Berthoud and Bryan, 2011; Figari, 2012). Moreover, self-employed individuals are known to either under- or over-report their incomes (Hurst et al., 2013). For these reasons, I exclude the top and bottom $1 \%$ within each wave of household income, as well as all self-employed individuals from the analysis. Since very few individuals younger than 20 years or older than 70 years are observed to have labor earnings (which is needed to instrument household income), I also exclude all individuals that fall outside of this range.

In the UKHLS, Life Satisfaction is measured on a 1-7 scale, with respondents first being presented the statement "Here are some questions about how you feel about your life. Please tick the number which you feel best describes how dissatisfied or satisfied you are with the following aspects of your current situation. $1=$ Not satisfied at all $7=$ Completely satisfied". After a set of domain-specific questions, respondents are presented with the question: "Using the same scale, how dissatisfied or satisfied are you with your life overall?". Within the GSOEP, life satisfaction is measured on a 0-10 scale, with respondents answering

\footnotetext{
${ }^{11}$ I thank an anonymous reviewer for this point.

${ }^{12}$ I exclude waves 1-5, as life satisfaction is not observed for these waves. Life satisfaction is also not observed in wave 11. Hence, this wave is excluded, too.
} 

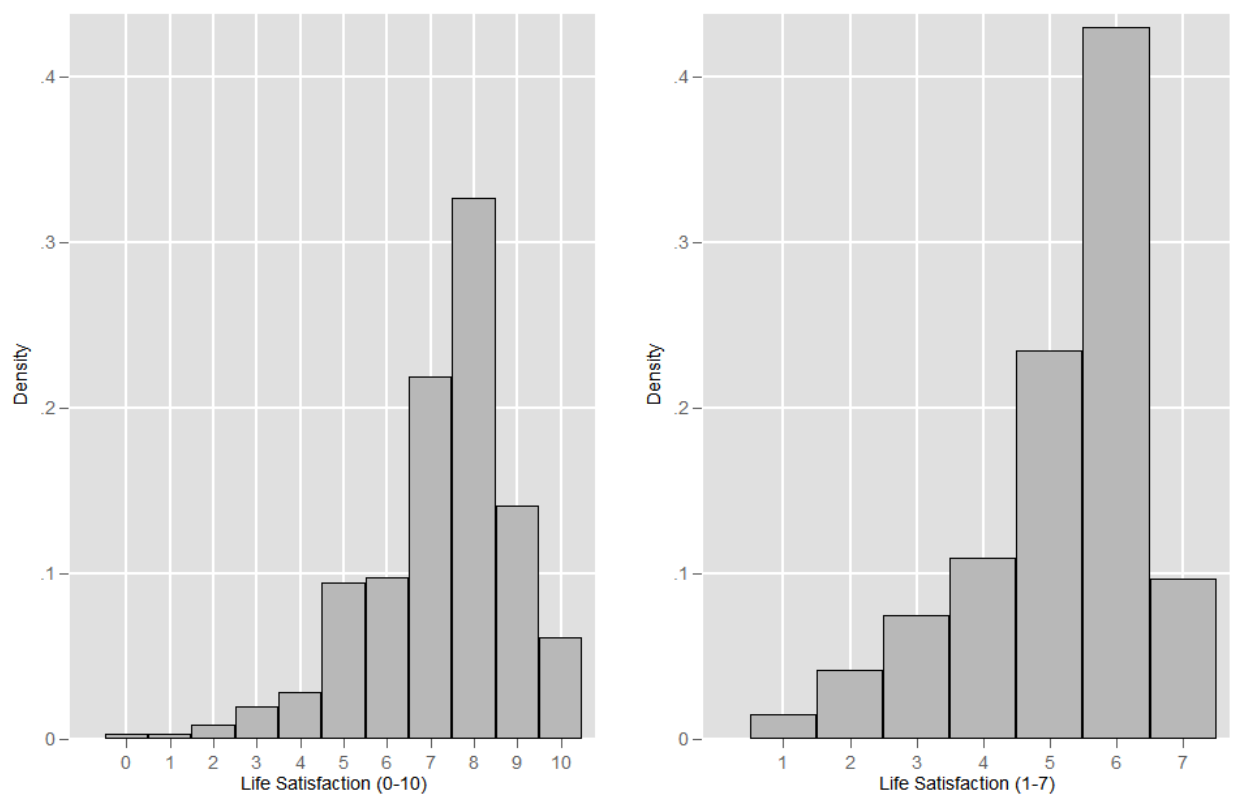

Figure 4: Distribution of life satisfaction in Germany (left) and the UK (right).

Table 1: Descriptive Statistics

\begin{tabular}{lcccccc}
\hline \hline & $\mathrm{N}$ & Mean & Median & SD & Min & Max \\
\hline Germany $(1984-2015)$ & & & & & & \\
Life satisfaction & 128850 & 7.179 & 8.000 & 1.629 & 0 & 10 \\
HH income $(2005 €)$ & 128850 & 39497 & 36790 & 16023 & 6086 & 124905 \\
Ln of HH income $(2005 €)$ & 128850 & 10.503 & 10.513 & 0.408 & 8.714 & 11.735 \\
Ln of ref.eq.HH income $(2005 €)$ & 128850 & 9.844 & 9.815 & 0.185 & 9.292 & 10.382 \\
\hline Germany (1996-2015) & & & & & & \\
Life satisfaction & 91776 & 7.156 & 7.000 & 1.610 & 0 & 10 \\
HH income $(2005 €)$ & 91776 & 40576 & 37756 & 16797 & 6100 & 124905 \\
Ln of HH income $(2005 €)$ & 91776 & 10.526 & 10.539 & 0.420 & 8.716 & 11.735 \\
Ln of ref.eq.HH income $(2005 €)$ & 91776 & 9.876 & 9.853 & 0.193 & 9.292 & 10.382 \\
\hline$U K$ (1996-2017) & & & & & & \\
Life satisfaction & 88170 & 5.195 & 6.000 & 1.269 & 1 & 7 \\
HH income $(2005 €)$ & 88170 & 31409 & 29148 & 14093 & 2602 & 114766 \\
Ln of HH income $(2005 €)$ & 88170 & 10.255 & 10.280 & 0.458 & 7.864 & 11.651 \\
Ln of ref.eq.HH income $(2005 €)$ & 88170 & 9.670 & 9.668 & 0.207 & 8.626 & 10.082 \\
\hline \hline
\end{tabular}


the question "In conclusion we would like to ask you about your satisfaction with your life in general, please answer according to the following scale: 0 means completely dissatisfied and 10 means completely satisfied: How satisfied are you with your life, all things considered?". As can be discerned from figure 4 , the distribution of responses to these questions is very similar across countries.

Regarding own income, unless otherwise noted and for both Germany and the UK, I use annual postgovernment (net of taxes and benefits) household income. This income variable is generated by Levy and Jenkins (2012) for the BHPS. It is directly provided in Understanding Society and the German SOEP. I deflate both income variables using the consumer price index (base=2005). In the main specifications, I do not adjust own household incomes for household size by means of an equivalization scale. This makes my specification most comparable to that of Di Tella et al. (2010). However, as made clear in section 4.4, including (lags of) controls for household composition is equivalent to equivalizing own incomes. Robustness regressions in which I use equivalized own household income verify this (see section 4.3). I define reference incomes by the mean annual equivalized net post-government household income of the set of individuals up to 5 years older or younger than the respondent, which have the same educational attainment as the respondent (as measured by a collapsed version of the CASMIN classification). Reference incomes are equivalized since explicitly controlling for household composition of the reference group would not be easily feasible. Generally, whenever an equivalization scale is used, I utilize the modified OECD scale. This scale assigns a weight of 1 to the first member of the household, a weight of 0.5 to every subsequent adult, and a weight of 0.3 for every child in the household. Definitions for all control variables can be found in table D.1 of the online appendix.

Table 1 provides summary statistics for my main variables of interest - household income and life satisfaction. The overall standard deviation of life satisfaction is roughly 1.62 in the German sample, whereas for the British sample it is roughly 1.30 . Thus, the ratio of standard deviations $(1.63 / 1.27 \approx 1.28)$ is reasonably similar to the ratios of the response scales $(11 / 7 \approx 1.57)$. This gives further assurance for my comparative purposes. ${ }^{13}$

The IV strategy primarily relies on variation in returns within occupations and industries. Therefore, tables D.2-D.5 in the online appendix show levels and year-to-year changes of observed and predicted household income across major occupational and industry groupings. Levels of income are ordered as one would expect across industry and occupation groupings (e.g incomes for the occupation grouping "professionals" are highest, and those for "agricultural workers" and "elementary occupations" are lowest). Unfortunately, no industry or occupation codes are observed for respectively $19.1 \%$ and $19.6 \%$ of included observations in Germany. For the UK, $11.3 \%$ (industry) and 10.4\% (occupation) of codes are missing. Most of these observations are of persons that are either unemployed, retired or otherwise outside the workforce. Since these individuals do not have labor incomes, they do not contribute to the construction of the instrument. They are nevertheless retained in the sample as other members of the household will have a labor income. In section 4.3, I show that my key conclusions do not depend on the inclusion of these observations.

Another source of variation in the instrument comes from individuals switching industry/occupation combinations. Tables D.2-D.5 of the online appendix also show levels and changes of observed and predicted income across observations in which such switches occurred and where they did not. In general,

\footnotetext{
${ }^{13}$ We need not expect these ratios to equal: It may well be that there is less variance in life satisfaction in Germany than in the UK.
} 
(predicted) household income levels do not differ much between stayers and leavers. However, and as may be expected, there is much greater variation in predicted income changes for switchers compared to leavers. This variation might primarily drive results. In section 4.3 I therefore discuss results which exclude these observations.

We may be concerned that the reference group (i.e. those of similar age and education) and the set of people with the same industry and occupation overlaps. Table D.6 of the online appendix provides summary statistics on the size of the reference group as well as its overlap with respondent's industries and occupations. The average size of the reference group is 702 and 848 persons in Germany and the UK, respectively. Although there is a small number of very small reference groups ${ }^{14}$, most reference groups have between 233 (1st percentile) and 1264 (99th percentile) members in Germany and between 185 and 1986 members in the UK. On average, only $6.4 \%$ (Germany) and 3.4\% (UK) of members in a reference group share the same industry and occupation combination as the respondent.

\section{Results}

Sections 4.1 and 4.2 present my main results for Germany and the UK, respectively. Section 4.3 provides extensive robustness checks which qualify these results. In section 4.4, I show how my estimates are relevant to the construction of equivalence scales that are sensitive to the short- and long-run.

\subsection{Results for Germany}

In this section, I present my results for my baseline estimations of variants of equations (1) and (5) using GSOEP data for the period 1984-2015. Thereafter, in section 4.2, I present results for the UK.

To provide a baseline, the estimates in column 1 of table 2 are obtained using equation (1) (i.e. no lags of controls), and do not instrument for own income. Throughout, I use 3-year lags for income. The estimates are thus closest to Di Tella et al. (2010). Like Di Tella et al. (2010), I find significant adaptation to own income that is roughly equal in magnitude to that which they find (-0.127 vs. -0.150 ; see their table 1 column 2). The contemporaneous effect that I obtain is similar to theirs (0.304 vs. 0.230). However, especially given my much larger sample (using an extra 15 years), I obtain a significant long-run effect, implying partial rather than full adaptation to own income. However, in column 2, I estimate equation (5), which thus now include lags of all controls. This inclusion has the important consequence that the long-run effect of own income is now slightly larger than the short-run effect. Consequently, all evidence of adaptation observed in column 1 vanishes in column 2. As explained in section 3.1, this suggests that significant adaptation observed in column 1 is the result of omitted variable bias, i.e. adaptation to one of the control variables which are correlated with income.

However, a crucial problem with these baseline results is that the sources of variation in own income are largely unknown and potentially endogenous. In particular, these estimates may suffer from reverse causality (more satisfied persons earn more), which may upwardly bias my estimates of both the shortand the long-run effects. Moreover, there may be unobserved hedonic costs to income generation (like stress), which negatively bias my effect estimates. Finally, measurement error in the income variable may present a further bias towards zero. To alleviate these concerns, columns 3 to 5 instrument for

\footnotetext{
${ }^{14}$ There are 92 and 4 observations with reference groups smaller than 10 members in Germany and the UK, respectively.
} 


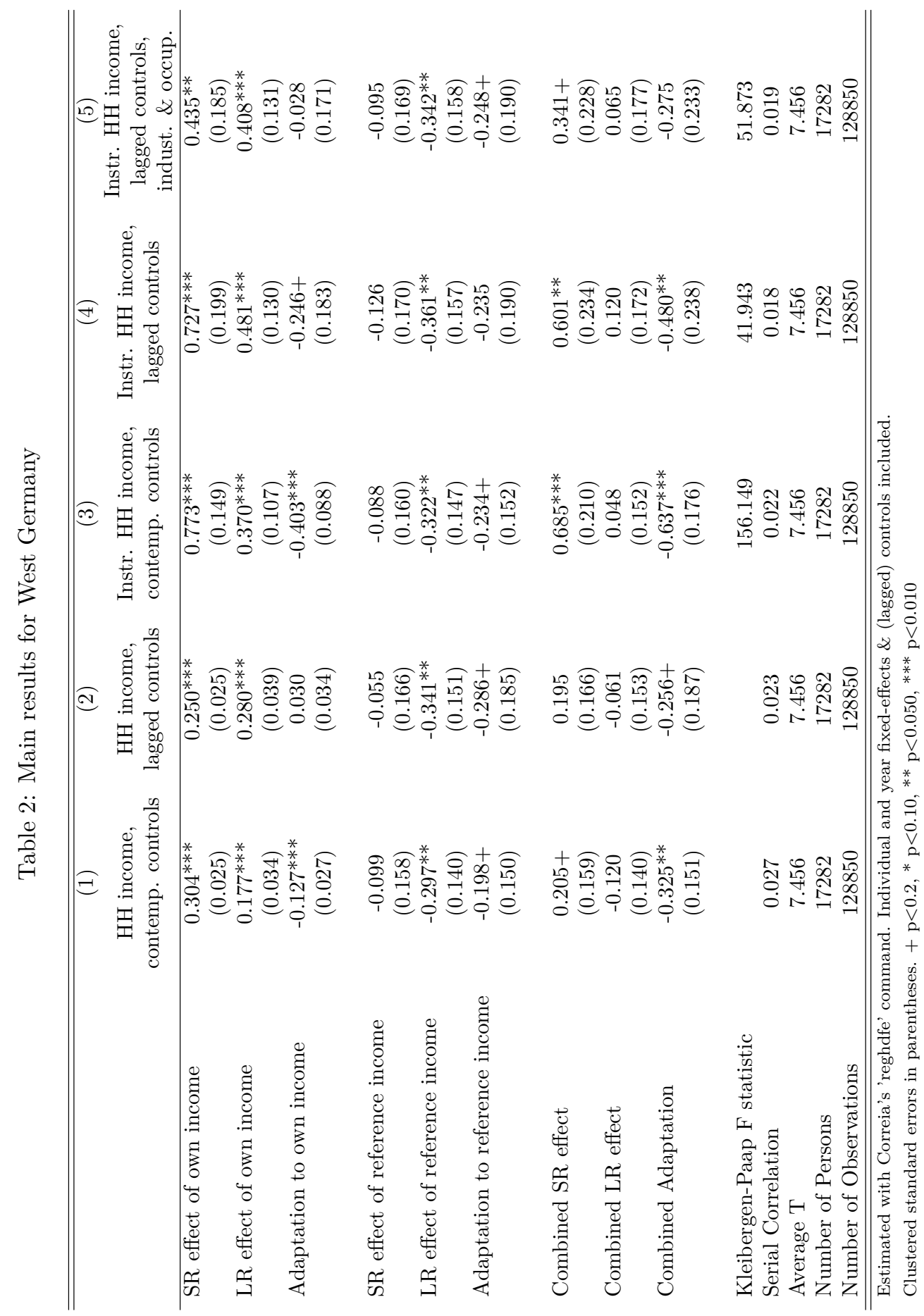


own income using the approach given in section 3.2. Generally, the effects estimates for own income are increased when instrumenting. This difference is in line with Powdthavee (2010), Luechinger (2009) and Knight and Gunatilaka (2010) who also find effect increases when instrumenting. ${ }^{15}$ In column 3, no lags of controls are included. I now find significant adaptation again. However, as was the case previously, adaptation turns marginally insignificant when including lags of all controls $(p=0.18)$ in column 4 . Finally, in column 5 I include contemporaneous and lagged values of all industry and occupation dummies to the regression. This addresses the concern raised in section 3.2, namely that the instrument may pick up further time-constant non-pecuniary effects of industry and occupation choice. The inclusion of these dummies depresses the estimates of the short- and long-run effects of own income. Importantly, the estimate of the short-run effect is depressed much more than the estimate of the long-run effect. Consequently, my estimate of adaptation to own income is also much diminished and insignificant ( $p=$ 0.87). Changes in occupation and industry typically come about via job changes. It therefore appears that most of the (insignificant) adaptation observed in column 4 was driven by adaptation to changing jobs. I therefore take the estimates of column 5 to be the preferred specification. Nevertheless, further robustness tests are given in section (4.3).

My results contradicts the finding of Vendrik (2013) who finds significant adaptation to own income when instrumenting. In table R.17 of the online appendix, I investigate the sensitivity of my estimates to the exclusion of each control. That exercise reveals that when I fail to include partner's employment, I do obtain significant estimates of adaptation. It turns out that there is a large positive contemporaneous effect of partner employment that is subject to full adaptation after three periods. Especially for Women, partner employment is strongly correlated with (instrumented) household income. As Vendrik (2013) does not include partner's employment status (nor does any other study that I am aware of), it seems that the estimates of Vendrik (2013) also suffer from omitted variable bias.

Concerning reference incomes, I find an insignificant short-run effect throughout. However, the longrun effect is sizable and significant in all specifications. As a consequence, I observe (marginally) insignificant reinforcement of the reference income effect. Thus we observe that the short- and long-run effects are roughly constant for own income, but that the effect of reference income may grow over time. This has the consequence that the combined effect of own and reference income is positive, significant and sizable in the short-run, but becomes insignificant and close to zero in the long-run. These combined estimates may be interpreted as the marginal short- and long-run effects of equally sized and permanent income changes of both the respondent and all members of the respondent's reference group. ${ }^{16}$ Therefore, as everybody grows richer, mean satisfaction does not increase in the long-run. This is in line with the Easterlin Paradox.

\subsection{Results for the UK}

I now turn to comparative results for the UK and a comparison with Germany. I am not aware of any previous paper in the literature on adaptation in life satisfaction that has been strongly comparative. The working paper by Pfaff (2013) uses the BHPS and GSOEP simultaneously, but is not very comparative. This general lack of cross-country comparison is problematic: Much of the previous happiness literature

\footnotetext{
${ }^{15}$ Knight and Gunatilaka (2010) and Powdthavee (2010) use different instruments to the one employed here. Vendrik (2013) and Luechinger (2009) use the same kind of instrument.

${ }^{16} \mathrm{In}$ some of the specifications the combined adaptation estimate is significant. We can think of this as collective adaptation to a common income shock.
} 


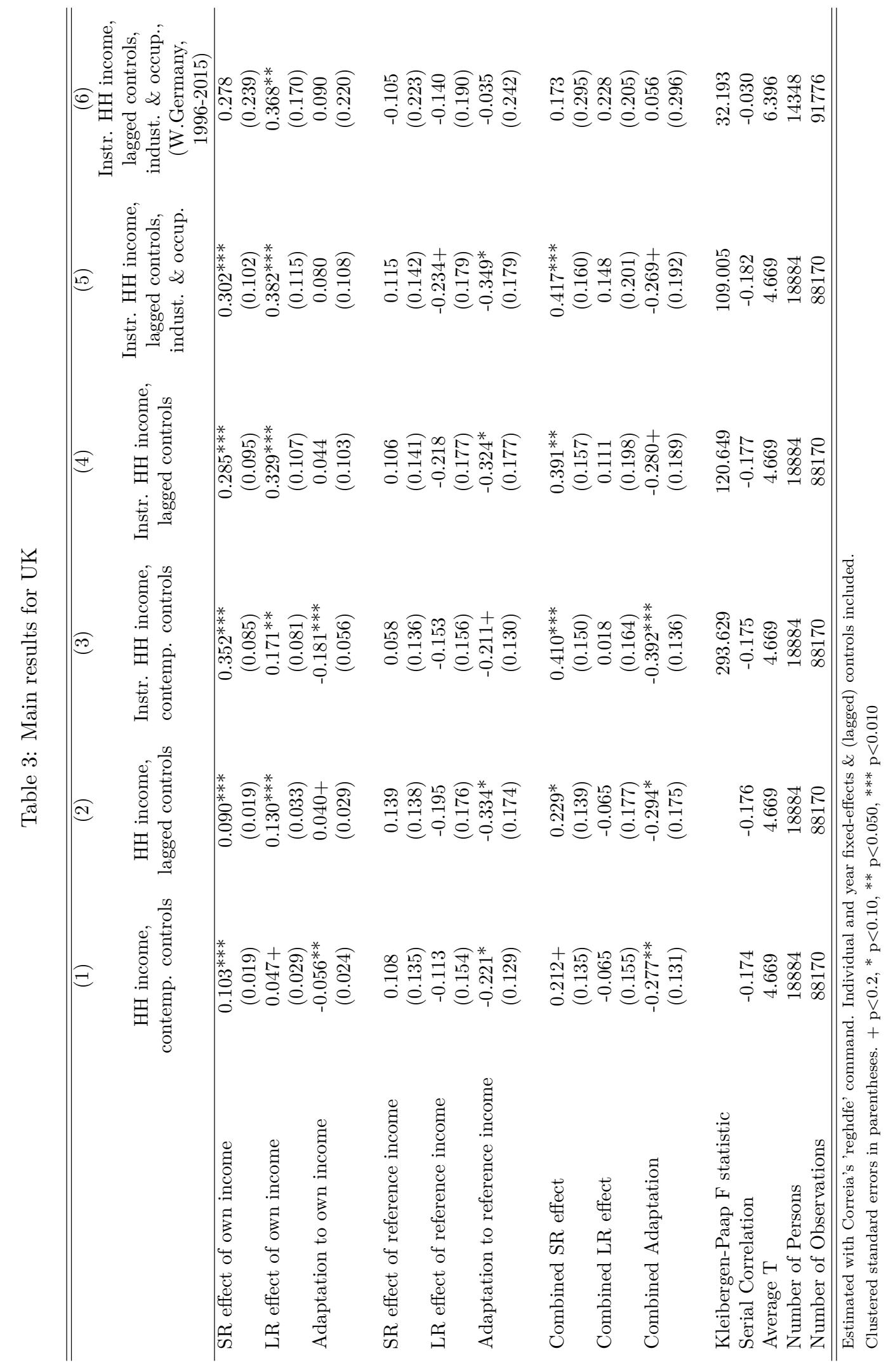


seems to implicitly view results that are obtained with data from only one country (i.e. Germany with GSOEP) as indicative of facts beyond this particular country (i.e. rich industrialized democracies). Pursuing a comparative approach is an informal test of this presumed external validity. Put differently, in response to a lack of replication and/or replicability in economics and psychology (Earp and Trafimow, 2015; Chang and Li, 2018), using UKHLS data alongside GSOEP data can be viewed as a replication of what is thought to be known from GSOEP data. To make results comparable I use the same set of controls for the UK as I did for Germany. Additionally I provide further estimates in which I restrict the estimation period for the German sample to the British sample as closely as possible.

Table 4 presents my results. Columns 1-5 mirror the econometric specifications of table 3. My substantive conclusions remain the same for the UK as for Germany. Both in the in the baseline and in the instrumented case, I find significant adaptation to own income when failing to include lags of controls (columns 1 and 3). However, when adding lags of controls, I find that the short-run effect of own income is smaller than the long-run effect (columns 2, 4, 5). This indicates (insignificant) reinforcement rather than adaptation. Unlike the case for Germany, the addition of dummies for industries and occupations makes little difference to my effect estimates (column 5).

As was the case previously, I find smaller effect estimates when using observed own income rather than instrumenting own income. These non-instrumented estimates for the UK are also smaller than the equivalent results for Germany (see table 2), even accounting for the fact that the UK response variable has fewer response options ( $7 \mathrm{vs.11}$ ), and a smaller standard deviation. ${ }^{17}$ Similarly small estimates were obtained by Pfaff (2013). However, my instrumented long-run effect estimates are, also when accounting for differences in the response variable, reasonably close to those obtained for Germany (see column 6). ${ }^{18}$ Given that the BHPS does not directly provide net income data and had to be generated with external information by Levy and Jenkins (2012), it is may be that the large difference in estimates between observed and instrumented income is caused by attenuation bias due to measurement error.

Surprisingly, all short- and long-run estimates for reference income in the UK are insignificant. The short-run effect is even positive, which may be driven by a "tunnel" effect as proposed by Senik (2004) (borrowing from Hirschman and Rothschild (1973)). Individuals may initially welcome increased incomes of others as signaling future increases in their own income. However, as time passes, the classical envy effect starts to dominate. Moreover, my measure of reference income can only imperfectly proxy for true perceived reference income. As a consequence these estimates are biased toward zero and will likely be larger in reality. ${ }^{19}$ Finally, despite the statistical insignificance of the negative long-run effect of reference income, I also find that the combined long-run effects of own and reference income are again insignificant and close to zero. Thus, increasing the incomes of all fails to increase the satisfaction of all in the UK, too.

In column 6, I provide results for Germany when restricting the observation period to 1996-2015 for comparability. My estimates for own income are very similar to those obtained in table 2 (column 5) on the unrestricted period. Again, there is no evidence of adaptation. Instead, I find insignificant reinforce-

\footnotetext{
${ }^{17}$ Using column 2 of tables 2 and 3, standardizing effect sizes via the number of response categories yields that the UK long-run effect equals $71.3 \%\left(\frac{11 / 7 \times 0.127}{0.280}=0.713\right)$ of the German effect. Standardizing via the respective standard deviations yields that UK's effect equals $58.2 \%$ of the German effect $\left(\frac{1.629 / 1.269 \times 0.127}{0.280}=0.582\right)$.

${ }^{18}$ Using column 5 of tables 2 and 3 , the UK long-run effect equals $137.9 \%\left(\frac{11 / 7 \times 0.127}{0.280}=1.379\right)$ of the German effect adjusting for the number of response categories. Adjusting via standard deviations, yields the UK effect to equal $112.6 \%$ of the German effect $\left(\frac{1.61 / 1.30 \times 0.127}{0.280}=1.126\right)$.

${ }^{19} \mathrm{I}$ thank an anonymous reviewer for this remark.
} 
ment. Furthermore, my estimated reference income effects are much diminished and now insignificant. Consequently, the long-run effect of own and reference income combined is more positive, but remains insignificant.

\subsection{Robustness tests}

This section reports on a number of robustness checks against which the main results of the previous sections are tested. All tables relating to these tests can be found in the online appendix.

Recall that previous studies which found a significant estimate of adaptation used raw household income (Vendrik (2013) only found adaptation when instrumenting). Pfaff (2013) and Binder and Coad (2010) in particular observed adaptation when using raw household income, but did not do so when using equivalized household income. To evaluate the robustness of my own results, in tables R.1 (Germany) and R.2 (UK), I re-estimated the specifications of tables 2 (Germany) and 3 (UK), using equivalized rather than raw household income. When doing so, I mostly find no adaptation to own income even when failing to include lags of all controls. It can be shown that equivalizing income amounts to controlling for (lags of) changes in household composition (see section 4.4). Therefore, as hinted at by Vendrik (2013), the significant estimate of adaptation to income observed in columns (1) and (3) of tables 2 and 3 was largely driven by adaptation to changes in household composition. This explains the puzzling findings of Pfaff (2013) and Binder and Coad (2010). Some implications of this finding to the construction of equivalence scales are discussed in the next section.

I also analyze how using non-equivalized reference income affects my estimates. See table R.3. Doing so raises the short-run reference income effect to also become positive in Germany. As a consequence, the negative long-run effect is no longer significant for Germany. A potential explanation may be analogous to that for own income: In the short-run, individuals in Germany react positively to household formation in the reference group, but adapt to such a positive effect over time. However, this does not appear to hold in the UK where estimates are not much affected.

While Di Tella et al. (2010) use four-year lags, I only use three year lags. One may therefore worry that the main results presented here are an artifact of the chosen number of lags. In general it is useful to evaluate how the number of lags impacts results. Therefore, in tables R.4 (Germany) and R.5 (UK), I use the preferred specification in column 5 of tables 2 and 3, but vary the number of lags from zero to six (with more lags, the instrument becomes weak). In tables R.6 and R.7, I apply the same procedure to the specification of column 4 in tables 2 and 3 (i.e. without the industry and occupation dummies). In general, results are quite robust to varying the number of lags. In Germany, the long-run effects of both own and reference income become larger with the addition of each lag, suggesting reinforcement rather than adaptation. In the UK, for $K>4$, the long-run effect of own income becomes insignificant, and is sometimes smaller than the short-run effect. However, the adaptation estimate remains insignificant. Thus, overall my key conclusion are robust to the choice of the number of lags.

It may be that individuals anticipate income changes. If so, the adaptation process may begin prior to the actual income change. As a consequence, the estimate of the short-run effect of own income would be biased downward and the adaptation estimate would be biased towards zero. To evaluate whether this is a concern, in table R.8 I replicate tables columns (4) and (5) of tables 2 and 3, but add a lead of own income and leads of controls to each specification. For both own and reference income, I here

define the "short-run effect" as the sum of the contemporaneous and the anticipation effect. Despite an 
increase in magnitude, I continue not to find a significant adaptation effect for own income, though the anticipation term is always positive. With respect to reference income, I also find a positive anticipation effect for both countries, with the total short-run effect always being smaller than the anticipation effect. This is in line with the hypothesized signaling function of reference income.

My instrument relies on over-time variation in industry/occupation premia that accrue to individuals. As already noted in section 3.2, variation in the instrument may either occur via variation within an industry/occupation combination, or via individuals switching into other industries/occupations (i.e. changing jobs). Such job switching behavior may be endogenous. To gauge the severity of this potential issue, table R.9 replicates columns (4) and (5) of tables 2 and 3, but restricts the sample to those that did not switch industries/occupations in the year they are observed. Doing so reduces the short-run effect, but generally increases the long-run effect of own income in both countries (but much more so in Germany). The long-run reference income effect for Germany is also diminished. Nevertheless, none of the key conclusions are affected. However, since the choice not to switch jobs may also be endogenous, these estimates cannot be regarded as a complete test of this concern.

The instrument also relies on being able to assign (where available) a unique industry and occupation to each respondent. However, when people have a second job this may not be possible. ${ }^{20}$ This is the case in $6.4 \%$ and $6.6 \%$ of observations in Germany and the UK, respectively. In table R.10, I exclude these observations and thereby evaluate whether my results depend on them. Moreover, and as a separate concern, since the instrument is estimated from within the sample, individuals to whom these estimates are assigned contribute to these estimations. To address this endogeneity concern, table R.11 excludes observations in which the number of people with the same occupation or industry in the same wave as the respondent is smaller than $50 .{ }^{21}$ The main results of tables 2 and 3 are not substantially affected by either of these exclusions.

Some individuals will be included in the sample who do not have an income of their own (due to e.g. unemployment or retirement). For these individuals, any variation in predicted household income will depend on other household members. While the inclusion of these individuals need not bias my estimates, these respondents may nevertheless react differently to variation in predicted household income than those who have a labor income of their own. Therefore, table R.12 excludes these individuals from my estimations. For Germany, their exclusion results in a much diminished short-run effect of own income, which is in line with the previous hypothesis that adaptation to job changes may drives the negative (though insignificant) estimate for adaptation in column 5 of table 2. My long-run effect estimates for reference income are also somewhat diminished and now insignificant.

The instrument for own income and (true) reference income may be positively correlated. The inclusion of reference income could then move the estimates for own income upwards (though this would not constitute a bias). In tables R.13 and R.14, it is shown that removing reference income from the estimation impacts the estimates for own income little, implying a weak correlation between own and reference income. Thus, if we believe that the reference group is partly constituted by individuals from the

\footnotetext{
${ }^{20}$ Unfortunately, the GSOEP documentation provides no information on how such cases are handled, i.e. which occupation is assigned when a respondent works more than one job. In the UK, the highest paying job is assigned, see: https://www.understandingsociety.ac.uk/documentation/mainstage/dataset-documentation/wave/8/questionnairemodule/currentemployment_w8

${ }^{21} \mathrm{~A}$ better approach would be to simply exclude each individual from the computation of the instrument or reference income assigned to her. However, since this would amount to a separate regression for each observation (i.e. 100,000 regressions) this was not feasible.
} 
same industry/occupation (such individuals may approximate colleagues), this small correlation implies that reference income is measured with considerable error. In turn, if this measurement error is random, this also implies that the true effects of reference income are larger than here estimated, and that my own income effects are biased downward. Moreover, if we believe that the true reference income effect is subject to reinforcement over time, my long-run effect of own income should be biased downward more than my short-run effect estimates, implying even less adaptation than currently observed.

The addition of dummies for industry and occupation in column 5 of tables 2 and 3 may be viewed as problematic in so far as a large portion of the variation in predicted incomes may be explained by these dummies, potentially making my IV estimates less stable. In table R.15, I check how the noninstrumented results react to the addition of these dummies. Results are virtually unchanged with these dummies. As a further test on the instrument and its reaction to the addition of industry/occupation dummies, in table R.16 I investigate the sensitivity of my results to constructing the instrument in a slightly different fashion: Instead of regressing labor incomes on industry and occupation dummies (+ sex \& age(-squared)) in each wave, I regress labor income on the interactions of these dummies in each wave ${ }^{22}$ and construct the instrument from these estimates. For both Germany and the UK, this results in an increase in the estimated short-run effect of own income. For Germany, and without separately adding industry/occupation dummies this increase results in a marginally significant adaptation estimate. My estimate of adaptation also remains negative when adding industry/occupation dummies. However, effects from merely changing jobs may now also be picked up by the instrument via the industry-occupation interactions and are therefore not entirely controlled for.

Vendrik (2013) includes a lag of the dependent variable - life satisfaction - to his estimated equation. This is to further guard against possible omitted variables biases and to implicitly model lags of income in the further past. A more in-depth account of this justification and the econometric approach is given in appendix A at the end of this paper. My results in table A.1, shown at the end of this paper, verify that my key results do not depend on such an alternative approach.

Finally, I assessed how robust my key estimates are against the removal of any of my controls. These results can be found in tables R.17 and R.18. This exercise shows that the estimates for own income are strongly diminished when excluding controls for the number of adults. This is because household income mechanically depends on the number of adults in the household, and each additional adult household member has a negative effect on life satisfaction (see section 4.4 below). This is consistent with the relative stability of results when using equivalized household income, but their relative instability when using raw household income. Moreover, concerning Germany, my estimate of adaptation also strongly depends on the employment status of the partner, yielding a sizable and significant estimate of adaptation when excluding this control. Lastly, in both countries my estimate of the long-run effect of reference income is very sensitive to the inclusion of wave dummies. This is probably due to a negative time-trend in life satisfaction across waves which is picked up by reference income, which is increasing with time. The exclusion of any other control variable does not change my substantive conclusions. 
Table 4: Undercompensation or overcompensation?

\begin{tabular}{|c|c|c|c|c|}
\hline & $\begin{array}{c}(1) \\
\text { W.Germany, } \\
\text { Instr.HH income, } \\
\text { lagged controls, } \\
\text { indust. \& occup. }\end{array}$ & $\begin{array}{c}(2) \\
\text { UK, } \\
\text { Instr.HH income, } \\
\text { lagged controls, } \\
\text { indust. \& occup. }\end{array}$ & $\begin{array}{c}(3) \\
\text { W.Germany, } \\
\text { Instr.HH income, } \\
\text { lagged controls, } \\
\text { indust. \& occup., } \\
\text { lagged } \ln \text { (\#adults) } \\
\& \ln (\# \text { children) }\end{array}$ & $\begin{array}{c}(4) \\
\text { UK, } \\
\text { Instr.HH income, } \\
\text { lagged controls, } \\
\text { indust. \& occup., } \\
\text { lagged } \ln \text { (\#adults) } \\
\& \ln \text { (\#children) }\end{array}$ \\
\hline SR effect of own income & $\begin{array}{l}0.281+ \\
(0.177)\end{array}$ & $\begin{array}{c}0.281^{* * *} \\
(0.096)\end{array}$ & $\begin{array}{l}0.326^{*} \\
(0.179)\end{array}$ & $\begin{array}{c}0.284^{* * *} \\
(0.098)\end{array}$ \\
\hline LR effect of own income & $\begin{array}{c}0.312^{* * *} \\
(0.113)\end{array}$ & $\begin{array}{c}0.388^{* * *} \\
(0.098)\end{array}$ & $\begin{array}{c}0.352^{* * *} \\
(0.128)\end{array}$ & $\begin{array}{c}0.381^{* * *} * \\
(0.113)\end{array}$ \\
\hline Adaptation to own income & $\begin{array}{c}0.031 \\
(0.167)\end{array}$ & $\begin{array}{c}0.107 \\
(0.101)\end{array}$ & $\begin{array}{c}0.026 \\
(0.167)\end{array}$ & $\begin{array}{c}0.097 \\
(0.106)\end{array}$ \\
\hline SR effect of HH size & $\begin{array}{l}-0.062 \\
(0.175)\end{array}$ & $\begin{array}{c}-0.319^{* * *} \\
(0.105)\end{array}$ & & \\
\hline LR effect of $\mathrm{HH}$ size & $\begin{array}{c}-0.428^{* * *} \\
(0.107)\end{array}$ & $\begin{array}{c}-0.591^{* * *} \\
(0.096)\end{array}$ & & \\
\hline Adaptation to $\mathrm{HH}$ size & $\begin{array}{c}-0.366^{* *} \\
(0.163)\end{array}$ & $\begin{array}{c}-0.272^{* * *} \\
(0.105)\end{array}$ & & \\
\hline SR Over-/under-compensation & $\begin{array}{c}0.219^{* * *} \\
(0.043)\end{array}$ & $\begin{array}{l}-0.038 \\
(0.041)\end{array}$ & & \\
\hline LR Over-/under-compensation & $\begin{array}{c}-0.116^{* *} \\
(0.047)\end{array}$ & $\begin{array}{c}-0.203^{* * *} \\
(0.053)\end{array}$ & & \\
\hline SR effect of number of adults & & & $\begin{array}{c}-0.094 \\
(0.117)\end{array}$ & $\begin{array}{c}-0.212^{* * *} \\
(0.069)\end{array}$ \\
\hline LR effect of number of adults & & & $\begin{array}{c}-0.319^{* * *} \\
(0.086)\end{array}$ & $\begin{array}{c}-0.373^{* * *} \\
(0.079)\end{array}$ \\
\hline Adaptation to number of adults & & & $\begin{array}{c}-0.225^{* *} \\
(0.108)\end{array}$ & $\begin{array}{c}-0.161^{* *} \\
(0.075)\end{array}$ \\
\hline SR effect of number of children & & & $\begin{array}{l}0.077^{*} \\
(0.046)\end{array}$ & $\begin{array}{l}-0.023 \\
(0.034)\end{array}$ \\
\hline LR effect of number of children & & & $\begin{array}{c}-0.045+ \\
(0.028)\end{array}$ & $\begin{array}{c}-0.123^{* * *} \\
(0.027)\end{array}$ \\
\hline Adaptation to number of children & & & $\begin{array}{c}-0.121^{* * *} \\
(0.044)\end{array}$ & $\begin{array}{c}-0.100^{* * *} \\
(0.034)\end{array}$ \\
\hline Kleibergen-Paap F statistic & 52.637 & 111.608 & 53.756 & 112.841 \\
\hline Serial Correlation & 0.021 & -0.181 & 0.021 & -0.181 \\
\hline Average $\mathrm{T}$ & 7.456 & 4.669 & 7.456 & 4.669 \\
\hline Number of Persons & 17282 & 18884 & 17282 & 18884 \\
\hline Number of Observations & 128850 & 88170 & 128850 & 88170 \\
\hline
\end{tabular}

Estimated with Correia's 'reghdfe' command. Individual and year fixed-effects \& (lagged) controls included.

Clustered standard errors in parentheses. $+\mathrm{p}<0.2,{ }^{*} \mathrm{p}<0.10,{ }^{* *} \mathrm{p}<0.050,{ }^{* * *} \mathrm{p}<0.010$ 


\subsection{Investigating adaptation/reinforcement to household composition}

In section 4.3, I asserted that results which show significant adaptation to raw household income are likely driven by adaptation to changes in household composition. Such adaptation to household composition is not accounted for when failing to include lags of controls. However, using equivalized household income amounts to an implicit control for lags of household composition.

Let $y_{i, t}^{e q}$ be equivalized $\mathrm{HH}$ income and $y_{i, t}^{\text {defl }}$ be non-equalized $\mathrm{HH}$ income. Let $E Q_{i, t} \equiv(1+$ $\gamma_{1}\left(\right.$ nadults $\left.\left._{i, t}-1\right)\right)+\gamma_{2}$ nchildren $_{i, t}$ denote the equivalization scale which depends on the number of adults and children. In the OECD equivalence scale, $\gamma_{1}$ and $\gamma_{2}$ are set to 0.5 and 0.3 , respectively. Thus, $y_{i, t}^{e q}=\frac{y_{i, t}^{d e f l}}{E Q_{i, t}}$. We can therefore, if we were using equivalized income for estimation, write eq.(1) as:

$$
L S_{i, t}=\sum_{k=0}^{K} \beta_{0-k} \ln \left(\frac{y_{i, t}^{\text {defl }}}{E Q_{i, t}}\right)+\sum_{k=0}^{K} \gamma_{0-k} \ln \left(y_{i, t-k}^{r e f}\right)+\phi X_{i, t}+\mu_{i}+\tau_{t}+\epsilon_{i, t}
$$

Which can be rewritten to give:

$$
L S_{i, t}=\sum_{k=0}^{3} \beta_{0-k}^{i n c} \ln \left(y_{i, t-k}^{\text {defl }}\right)+\sum_{k=0}^{3} \beta_{0-k}^{\text {comp }} \ln \left(E Q_{i, t-k}\right)+\ldots
$$

Hence, terms for own equivalized income implicitly include controls for the ln of the number of adults and children in the household. It is assumed that for all $k, \beta_{0-k}^{\text {comp }}=-\beta_{0-k}^{i n c}$. If one thinks that household income should be equivalized with respect to life satisfaction, this is a substantive assumption. In so far as many in the literature view life satisfaction as a proxy for utility (e.g. Layard et al. (2008), Stutzer (2004), Bayer and Juessen (2015)), and view equivalence scales as a means by which to assess - loosely speaking - how much more income one would need in an $n$-person household to attain the same utility as living alone (Rojas, 2007; Ferrer-i Carbonell and Van Praag, 2008; Deaton and Muellbauer, 1986), this appears plausible.

Only when it is in fact true that $\beta_{0}^{\text {comp }}=-\beta_{0}^{i n c}$, is the contemporaneous life satisfaction effect of own equivalized income comparable across household compositions. Similarly, only when it is true that $\sum_{k=0}^{\infty} \beta_{0}^{i n c}=\sum_{k=0}^{\infty}-\beta_{0}^{\text {comp }}$, is the long-run life satisfaction effect of own equivalized income comparable across household compositions. When it is for example the case that $\beta_{0}^{i n c}+\beta_{0}^{\text {comp }}>0$, then the negative effect of an increase in household size is smaller than is assumed by the equivalization scale. In that case, and if one would wish to equivalize on life satisfaction effects, one ought to decrease the weight on either the number of adults $\left(\gamma_{1}\right)$ or the number of children $\left(\gamma_{2}\right)$.

I pursue the question of under- vs over-compensation in columns 1 and 2 of table 4 . There, I estimate equation (7), but let all $\beta_{0-k}^{i n c}$ and $\beta_{0-k}^{c o m p}$ be estimated freely ( + remove the control for child birth). For both countries, the negative effect of household composition is much larger in the long-run than in the short-run, implying significant reinforcement. Furthermore, in Germany the OECD equivalence scales overcompensates (i.e. $\beta_{0}^{\text {inc }}+\beta_{0}^{\text {comp }}>0$ ) in the short-run, but undercompensates (i.e. $\sum_{k=0}^{3} \beta_{0-k}^{\text {inc }}+$ $\left.\sum_{k=0}^{3} \beta_{0-k}^{c o m p}<0\right)$ in the long-run. In the UK, the OECD scale neither under- nor overcompensates in the short-run, but severely undercompensates in the long-run.

Several prior studies have derived equivalence scales using subjective satisfaction data. Examples of

\footnotetext{
${ }^{22}$ In other words, for each wave, I estimate: $y_{i}^{\text {labour }}=\alpha+\beta_{1} M A L E+\beta_{2}, A G E+\beta_{3} A G E^{2}+\delta_{\text {ind,occ }}\left(\right.$ INDUSTRY IN $_{i}$ $\left.O C C U P A T I O N_{i}\right)+\epsilon_{i}$, where $\delta_{i n d, o c c}$ is an estimated parameter specific to each industry-occupation combination.
} 
this are Schwarze (2003), Borah et al. (2019), Biewen and Juhasz (2017) and Van Praag and Ferrer-i Carbonell (2008) in the German case, Bollinger et al. (2012) and Van Praag and Ferrer-i Carbonell (2008) in the British case, or Rojas (2007) in the Mexican case. All these studies find that the OECD equivalence scale overcompensates. However, every study exclusively estimated short-run equivalence scales, failing to take into account reinforcement in the negative effect of household composition. My results imply that an equivalence scale that takes into account adaptation and reinforcement dynamics to both income and household composition, yields much smaller economies of scale in the long-run. Importantly these would be even smaller than implied by the OECD.

It is a further question whether it is the number of adults or the number of children that drives these results. It would have been nice to estimate $\beta_{0-k}^{c o m p}, \gamma_{1}$ and $\gamma_{2}$ freely (as do Biewen and Juhasz (2017)), but this would not be estimable linearly and thus be not easily accomplished in my panel-IV context. I therefore estimated the following, simpler equation in columns 3 and 4 of table 4 :

$$
\begin{aligned}
L S_{i, t} & =\sum_{k=0}^{3} \beta_{0-k}^{\text {inc }} \ln \left(y_{i, t-k}^{\text {defl }}\right)+\sum_{k=0}^{3} \beta_{0-k}^{\text {adu }} \ln \left(\text { nadults }_{i, t-k}\right)+\sum_{k=0}^{3} \beta_{0-k}^{k i d} \ln \left(1+\text { nkids }_{i, t-k}\right) \\
& +\sum_{k=0}^{3} \gamma_{0-k} \ln \left(y_{i, t-k}^{\text {ref }}\right)+\sum_{k=0}^{3} \phi_{0-k} X_{i, t-k}+\mu_{i}+\tau_{t}+\epsilon_{i, t}
\end{aligned}
$$

Independent of the country considered, the negative effect of additional adults in the household always far exceeds that of additional children, even beyond the difference implied by the OECD scale. For Germany, I even find positive short-run effects of additional children, which turn negative in the long-run. These results for children are in line with previous results that show full adaptation to childbirth (see Angeles (2010); Clark et al. (2008); Clark and Georgellis (2013)). Finally, the specification of equation (8) allows me to derive short- and long-run equivalence scales (cf. Rojas, 2007). Taking a single adult living alone as the reference case, I can find the amount of additional income necessary to obtain the same life satisfaction as when living with additional $n^{a d u}$ adults and $n^{k i d}$ children. This is given by:

$$
R_{S R}\left(Y_{0} \rightarrow Y_{n^{a d u}, n^{k i d}}\right)=\exp \left[\ln \left(\frac{1}{n^{\text {adu }}}\right) * \frac{\beta_{0}^{\text {adu }}}{\beta_{0}^{\text {inc }}}+\ln \left(\frac{1}{1+n^{k i d}}\right) * \frac{\beta_{0}^{\text {kid }}}{\beta_{0}^{\text {inc }}}\right]
$$

To see this, solve for $y^{\text {defl }}$ in equation (8). Then take the ratio of this expression when nadults $=n^{a d u}$ to when nadults $=1$, and when $n k i d s=n^{k i d s}$ to when $n k i d s=0$ and simplify. For the long-run, replace the short-run coefficients $\beta_{0}^{i n c}, \beta_{0}^{a d u}$, and $\beta_{0}^{k i d}$ by their long-run equivalents $\sum_{k=0}^{3} \beta_{0-k}^{\text {inc }}, \sum_{k=0}^{3} \beta_{0-k}^{a d u}$, and $\sum_{k=0}^{3} \beta_{0-k}^{k i d}$ to obtain:

$$
R_{L R}\left(Y_{0} \rightarrow Y_{n^{a d u}, n^{k i d}}\right)=\exp \left[\ln \left(\frac{1}{n^{a d u}}\right) * \frac{\sum_{k=0}^{3} \beta_{0-k}^{a d u}}{\sum_{k=0}^{3} \beta_{0-k}^{\text {inc }}}+\ln \left(\frac{1}{1+n^{k i d}}\right) * \frac{\sum_{k=0}^{3} \beta_{0-k}^{k i d}}{\sum_{k=0}^{3} \beta_{0-k}^{\text {inc }}}\right]
$$

I plot results of that exercise in figure 5. Full tables are given in appendix B at the end of this paper. From figure 5 it becomes evident that the OECD equivalence scales completely overcompensates for additional children, both in the short- and in the long-run. However, the OECD scale only overcompensates for additional adults in the short-run for Germany. In the long-run, the OECD scale severely undercompensates for the effect of additional adults. Indeed, in the British case there appear to be no economies 

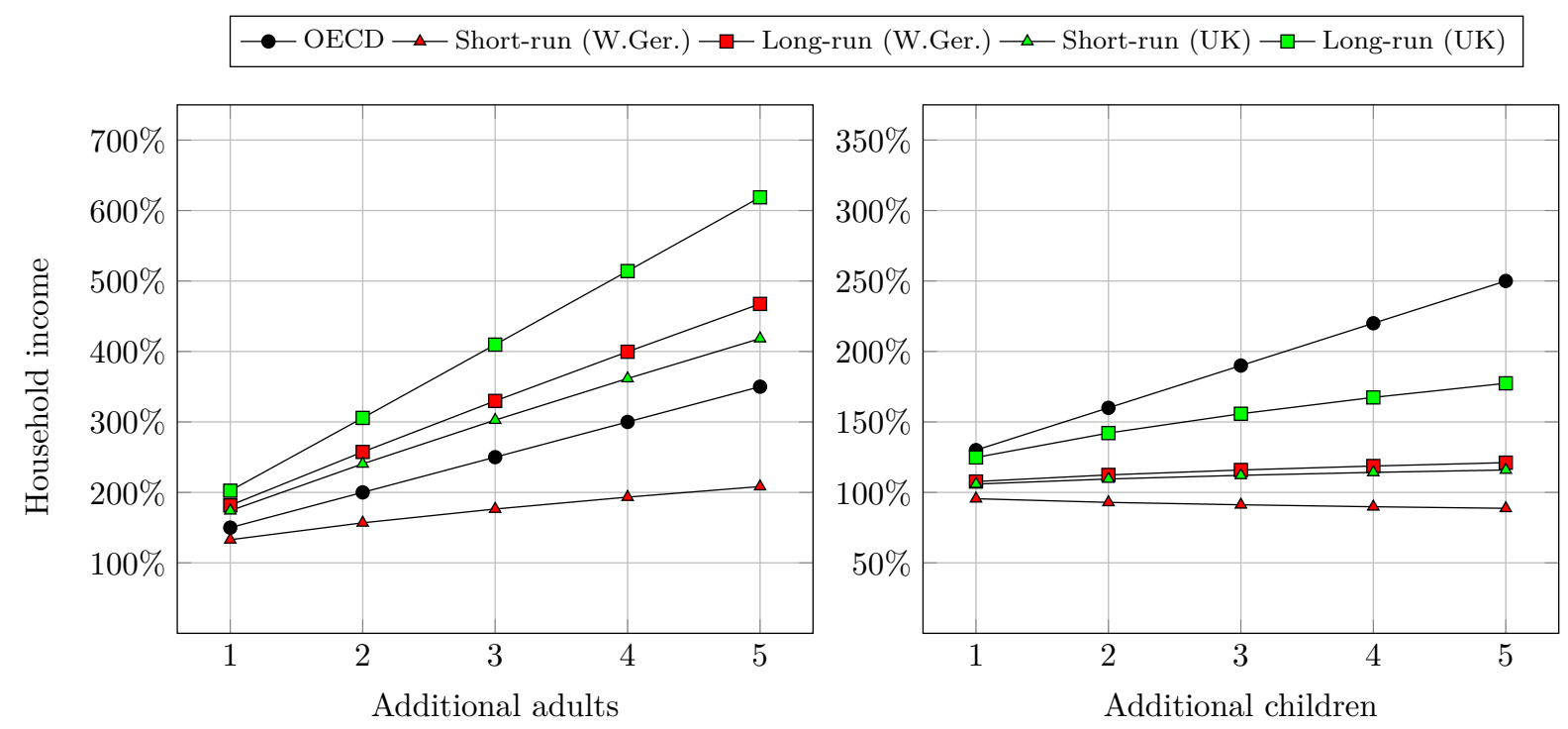

Figure 5: Illustration of equivalence scales computed from equations (9) and (10) on the basis of parameter estimates from table 4 , columns 3 (Germany) and 4 (UK). In both panels a single adult living alone is taken to be the reference case. The panel on the left shows the amount of household income (in $\%$ of the reference case) necessary to compensate (i.e. to obtain the same level of life satisfaction as in the reference case) for each additional adult in the household. The right panel show the amount of household income necessary to maintain constant life satisfaction with each additional child in the household.

of scale in the long-run at all. ${ }^{23}$ In so far as the German welfare state is much more comprehensive with respect to child-care than the British (thus lessening the burden of additional children), and more willing to support partnered households, these observed country differences may be driven by the institutional structure of these countries.

\section{Conclusion}

Substantively I make four main points. First, I find no significant evidence of adaptation to own income. All cases in which my estimate of adaptation is significant and negative occur when omitting variables relating to household composition. This finding is in direct disagreement with most of the previous literature and implies that higher own incomes have lastingly positive effects on life satisfaction. Second, the effects of reference income have been consistently negative across countries and did not dissipate with time. To the contrary, I find some (albeit insignificant) indication that in the short-run the effects of reference incomes are positive. This may indicate that a signaling mechanism of the sort described by Senik (2004) dominates in the short-run, while a social comparison mechanism ${ }^{24}$ dominates in the long-run. Third, in the long-run the effects of own and reference income are of similar absolute magnitude in most specifications. As a consequence, the combined effects of own and reference income is always insignificant. ${ }^{25}$ Thus, if everybody gets richer, nobody becomes happier. Although this is a sad result, it validates the much discussed Easterlin Paradox. Finally, previous endeavors that derived equivalence

\footnotetext{
${ }^{23}$ Note that I control for marital status. Therefore much of the positive effect of being in a multi-adult household will be captured by this variable.

${ }^{24}$ Vendrik and Woltjer (2007) propose an alternative mechanism where greater reference incomes may stifle the ability of individuals to participate in social activities.

${ }^{25}$ Except when using non-equivalized reference income and with small lag lengths $(K<2)$ in Germany.
} 
scales from life satisfaction data did not take into account adaptation to household size. The resulting bias appears to be substantial, indicating that the OECD equivalence scale severely undercompensates in the long-run.

Methodologically two major points are worth noting: First, instrumenting for own income is paramount. I find much larger income effects when instrumenting, especially with respect to the UK. The pronounced rise in effect sizes when instrumenting is in line with the IV results of Vendrik (2013), Powdthavee (2010), Luechinger (2009) and Knight and Gunatilaka (2010). Second, the use of lags of controls was crucial. In particular, what was previously taken to be adaptation to income, appears in fact to have been reinforcement of a negative household composition effect. In the present application, such adaptation can be controlled for via the use of equivalized income. However, this is not generally true. It may therefore be the case that similar problems apply to the effects of other socio-economic variables for which adaptation processes are thought to occur.

An important limitation of this study is the use of yearly data. If adaptation to income occurs much faster than within the first year, such adaptation could not be detected (Ferrer-i Carbonell and Van Praag, 2008). Tackling this problem with temporally more fine-grained data (perhaps the Australian data Frijters et al. (2011) use) seems like a useful avenue for future research. However, given that I do find sizable short-run effects of income, it seems that adaptation would have to follow from a very large, and possibly implausibly large, initial effect of income. Moreover, my significant long-run effects imply that any adaptation must be partial at best. Nevertheless, and to quote Ferrer-i Carbonell and Van Praag (2008), the discussion is not finished yet.

\section{Acknowledgments}

I especially thank Maarten Vendrik, Brian Nolan and two anonymous reviewers for their extensive and insightful comments and suggestions. I also thank Anders Malthe Bach-Mortensen, Bess Bukodi, JanEmmanuel De Neve, John Ermish, Andrew Oswald, Karl Overdick, Mariano Rojas, Nhat An Trinh, as well as participants of the Oxford DSPI Poverty and Inequality Research Groups for helpful comments on earlier drafts. Funding from Nuffield College, the Department of Social Policy and Intervention and the Wellbeing Research Centre (Oxford) is gratefully acknowledged.

\section{References}

Angeles, L. (2010). Adaptation and anticipation effects to life events in the United Kingdom. Working Paper.

Bayer, C. and F. Juessen (2015). Happiness and the persistence of income shocks. American Economic Journal: Macroeconomics 7(4), 160-187.

Berthoud, R. and M. Bryan (2011). Income, Deprivation and Poverty: a longitudinal analysis. Journal of Social Policy 40(1), 135-156.

Biewen, M. and A. Juhasz (2017). Direct Estimation of Equivalence Scales and More Evidence on Independence of Base. Oxford Bulletin of Economics and Statistics 79(5), 875-905. 
Binder, M. and A. Coad (2010). An examination of the dynamics of well-being and life events using vector autoregressions. Journal of Economic Behavior \& Organization 76 (2), 352-371.

Bollinger, C., C. Nicoletti, and S. Pudney (2012). Two Can Live as Cheaply as One...But Three's a Crowd. University of Kentucky Center for Poverty Research Discussion Paper Series.

Borah, M., C. Keldenich, and A. Knabe (2019). Reference Income Effects in the Determination of Equivalence Scales Using Income Satisfaction Data. Review of Income and Wealth 65(4), 736-770.

Chang, A. C. and P. Li (2018). Is Economics Research Replicable? Sixty Published Papers from Thirteen Journals Say 'Often Not'. Critical Finance Review \%.

Clark, A. E. (1999). Are wages habit-forming? evidence from micro data. Journal of Economic Behavior \& Organization 39(2), 179-200.

Clark, A. E. (2016). Adaptation and the easterlin paradox. In Advances in happiness research, pp. 75-94. Springer.

Clark, A. E., E. Diener, Y. Georgellis, and R. E. Lucas (2008). Lags and Leads in Life Satisfaction : a Test of the Baseline Hypothesis. The Economic Journal 118, 222-243.

Clark, A. E., P. Frijters, and M. A. Shields (2008). Relative Income, Happiness, and Utility: An Explanation for the Easterlin Paradox and Other Puzzles. Journal of Economic Literature 46(461), $95-144$.

Clark, A. E. and Y. Georgellis (2013). Back to Baseline in Britain: Adaptation in the British Household Panel Survey. Economica 80(319), 496-512.

Clark, A. E., C. Senik, and K. Yamada (2017). When experienced and decision utility concur: The case of income comparisons. Journal of Behavioral and Experimental Economics 70, 1-9.

D'Ambrosio, C. and J. R. Frick (2012). Individual Wellbeing in a Dynamic Perspective. Economica $79(314), 284-302$.

De Vos, I., I. Ruyssen, and G. Everaert (2015). XTBCFE: Stata module to perform bootstrap-corrected Fixed Effects estimation and inference in dynamic panel models. Statistical Software Components.

Deaton, A. S. and J. Muellbauer (1986). On Measuring Child Costs: With Applications to Poor Countries. Journal of Political Economy 94(4), 720-744.

Di Tella, R., J. Haisken-De New, and R. MacCulloch (2010). Happiness adaptation to income and to status in an individual panel. Journal of Economic Behavior and Organization 76 (3), 834-852.

Di Tella, R. and R. MacCulloch (2010). Happiness Adaptation to Income beyond "Basic Needs". In E. Diener, J. Helliwell, and D. Kahneman (Eds.), International Differences in Wellbeing. Oxford University Press.

Dumludag, D., O. Gokdemir, and S. Giray (2016). Income comparison, collectivism and life satisfaction in Turkey. Quality $\& 3$ Quantity 50(3), 955-980. 
Earp, B. D. and D. Trafimow (2015). Replication, falsification, and the crisis of confidence in social psychology. Frontiers in Psychology 6.

Easterlin, R. (2016). Paradox Lost? IZA Discussion Paper (9676).

Easterlin, R. A. (2005). A puzzle for adaptive theory. Journal of Economic Behavior and Organization 56(4 SPEC. ISS.), 513-521.

Ferrer-i Carbonell, A. (2005). Income and well-being: An empirical analysis of the comparison income effect. Journal of Public Economics 89(5-6), 997-1019.

Ferrer-i Carbonell, A. and P. Frijters (2004). How important is methodology for the estimates of the determinants of happiness? The Economic Journal 114(497), 641-659.

Ferrer-i Carbonell, A. and B. M. S. Van Praag (2008). Do people adapt to changes in income and other circumstances? The discussion is not finished yet.

Figari, F. (2012). Cross-national differences in determinants of multiple deprivation in Europe. Journal of Economic Inequality 10(3), 397-418.

Frijters, P., D. W. Johnston, and M. A. Shields (2011). Happiness Dynamics with Quarterly Life Event Data. Scandinavian Journal of Economics 113(1), 190-211.

Goerke, L. and M. Pannenberg (2015). Direct evidence for income comparisons and subjective well-being across reference groups. Economics Letters 137, 95-101.

Graham, C. and M. Nikolova (2015). Bentham or Aristotle in the Development Process? An Empirical Investigation of Capabilities and Subjective Well-Being. World Development 68(1), 163-179.

Hamermesh, D. S. (2007). Viewpoint: Replication in economics. Canadian Journal of Economics/Revue canadienne d'economique 40(3), 715-733.

Hanglberger, D. and J. Merz (2011). Are Self-Employed Really Happier Than Employees? An Approach Modelling Adaptation and Anticipation Effects to Self-Employment and General Job Changes. IZA Discussion Paper (5629).

Hirschman, A. O. and M. Rothschild (1973). The Changing Tolerance for Income Inequality in the Course of Economic Development* With A Mathematical Appendix. The Quarterly Journal of Economics 87(4), 544-566.

Hurst, E., G. Li, and B. Pugsley (2013). Are Household Surveys Like Tax Forms? Evidence from Income Underreporting of the Self-Employed. The Review of Economics and Statistics 96(1), 19-33.

Ifcher, J., H. Zarghamee, and C. Graham (2018). Local neighbors as positives, regional neighbors as negatives: Competing channels in the relationship between others' income, health, and happiness. Journal of health economics 57, 263-276. Publisher: Elsevier.

Jayawickreme, E. and J. O. Pawelski (2012). Positivity and the capabilities approach. Philosophical Psychology 5089(December), 1-18. 
Kingdon, G. G. and J. Knight (2007). Community, comparisons and subjective well-being in a divided society. Journal of Economic Behavior and Organization 64(1), 69-90.

Knight, J. and R. Gunatilaka (2010). Great expectations? The subjective well-being of rural-urban migrants in China. World Development 38(1), 113-124.

Layard, R., G. Mayraz, and S. Nickell (2008). The marginal utility of income. Journal of Public Economics 92(8), 1846-1857.

Levy, H. and S. P. Jenkins (2012). Documentation for Derived Current and Annual Net Household Income Variables, BHPS waves 1-18. UK Data Archive Study Number 3909.

Luechinger, S. (2009). Valuing Air Quality Using the Life Satisfaction Approach. The Economic Journal 119(536), 482-515.

Luttmer, E. F. (2005). Neighbors as negatives: relative earnings and well-being. The Quarterly journal of economics 120(3), 963-1002.

Mayraz, G., G. Wagner, and J. Schupp (2009). Life Satisfaction and Relative Income : Perceptions and Evidence. CEP Discussion Paper (938).

McBride, M. (2001). Relative-income effects on subjective well-being in the cross-section. Journal of Economic Behavior 83 Organization 45(3), 251-278.

Nussbaum, M. C. (2000). Women and human development: the capabilities approach. Cambridge University Press.

Paul, S. and D. Guilbert (2013). Income-happiness paradox in Australia: Testing the theories of adaptation and social comparison. Economic Modelling 30(Supplement C), 900-910.

Pfaff, T. (2013). Income comparisons, income adaptation, and life satisfaction: How robust are estimates from survey data? SOEPpapers (555).

Pischke, J.-S. and H. Schwandt (2012). A cautionary note on using industry affiliation to predict income. IZA Discussion Paper (6840).

Powdthavee, N. (2010). How much does money really matter? Estimating the causal effects of income on happiness. Empirical Economics 39(1), 77-92.

Qizilbash, M. (2006). Well-being, adaptation and human limitations. Royal Institute of Philosophy Supplements 59, 83-109.

Riedl, M. and I. Geishecker (2014). Keep it simple: estimation strategies for ordered response models with fixed effects. Journal of Applied Statistics 41(11), 2358-2374.

Rojas, M. (2007). A subjective well-being equivalence scale for Mexico: Estimation and poverty and income-distribution implications. Oxford Development Studies 35(3), 273-293.

Schokkaert, E. (2007). Capabilities and Satisfaction with Life. Journal of Human Development 8(3), $415-430$. 
Schwarze, J. (2003). Using Panel Data on Income Satisfaction to Estimate Equivalence Scale Elasticity. Review of Income and Wealth 49(3), 359-372.

Sen, A. (1985). Commodities and Capabilities. Amsterdam: North-Holland.

Senik, C. (2004). When information dominates comparison: Learning from Russian subjective panel data. Journal of Public Economics 88(9), 2099-2123.

Senik, C. (2008). Ambition and jealousy: Income interactions in the 'Old' Europe versus the 'New' Europe and the United States. Economica 75(299), 495-513.

Senik, C. (2009). Direct evidence on income comparisons and their welfare effects. Journal of Economic Behavior and Organization 72(1), 408-424.

Stutzer, A. (2004). The role of income aspirations in individual happiness. Journal of Economic Behavior and Organization 54(1), 89-109.

Van Praag, B. M. S. (1971). The welfare function of income in Belgium: An empirical investigation. European Economic Review 2(3), 337-369.

Van Praag, B. M. S. and A. Ferrer-i Carbonell (2008). Happiness quantified: A satisfaction calculus approach (2 ed.). Oxford University Press.

Vendrik, M. C. M. (2013). Adaptation, anticipation and social interaction in happiness: An integrated error-correction approach. Journal of Public Economics 105, 131-149.

Vendrik, M. C. M. and G. B. Woltjer (2007). Happiness and loss aversion: Is utility concave or convex in relative income? Journal of Public Economics 91(7-8), 1423-1448.

Wolbring, T., M. Keuschnigg, and E. Negele (2013). Needs, Comparisons, and Adaptation: The Importance of Relative Income for Life Satisfaction. European Sociological Review 29(1), 86-104. 


\section{Appendix}

\section{A Addition of lagged life satisfaction}

Vendrik (2013) uses an error-correction model as his primary specification. An alternative representation of such a model is an autoregressive distributed lag model, which may be written as :

$$
L S_{i, t}=\sum_{k=0}^{K} \beta_{0-k} \ln \left(y_{i, t-k}\right)+\sum_{k=0}^{K} \gamma_{0-k} \ln \left(y_{i, t-k}^{r e f}\right)+\sum_{k=0}^{K} \phi_{0-k} X_{i, t-k}+\rho L S_{i, t-1}+\mu_{i}+\tau_{t}+\epsilon_{i, t}
$$

Using repeated substitutions, equation (11) can be rewritten as follows (controls omitted for brevity):

$$
\begin{aligned}
L S_{i, t} & =\beta_{0} \ln \left(y_{i, t}\right)+\left(\beta_{-1}+\rho \beta_{o}\right) \ln \left(y_{i, t-1}\right)+\left(\beta_{-2}+\rho \beta_{-1}+\rho^{2} \beta_{0}\right) \ln \left(y_{i, t-2}\right)+\ldots \\
& +\left(\beta_{-4}+\rho \beta_{-3}+\cdots+\rho^{K} \beta_{o}\right) \ln \left(y_{i, t-K}\right)+\sum_{m=1}^{\infty} \rho^{m}\left(\sum_{l=0}^{K} \rho^{l} \beta_{-K-l}\right) \ln \left(y_{i, t-K-m}\right)+\ldots
\end{aligned}
$$

Defining $\beta_{0-k}^{*}, \gamma_{0-k}^{*}$, and $\phi_{0-k}^{*}$ appropriately this can be written as:

$$
\begin{gathered}
L S_{i, t}=\beta_{0} \ln \left(y_{i, t}\right)+\sum_{k=1}^{\infty} \beta_{0-k}^{*} \ln \left(y_{i, t-k}\right)+\gamma_{o} \ln \left(y_{i, t}^{r e f}\right)+\sum_{k=0}^{\infty} \gamma_{0-k}^{*} \ln \left(y_{i, t-k}^{r e f}\right)+ \\
\phi_{0-k} X_{i, t}+\sum_{k=0}^{\infty} \phi_{0-k}^{*} X_{i, t-k}+\mu_{i}^{*}+\tau_{t}^{*}+\epsilon_{i, t}^{*}
\end{gathered}
$$

The addition of lagged life satisfaction therefore implicitly models the effects of indefinitely long lags of own and reference income, as well as all controls. In this model, we must assume that life satisfaction, beyond the part that is explicitly modeled, is an autoregressive process of order 1 , with $0 \leq \rho<1$. The effects of income and all controls at $t-K-m$ are assumed to decay at rate $\rho^{m}$ for $m>0$. This homogeneous rate of decay is also assumed for the effects of the unobserved time-varying controls. To obtain the $S R, L R$, and adaptation effects, the same formulas as those presented in section 3.1 can be applied to equation (13). The sum $\beta_{0}+\sum_{k=1}^{\infty} \beta_{0-k}^{*}$, i.e. the long-run effect of own income, can be expressed as $\frac{\sum_{k=0}^{K} \beta_{0-k}}{1-\rho}$ (the same goes for reference incomes). ${ }^{26}$ In a fixed effects setting, the OLS estimate of $\rho$ will be downwardly biased for finite $T$ (Nickell Bias). I therefore apply the bootstrap bias correction of De Vos et al. (2015). Vendrik (2013) finds a further small- $T$ bias in the estimate of $\rho$ that goes beyond the Nickell Bias. This is why he fixates $\rho$ to an estimate from a balanced panel with $T=21$. I observe the same: with the full German sample I obtain $\rho=0.13$. When only selecting respondents who are observed in every wave (which yields an effective $T$ of 29 ), the estimated $\rho$ increases to 0.26 , which is close to Vendrik's estimate $(=0.27)$. Therefore, I also fixate $\rho$ to the estimate with largest possible $T$, making these estimates most comparable to Vendrik (2013). ${ }^{27}$ Results are given in table A.1.

\footnotetext{
${ }^{26}$ To see this, set $L S$ and $\ln (y)$ to their unchanging long-run values in equation (11) and rearrange.

${ }^{27}$ Moreover, when selecting the same subset of respondents, but randomly selecting an observation window of seven
} 
Table A.1: Main specifications after adding lags of life satisfaction

\begin{tabular}{|c|c|c|c|c|}
\hline & $\begin{array}{c}(1) \\
\text { W.Germany, } \\
\text { instr. HH income, } \\
\text { lagged controls }\end{array}$ & $\begin{array}{c}(2) \\
\text { W.Germany, } \\
\text { instr. HH income, } \\
\text { lagged controls, } \\
\text { indust. \& occup. }\end{array}$ & $\begin{array}{c}(3) \\
\text { UK, } \\
\text { instr. HH income, } \\
\text { lagged controls }\end{array}$ & $\begin{array}{c}(4) \\
\text { UK, } \\
\text { instr. HH income, } \\
\text { lagged controls, } \\
\text { indust. \& occup. }\end{array}$ \\
\hline Lagged life satisfaction & 0.266 & 0.266 & 0.168 & 0.168 \\
\hline SR effect of own income & $\begin{array}{c}0.671^{* * *} \\
(0.206)\end{array}$ & $\begin{array}{c}0.369^{*} \\
(0.191)\end{array}$ & $\begin{array}{c}0.206^{* *} \\
(0.100)\end{array}$ & $\begin{array}{l}0.201^{*} \\
(0.107)\end{array}$ \\
\hline LR effect of own income & $\begin{array}{c}0.437^{* * *} \\
(0.146)\end{array}$ & $\begin{array}{c}0.357^{* *} \\
(0.148)\end{array}$ & $\begin{array}{c}0.317^{* *} \\
(0.128)\end{array}$ & $\begin{array}{c}0.342^{* *} \\
(0.137)\end{array}$ \\
\hline Adaptation to own income & $\begin{array}{l}-0.235 \\
(0.194)\end{array}$ & $\begin{array}{l}-0.012 \\
(0.182)\end{array}$ & $\begin{array}{c}0.111 \\
(0.122)\end{array}$ & $\begin{array}{c}0.141 \\
(0.127)\end{array}$ \\
\hline SR effect of reference income & $\begin{array}{l}-0.198 \\
(0.168)\end{array}$ & $\begin{array}{l}-0.157 \\
(0.167)\end{array}$ & $\begin{array}{l}0.199+ \\
(0.155)\end{array}$ & $\begin{array}{l}0.217+ \\
(0.157)\end{array}$ \\
\hline LR effect of reference income & $\begin{array}{c}-0.345^{* *} \\
(0.168)\end{array}$ & $\begin{array}{c}-0.321^{*} \\
(0.169)\end{array}$ & $\begin{array}{l}-0.177 \\
(0.206)\end{array}$ & $\begin{array}{l}-0.186 \\
(0.210)\end{array}$ \\
\hline Adaptation to reference income & $\begin{array}{c}-0.148 \\
(0.201)\end{array}$ & $\begin{array}{c}-0.164 \\
(0.201)\end{array}$ & $\begin{array}{c}-0.376^{*} \\
(0.206)\end{array}$ & $\begin{array}{c}-0.403^{*} \\
(0.209)\end{array}$ \\
\hline Combined SR effect & $\begin{array}{c}0.474^{* *} \\
(0.238)\end{array}$ & $\begin{array}{c}0.212 \\
(0.230)\end{array}$ & $\begin{array}{c}0.405^{* *} \\
(0.170)\end{array}$ & $\begin{array}{c}0.418^{* *} \\
(0.173)\end{array}$ \\
\hline Combined LR effect & $\begin{array}{c}0.091 \\
(0.188)\end{array}$ & $\begin{array}{c}0.036 \\
(0.194)\end{array}$ & $\begin{array}{c}0.140 \\
(0.229)\end{array}$ & $\begin{array}{c}0.156 \\
(0.233)\end{array}$ \\
\hline Combined Adaptation & $\begin{array}{r}-0.382+ \\
(0.249)\end{array}$ & $\begin{array}{l}-0.176 \\
(0.244)\end{array}$ & $\begin{array}{l}-0.265 \\
(0.220)\end{array}$ & $\begin{array}{l}-0.262 \\
(0.224)\end{array}$ \\
\hline Kleibergen-Paap F statistic & 42.036 & 52.028 & 113.595 & 100.727 \\
\hline Serial Correlation & -0.229 & -0.226 & -0.321 & -0.325 \\
\hline Average $\mathrm{T}$ & 7.448 & 7.448 & 4.400 & 4.400 \\
\hline Number of Persons & 17267 & 17267 & 18063 & 18063 \\
\hline Number of Observations & 128608 & 128608 & 79474 & 79474 \\
\hline
\end{tabular}

Estimated with Correia's 'reghdfe' command. Individual and year fixed-effects \& (lagged) controls included.

Clustered standard errors in parentheses. $+\mathrm{p}<0.2,{ }^{*} \mathrm{p}<0.10,{ }^{* *} \mathrm{p}<0.050,{ }^{* * *} \mathrm{p}<0.010$ 


\section{B Full Results for equivalization scales}

Table B.1: Short- and long-run equivalence scales for Germany

\begin{tabular}{cclllllll}
\hline & \multicolumn{7}{c}{ Number of children } \\
\hline & & \multicolumn{1}{c}{0} & 1 & 2 & 3 & 4 & 5 & 6 \\
& 1 & $1.000 /$ & $0.955 /$ & $0.929 /$ & $0.912 /$ & $0.898 /$ & $0.887 /$ & $0.878 /$ \\
& & 1.000 & 1.077 & 1.124 & 1.159 & 1.187 & 1.211 & 1.231 \\
Number of & 2 & $1.328 /$ & $1.268 /$ & $1.234 /$ & $1.211 /$ & $1.193 /$ & $1.179 /$ & $1.167 /$ \\
Adults & & 1.816 & 1.955 & 2.042 & 2.105 & 2.156 & 2.199 & 2.235 \\
& \multirow{2}{*}{3} & $1.568 /$ & $1.497 /$ & $1.457 /$ & $1.430 /$ & $1.409 /$ & $1.392 /$ & $1.377 /$ \\
& & 2.574 & 2.772 & 2.895 & 2.985 & 3.057 & 3.117 & 3.168 \\
& \multirow{2}{*}{4} & $1.764 /$ & $1.685 /$ & $1.640 /$ & $1.608 /$ & $1.585 /$ & $1.566 /$ & $1.549 /$ \\
& & 3.298 & 3.551 & 3.708 & 3.824 & 3.916 & 3.993 & 4.059 \\
& \multirow{2}{*}{5} & $1.933 /$ & $1.846 /$ & $1.797 /$ & $1.762 /$ & $1.736 /$ & $1.715 /$ & $1.698 /$ \\
& & 3.996 & 4.303 & 4.493 & 4.633 & 4.745 & 4.838 & 4.918 \\
& \multirow{2}{*}{6} & $2.083 /$ & $1.989 /$ & $1.936 /$ & $1.899 /$ & $1.871 /$ & $1.848 /$ & $1.829 /$ \\
& 4.675 & 5.034 & 5.257 & 5.420 & 5.551 & 5.660 & 5.754 \\
\hline
\end{tabular}

Calculated with parameter estimates from the specification of table 4, column 3.

First element of each cell refers to the short-run, second element refers to the long-run

Table B.2: Short- and long-run equivalence scales for the UK

\begin{tabular}{cllllllll}
\hline & \multicolumn{7}{c}{ Number of children } \\
\hline & & \multicolumn{1}{c}{0} & 1 & 2 & 3 & 4 & 5 & 6 \\
& 1 & $1.000 /$ & $1.059 /$ & $1.095 /$ & $1.121 /$ & $1.142 /$ & $1.159 /$ & $1.174 /$ \\
Number of & 2 & 1.000 & 1.248 & 1.421 & 1.558 & 1.674 & 1.774 & 1.864 \\
Adults & & 2.024 & 2.527 & 2.877 & 3.154 & 3.388 & 3.592 & 3.773 \\
& \multirow{2}{*}{3} & $2.405 /$ & $2.546 /$ & $2.632 /$ & $2.696 /$ & $2.746 /$ & $2.787 /$ & $2.823 /$ \\
& & 3.057 & 3.817 & 4.346 & 4.765 & 5.118 & 5.425 & 5.700 \\
& \multirow{2}{*}{4} & $3.026 /$ & $3.204 /$ & $3.312 /$ & $3.392 /$ & $3.455 /$ & $3.507 /$ & $3.552 /$ \\
& & 4.097 & 5.114 & 5.823 & 6.385 & 6.857 & 7.269 & 7.637 \\
& \multirow{2}{*}{5} & $3.616 /$ & $3.829 /$ & $3.959 /$ & $4.054 /$ & $4.129 /$ & $4.191 /$ & $4.245 /$ \\
& & 5.141 & 6.418 & 7.307 & 8.012 & 8.605 & 9.122 & 9.583 \\
& 6 & $4.183 /$ & $4.429 /$ & $4.579 /$ & $4.689 /$ & $4.776 /$ & $4.848 /$ & $4.910 /$ \\
& 6.188 & 7.725 & 8.796 & 9.644 & 10.358 & 10.981 & 11.536 \\
\hline
\end{tabular}

Calculated with parameter estimates from the specification of table 4, column 4.

First element of each cell refers to the short-run, second element refers to the long-run

periods (which is closest to mean $T$ when using the full set of respondents) for each of these respondents, I get an estimate of $\rho=0.14$. This is thus very close to the estimate obtained from the full set of respondents. It may therefore be concluded that the smaller estimate of $\rho$ from the full sample indeed arises from a further, unaccounted-for small- $T$ bias, and that the larger estimate for $\rho$ obtained when $T=29$ is less biased and not driven by selection effects. 
Online Appendix 


\section{Descriptives tables}

Table D.1: Description of Controls (continued on next page)

\begin{tabular}{|c|c|c|c|c|}
\hline Concept & GSOEP & & UKHLS & \\
\hline \multirow{8}{*}{ Number of children } & Dummies for: & & Dummies for: & \\
\hline & 0 & $(55.1 \%)$ & 0 & $(57.3 \%)$ \\
\hline & 1 & $(20.4 \%)$ & 1 & $(18.1 \%)$ \\
\hline & 2 & $(17.9 \%)$ & 2 & $(18.9 \%)$ \\
\hline & 3 & $(5.17 \%)$ & 3 & $(4.87 \%)$ \\
\hline & 4 & $(1.05 \%)$ & 4 & $(0.86 \%)$ \\
\hline & 5 & $(0.26 \%)$ & 5 & $(0.10 \%)$ \\
\hline & 6 or more & $(0.10 \%)$ & 6 or more & $(0.01 \%)$ \\
\hline \multirow[t]{7}{*}{ Number of adults } & Dummies for: & & Dummies for: & \\
\hline & 1 & $(10.0 \%)$ & 1 & $(11.1 \%)$ \\
\hline & 2 & $(59.8 \%)$ & 2 & $(61.4 \%)$ \\
\hline & 3 & $(18.9 \%)$ & 3 & $(17.7 \%)$ \\
\hline & 4 & $(8.89 \%)$ & 4 & $(7.91 \%)$ \\
\hline & 5 & $(1.88 \%)$ & 5 & $(1.45 \%)$ \\
\hline & 6 or more & $(0.53 \%)$ & 6 or more & $(0.44 \%)$ \\
\hline \multirow[t]{7}{*}{ Employment status } & Dummies for: & & Dummies for: & \\
\hline & Non-working & $(10.5 \%)$ & Lt.sick or disabled & $(1.52 \%)$ \\
\hline & Retired & $(1.20 \%)$ & Retired & $(3.34 \%)$ \\
\hline & Unemployed & $(2.16 \%)$ & Unemployed & $(1.34 \%)$ \\
\hline & Student & $(0.96 \%)$ & Student & $(0.53 \%)$ \\
\hline & Maternity leave & $(1.58 \%)$ & Family Care & $(4.83 \%)$ \\
\hline & Working & $(81.4 \%)$ & Working & $(88.2 \%)$ \\
\hline \multirow{5}{*}{$\begin{array}{l}\text { Partner employment } \\
\text { status }\end{array}$} & Dummies for: & & Dummies for: & \\
\hline & Working & $(60.4 \%)$ & Working & $(65.3 \%)$ \\
\hline & No partner / NA & $(22.3 \%)$ & No partner / NA & $(23.3 \%)$ \\
\hline & Unemployed & $(1.92 \%)$ & Unemployed & $(1.20 \%)$ \\
\hline & Non-working & $(15.4 \%)$ & Non-working & $(10.4 \%)$ \\
\hline \multirow[t]{2}{*}{ Age } & Mean $=43.64$ & $\mathrm{SD}=11.07$ & Mean $=44.06$ & $\mathrm{SD}=11.08$ \\
\hline & $\operatorname{Min}=23$ & $\operatorname{Max}=70$ & $\operatorname{Min}=22$ & $\operatorname{Max}=70$ \\
\hline \multirow[t]{2}{*}{ Age squared } & Mean $=2026$ & $\mathrm{SD}=981.0$ & Mean=2064 & $\mathrm{SD}=997.4$ \\
\hline & $\operatorname{Min}=529$ & $\operatorname{Max}=4900$ & $\operatorname{Min}=484$ & $\mathrm{Max}=4900$ \\
\hline
\end{tabular}


Table D.1: (continued)

\begin{tabular}{|c|c|c|c|c|}
\hline \multirow{2}{*}{$\begin{array}{l}\text { Concept } \\
\text { Marital status }\end{array}$} & \multicolumn{2}{|l|}{ GSOEP } & \multicolumn{2}{|l|}{ UKHLS } \\
\hline & Dummies for: & & Dummies for: & \\
\hline & Married/Couple & $(73.2 \%)$ & Married & $(66.8 \%)$ \\
\hline & Single & $(16.5 \%)$ & Single & $(11.7 \%)$ \\
\hline & Widowed & $(1.51 \%)$ & Widowed & $(1.26 \%)$ \\
\hline & Divorced & $(6.27 \%)$ & Divorced & $(7.37 \%)$ \\
\hline & Separated & $(2.32 \%)$ & Living as couple & $(12.9 \%)$ \\
\hline & Other & $(0.22 \%)$ & & \\
\hline \multirow[t]{4}{*}{ Housing } & Dummies for: & & Dummies for: & \\
\hline & Own & $(52.1 \%)$ & Own & $(82.3 \%)$ \\
\hline & Rented & $(47.9 \%)$ & Rented privately & $(8.43 \%)$ \\
\hline & & & Social housing & $(9.29 \%)$ \\
\hline \multirow[t]{3}{*}{ Working hours } & $\ln$ (yearly working hours) & & $\ln$ (weekly working hours & \\
\hline & Mean $=6.30$ & $\mathrm{SD}=2.73$ & Mean $=3.09$ & $\mathrm{SD}=1.16$ \\
\hline & $\operatorname{Min}=0$ & $\operatorname{Max}=8.80$ & $\operatorname{Min}=0$ & $\operatorname{Max}=4.61$ \\
\hline \multirow{4}{*}{ Ill health } & Dummy over 0-10 & & Dummy over 1-7 & \\
\hline & subj. health variable & & subj. health variable & \\
\hline & $=1$ if subj.health $<5$ & $(13.4 \%)$ & $=1$ if subj.health $<4$ & $(21.4 \%)$ \\
\hline & $=0$ if subj.health $>4$ & $(86.5 \%)$ & $=1$ if subj.health $>3$ & $(78.5 \%)$ \\
\hline \multirow[t]{3}{*}{ Birth of children } & Dummies for & & Dummies for & \\
\hline & Birth & $(3.99 \%)$ & Birth & $(3.67 \%)$ \\
\hline & No birth & $(96.0 \%)$ & No birth & $(96.3 \%)$ \\
\hline \multirow[t]{6}{*}{ Education } & Dummies for: & & Dummies for: & \\
\hline & Inadequate/elementary & $(16.3 \%)$ & No Qualification & $(6.92 \%)$ \\
\hline & Mittlere Reife & $(32.7 \%)$ & GCSE & $(22.9 \%)$ \\
\hline & Abitur \& Ausbildung & $(33.5 \%)$ & A-levels & $(21.8 \%)$ \\
\hline & Tertiary education & $(16.0 \%)$ & Tertiary degree & $(26.9 \%)$ \\
\hline & Other/missing & $(1.45 \%)$ & Other higher & $(12.5 \%)$ \\
\hline Region & Bundeslander dummies & $(11)$ & Govt. region dummies & $(11)$ \\
\hline Wave & Waves dummies & $(28)$ & Waves dummies & $(18)$ \\
\hline Regional time trend & \multicolumn{2}{|c|}{ Interactions of region and waves } & \multicolumn{2}{|c|}{ Interactions of region and waves } \\
\hline
\end{tabular}


Table D.2: Descriptive statistics for observed ln household income across groups, Germany

\begin{tabular}{|c|c|c|c|c|c|c|c|c|c|}
\hline & $\mathrm{N}$ & Mean & $\mathrm{SD}$ & Min & Max & $\begin{array}{c}\text { Mean } \\
\Delta\end{array}$ & $\begin{array}{c}\mathrm{SD} \\
\Delta\end{array}$ & $\underset{\Delta}{\operatorname{Min}}$ & $\begin{array}{c}\operatorname{Max} \\
\Delta\end{array}$ \\
\hline Leavers & 29588 & 10.50 & 0.41 & 8.72 & 11.74 & 0.01 & 0.25 & -2.64 & 1.96 \\
\hline Stayers & 9262 & 0.50 & 0.41 & 8.71 & 174 & 0.01 & 0.21 & -2.11 & 1.82 \\
\hline \multicolumn{10}{|l|}{ Occupation: } \\
\hline Legislators, senio & 5068 & 10.73 & 0.41 & 8.93 & 11.73 & 0.02 & 0.20 & -1.59 & 0.97 \\
\hline Professionals & 16097 & 10.75 & 0.40 & 8.80 & & 0.02 & 0.21 & -2.10 & 1.74 \\
\hline Techni & 23898 & 10.54 & 0.40 & 8.74 & & 0.01 & 0.22 & -2.32 & 1.77 \\
\hline Office Clerks & 13555 & 10.51 & 0.42 & 8.72 & 11.70 & 0.01 & 0.22 & -2.05 & 1.58 \\
\hline Servi & 10432 & 10.39 & 0.41 & 8.71 & & 0.00 & 0.24 & -2.11 & 1.82 \\
\hline $\mathrm{S}$ & 534 & 10.32 & 0.46 & 8.89 & & 0.00 & 0.23 & -1.19 & 1.08 \\
\hline Craft & 16262 & 10.41 & 0.35 & & & 0.01 & 0.21 & -1.59 & 1.96 \\
\hline Plant & 10075 & & 0.35 & 8.72 & & 0.00 & 0.22 & -1.79 & 1.77 \\
\hline Elem & 8284 & 10.32 & 0.40 & 8.73 & & 0.00 & 0.24 & -2.64 & 1.62 \\
\hline Missing & 24645 & 10.48 & 0.37 & 8.74 & 11.74 & 0.00 & 0.21 & -2.05 & 1.36 \\
\hline \multicolumn{10}{|l|}{ Industry: } \\
\hline Agriculture & 726 & 10.40 & 0.45 & 8.89 & 1.44 & 0.00 & 0.21 & -1.52 & 0.88 \\
\hline Fishing & 7 & 10.05 & 0.84 & 9.20 & 11.27 & 0.07 & 0.48 & -0.55 & 1.06 \\
\hline Minir & 474 & 10.44 & 0.40 & 9.22 & 11.74 & 0.00 & 0.22 & -1.32 & 1.00 \\
\hline Manuf & 32990 & 10.51 & 0.39 & 8.80 & 11.71 & 0.01 & 0.21 & -1.85 & 1.73 \\
\hline Electr & 1239 & 10.63 & 0.39 & 9.35 & 11.64 & 0.02 & 0.22 & -1.27 & 1.44 \\
\hline Construction & 5842 & 10.43 & 0.36 & 8.74 & 11.73 & 0.01 & 0.22 & -1.59 & 1.63 \\
\hline Wholesale \& r & 11689 & 10.42 & 0.41 & 8.78 & 11.70 & 0.01 & 0.24 & -2.05 & 1.96 \\
\hline Hotels \& restaurans & 1733 & 10.32 & 0.44 & 8.71 & 11.62 & 0.00 & 0.28 & -1.55 & 1.64 \\
\hline Transport, storage \& communication & 5326 & 10.45 & 0.41 & 8.72 & 11.64 & 0.01 & 0.22 & -2.09 & 1.77 \\
\hline Financial intermediation & 4762 & 10.68 & 0.41 & 8.90 & 11.70 & 0.02 & 0.21 & -1.54 & 1.24 \\
\hline Real estate, renting \& busin & 6267 & 10.54 & 0.47 & 8.74 & 11.71 & 0.01 & 0.25 & -2.32 & 1.74 \\
\hline Public admin. \& defence; social security & 10255 & 10.57 & 0.39 & 8.92 & 11.66 & 0.01 & 0.20 & -1.85 & 1.35 \\
\hline Education & 7028 & 10.69 & 0.42 & 8.83 & 11.74 & 0.01 & 0.22 & -2.10 & 1.73 \\
\hline Health \& Social Work & 11133 & 10.45 & 0.44 & 8.72 & 11.69 & 0.01 & 0.24 & -2.11 & 1.82 \\
\hline Other community, social \& personal services & 3566 & 10.52 & 0.43 & 8.78 & 11.71 & 0.01 & 0.22 & -2.64 & 1.48 \\
\hline Private households with employed persons & 376 & 10.26 & 0.40 & 8.86 & 11.38 & 0.01 & 0.24 & -1.34 & 1.09 \\
\hline Extra-territorial organisations \& bodies & 119 & 10.36 & 0.38 & 9.34 & 11.28 & 0.00 & 0.25 & -1.31 & 0.71 \\
\hline Missing & 25318 & 10.48 & 0.37 & 8.74 & 11.74 & 0.00 & 0.21 & -2.05 & 1.36 \\
\hline
\end{tabular}

"Stayers" are observations in which industry/occupation combination did not change since last observation.

"Leavers" are observations in which industry/occupation combination did change since last observation.

Rows for occupation are major groupings from ISCO88. Rows for industry are major groupings from NACE1.1.

$\Delta$ means change between years. 
Table D.3: Descriptive statistics for observed ln household income across groups, UK

\begin{tabular}{|c|c|c|c|c|c|c|c|c|c|}
\hline & $\mathrm{N}$ & Mean & $\mathrm{SD}$ & Min & Max & $\begin{array}{c}\text { Mean } \\
\Delta\end{array}$ & $\begin{array}{l}\mathrm{SD} \\
\Delta\end{array}$ & $\underset{\Delta}{\operatorname{Min}}$ & $\underset{\Delta}{\operatorname{Max}}$ \\
\hline Leavers & 24729 & 10.21 & 0.45 & 7.94 & 11.61 & 0.01 & 0.31 & -2.12 & 2.10 \\
\hline Stay & 63441 & 10.27 & 0.46 & 7.86 & 11.65 & 0.02 & 0.28 & -2.40 & 2.23 \\
\hline \multicolumn{10}{|l|}{ Occupation: } \\
\hline Legislators, senior & 12512 & 10.44 & 0.42 & 8.47 & 11.59 & 0.03 & 0.26 & -2.34 & 2.10 \\
\hline Professionals & 11985 & 1( & 0.41 & 8.25 & 11.63 & 0.02 & 0.27 & -2.12 & 2.12 \\
\hline Technicians \& associate professionals & 12273 & 10.33 & 0.43 & 8.22 & 11.65 & 0.02 & 0.27 & -1.97 & 1.86 \\
\hline Office Clerks & 12456 & 10.19 & 0.44 & 8.18 & 11.57 & 0.02 & 0.29 & -2.30 & 2.11 \\
\hline in \& market sales workers & 12442 & 10.13 & 0.48 & 7.86 & 11.59 & 0.01 & 0.32 & -2.40 & 1.74 \\
\hline Skilled & 355 & 9.95 & 0.47 & 8.96 & 11.08 & 0.04 & 0.30 & -1.48 & 1.37 \\
\hline Craft \& 1 & 5116 & 10.19 & 0.39 & 8.43 & 11.61 & 0.03 & 0.25 & -1.78 & 1.53 \\
\hline Plant \& & 5075 & 10 & 0.42 & 8.07 & 11.64 & 0.02 & 0.26 & -2.09 & 2.02 \\
\hline Elementa & 5999 & 10.05 & 0.47 & 7.94 & 11.65 & 0.02 & 0.31 & -2.02 & 2.23 \\
\hline Missing & 9957 & 10.17 & 0.44 & 7.86 & 11.64 & -0.02 & 0.31 & -1.95 & 2.23 \\
\hline \multicolumn{10}{|l|}{ Industry: } \\
\hline $\begin{array}{l}\text { Agriculture, hunting \& forestry } \\
\text { Fishing }\end{array}$ & 162 & 10.28 & 0.49 & 9.20 & 11.54 & 0.04 & 0.32 & -0.83 & 2.02 \\
\hline Mining \& quarrying & 521 & 4 & 0.50 & & 1 & 0.05 & 0.26 & -1.48 & 1.06 \\
\hline Manv & 11365 & 10.23 & 0.42 & 8.07 & 11.54 & 0.03 & 0.25 & -2.09 & 2.09 \\
\hline Electric & 852 & 10.26 & 0.46 & 8.43 & 11.52 & 0.03 & 0.32 & -1.91 & 1.50 \\
\hline Constru & 2566 & 10.31 & 0.43 & 8.47 & 11.61 & 0.03 & 0.28 & -1.78 & 2.10 \\
\hline Wholesa & 8585 & 10.16 & 0.46 & 8.07 & 11.59 & 0.01 & 0.31 & -2.34 & 2.06 \\
\hline Hotels & 1822 & 10.08 & 0.49 & 8.45 & 11.65 & 0.02 & 0.35 & -2.30 & 2.23 \\
\hline munication & 6077 & 10.26 & 0.46 & 8.18 & 11.64 & 0.02 & 0.28 & -1.74 & 1.92 \\
\hline Finan & 5963 & 10.30 & 0.48 & 7.86 & 11.59 & 0.03 & 0.28 & -1.98 & 2.12 \\
\hline Real e & 5334 & 10.34 & 0.46 & 7.94 & 11.57 & 0.03 & 0.28 & -1.97 & 1.73 \\
\hline Public admin. \& defence; social security & 6517 & 10.35 & 0.43 & 8.45 & 11.57 & 0.02 & 0.26 & -1.70 & 2.09 \\
\hline Education & 9140 & 10.38 & 0.45 & 8.38 & 11.58 & 0.01 & 0.29 & -2.40 & 1.69 \\
\hline Health \& S & 12082 & 10.29 & 0.45 & 8.21 & 11.65 & 0.02 & 0.30 & -2.00 & 2.04 \\
\hline Other c & 5491 & 10.20 & 0.45 & 8.03 & 11.54 & 0.02 & 0.28 & -1.95 & 2.11 \\
\hline Private & 954 & 10.08 & 0.45 & 8.39 & 11.07 & 0.03 & 0.25 & -1.58 & 1.13 \\
\hline erritorial organisations \& bodies & 1539 & 10.13 & 0.48 & 8.11 & 11.61 & 0.04 & 0.29 & -2.07 & 1.40 \\
\hline Missing & 9198 & 10.14 & 0.43 & 7.86 & 11.55 & -0.02 & 0.32 & -1.95 & 2.23 \\
\hline
\end{tabular}

"Stayers" are observations in which industry/occupation combination did not change since last observation.

"Leavers" are observations in which industry/occupation combination did change since last observation.

Rows for occupation are major groupings from ISCO88. Rows for industry are major groupings from NACE1.1.

$\Delta$ means change between years. 
Table D.4: Descriptive statistics for predicted ln household income across groups, DE

\begin{tabular}{|c|c|c|c|c|c|c|c|c|c|}
\hline & $\mathrm{N}$ & Mean & $\mathrm{SD}$ & Min & Max & $\begin{array}{c}\text { Mean } \\
\Delta\end{array}$ & $\begin{array}{c}\mathrm{SD} \\
\Delta\end{array}$ & $\underset{\Delta}{\operatorname{Min}}$ & $\begin{array}{c}\operatorname{Max} \\
\Delta\end{array}$ \\
\hline Leavers & 29588 & 10.67 & 0.56 & 4.47 & 12.27 & 0.00 & 0.50 & -5.37 & 4.21 \\
\hline Stayers & 9262 & 10.64 & 0.55 & 2.77 & 227 & 0.00 & 0.28 & -7.13 & 5.25 \\
\hline \multicolumn{10}{|l|}{ Occupation: } \\
\hline Legislators, senio & 5068 & 11.11 & 0.39 & 8.03 & 12.17 & 0.09 & 0.29 & -2.23 & 2.98 \\
\hline Professionals & 16097 & 11.02 & 0.40 & 8.71 & 12.27 & 0.03 & 0.26 & -2.07 & 3.60 \\
\hline Techni & 23898 & 74 & 0.50 & 7.52 & 12.27 & 0.02 & 0.30 & -2.90 & 3.05 \\
\hline Office & 13555 & 10.66 & 0.57 & 5.05 & 12.07 & 0.01 & 0.34 & -5.93 & 4.21 \\
\hline Servi & 10432 & 10.46 & 0.65 & 4.22 & & 0.00 & 0.40 & -7.13 & 4.21 \\
\hline $\mathrm{S}$ & 534 & 10.42 & 0.69 & 6.03 & & 0.01 & 0.46 & -4.55 & 3.60 \\
\hline Craft & 16262 & 10.63 & 0.42 & 5.81 & 27 & 0.02 & 0.29 & -3.50 & 3.79 \\
\hline Plant & 10075 & & 0.44 & & & 0.02 & 0.30 & -3.11 & 2.94 \\
\hline Elem & 8284 & 10.34 & 0.69 & 2.77 & & -0.01 & 0.46 & -5.37 & 5.25 \\
\hline Missing & 24645 & 10.44 & 0.53 & 4.47 & 12.27 & -0.08 & 0.38 & -5.23 & 3.83 \\
\hline \multicolumn{10}{|l|}{ Industry: } \\
\hline Agriculture & 726 & 10.53 & 0.59 & 7.36 & 1 & 0.03 & 0.39 & -2.48 & 3.60 \\
\hline Fishing & 7 & 9.93 & 0.43 & 9.48 & 10.50 & -0.06 & 0.10 & -0.28 & 0.03 \\
\hline Minir & 474 & 10.72 & 0.50 & 6.80 & 12.27 & 0.04 & 0.34 & -3.11 & 2.83 \\
\hline Manu & 32990 & 10.76 & 0.46 & 6.69 & 12.27 & 0.03 & 0.28 & -3.48 & 3.79 \\
\hline Electı & 1239 & 10.94 & 0.40 & 9.30 & 11.86 & 0.04 & 0.28 & -1.97 & 1.95 \\
\hline Construc & 5842 & 10.62 & 0.44 & 7.99 & 11.99 & 0.03 & 0.29 & -1.89 & 3.05 \\
\hline Wholesa & 11689 & 10.52 & 0.64 & 4.22 & 12.08 & 0.00 & 0.40 & -7.13 & 3.79 \\
\hline Hotels \& restaurans & 1733 & 10.33 & 0.70 & 6.71 & 12.21 & 0.01 & 0.45 & -3.67 & 2.83 \\
\hline Transport, storage \& communication & 5326 & 10.65 & 0.51 & 7.29 & 12.05 & 0.03 & 0.32 & -2.62 & 2.94 \\
\hline Financial intermediation & 4762 & 11.00 & 0.40 & 8.16 & 12.21 & 0.03 & 0.25 & -1.47 & 2.98 \\
\hline Real estate, renting \& busin & 6267 & 10.71 & 0.62 & 7.14 & 12.17 & 0.02 & 0.37 & -3.34 & 3.60 \\
\hline Public admin. \& defence; social security & 10255 & 10.76 & 0.50 & 4.55 & 12.21 & 0.01 & 0.27 & -3.70 & 2.90 \\
\hline Education & 7028 & 10.82 & 0.54 & 6.70 & 12.05 & 0.01 & 0.30 & -3.13 & 2.74 \\
\hline Health \& Social Work & 11133 & 10.57 & 0.63 & 5.68 & 12.15 & 0.01 & 0.37 & -5.37 & 5.24 \\
\hline Other community, social \& personal services & 3566 & 10.64 & 0.63 & 6.41 & 12.12 & 0.00 & 0.38 & -4.15 & 4.68 \\
\hline Private households with employed persons & 376 & 10.16 & 0.98 & 2.77 & 11.68 & -0.08 & 0.73 & -5.25 & 5.25 \\
\hline Extra-territorial organisations \& bodies & 119 & 10.63 & 0.48 & 9.17 & 12.17 & -0.01 & 0.34 & -1.65 & 1.19 \\
\hline Missing & 25318 & 10.43 & 0.53 & 4.47 & 12.27 & -0.08 & 0.38 & -5.23 & 3.83 \\
\hline
\end{tabular}

"Stayers" are observations in which industry/occupation combination did not change since last observation.

"Leavers" are observations in which industry/occupation combination did change since last observation.

Rows for occupation are major groupings from ISCO88. Rows for industry are major groupings from NACE1.1.

$\Delta$ means change between years. 
Table D.5: Descriptive statistics for predicted ln household income across groups, UK

\begin{tabular}{|c|c|c|c|c|c|c|c|c|c|}
\hline & $\mathrm{N}$ & Mean & $\mathrm{SD}$ & Min & Max & $\begin{array}{c}\text { Mean } \\
\Delta\end{array}$ & $\begin{array}{c}\mathrm{SD} \\
\Delta\end{array}$ & $\underset{\Delta}{\operatorname{Min}}$ & $\begin{array}{c}\operatorname{Max} \\
\Delta\end{array}$ \\
\hline Leavers & 24729 & 10.28 & 0.56 & 4.45 & 11.87 & 0.01 & 0.45 & -4.16 & 3.49 \\
\hline Stayers & 63441 & 10.27 & 0.59 & 3.40 & 1.87 & 0.01 & 0.30 & -3.87 & 3.63 \\
\hline \multicolumn{10}{|l|}{ Occupation: } \\
\hline Legislators, senio & 12512 & 10.64 & 0.37 & 8.95 & 11.87 & 0.06 & 0.29 & -2.27 & 3.19 \\
\hline Professionals & 11985 & 10.61 & 0.39 & 8.78 & 11.72 & 0.03 & 0.28 & -1.44 & 3.14 \\
\hline Technic & 12273 & 10.41 & 0.46 & 8.57 & 11.87 & 0.02 & 0.31 & -1.72 & 2.82 \\
\hline Office Clerks & 12456 & 10.17 & 0.58 & 5.24 & 11.68 & -0.01 & 0.38 & -3.81 & 3.49 \\
\hline Servi & 12442 & 10.00 & 0.68 & 4.45 & & 0.01 & 0.42 & -3.26 & 3.35 \\
\hline Skille & 355 & 9.94 & 0.49 & 8.68 & & 0.00 & 0.37 & -1.70 & 1.22 \\
\hline Craft \& & 5116 & 10.31 & 0.39 & 8.09 & 11.56 & 0.02 & 0.28 & -2.34 & 2.20 \\
\hline Plant \& & 5075 & 10.19 & 0.44 & 6.92 & & 0.02 & 0.30 & -2.08 & 3.33 \\
\hline Eleme & 5999 & 9.95 & 0.68 & 3.40 & 6 & 0.00 & 0.40 & -4.16 & 3.33 \\
\hline Missing & 9957 & 9.95 & 0.59 & 4.82 & 11.87 & -0.09 & 0.43 & -4.16 & 3.63 \\
\hline \multicolumn{10}{|l|}{ Industry: } \\
\hline \multirow{2}{*}{\multicolumn{10}{|c|}{ Fishing }} \\
\hline & & & & & & & & & \\
\hline Mining \& & 521 & 10.29 & 0.59 & 7.30 & 11.56 & 0.05 & 0.37 & -1.67 & 2.36 \\
\hline Manufact & 11365 & 10.38 & 0.44 & 6.75 & 11.83 & 0.03 & 0.28 & -2.34 & 2.12 \\
\hline Gas \& water & 852 & 10.40 & 0.48 & 7.96 & 11.49 & 0.03 & 0.29 & -1.54 & 1.94 \\
\hline Construction & 2566 & 10.43 & 0.43 & 8.77 & 11.52 & 0.03 & 0.28 & -1.34 & 2.90 \\
\hline Wholesale \& re & 8585 & 10.10 & 0.65 & 6.50 & 11.65 & 0.01 & 0.39 & -3.62 & 3.49 \\
\hline Hotels \& restaurans & 1822 & 9.88 & 0.77 & 6.16 & 11.63 & 0.00 & 0.45 & -2.77 & 2.52 \\
\hline Transport, storage \& communication & 6077 & 10.35 & 0.53 & 7.49 & 11.63 & 0.02 & 0.32 & -2.44 & 2.67 \\
\hline Financial intermediation & 5963 & 10.44 & 0.57 & 3.40 & 11.80 & 0.03 & 0.34 & -4.16 & 2.95 \\
\hline Real estate, renting \& busin & 5334 & 10.47 & 0.50 & 7.81 & 11.63 & 0.04 & 0.33 & -2.11 & 3.35 \\
\hline Public admin. \& defence; social security & 6517 & 10.46 & 0.47 & 8.74 & 11.87 & 0.02 & 0.30 & -1.79 & 3.13 \\
\hline Education & 9140 & 10.39 & 0.57 & 6.67 & 11.87 & 0.01 & 0.35 & -2.16 & 3.14 \\
\hline Health \& Social Work & 12082 & 10.27 & 0.59 & 6.95 & 11.80 & 0.02 & 0.35 & -2.15 & 3.19 \\
\hline Other community, social \& personal services & 5491 & 10.21 & 0.59 & 5.24 & 11.61 & 0.02 & 0.36 & -3.81 & 2.55 \\
\hline Private households with employed persons & 954 & 10.13 & 0.65 & 4.45 & 11.61 & 0.03 & 0.38 & -3.26 & 1.99 \\
\hline Extra-territorial organisations \& bodies & 1539 & 10.17 & 0.64 & 7.02 & 11.63 & 0.04 & 0.42 & -2.46 & 3.33 \\
\hline Missing & 9198 & 9.90 & 0.57 & 4.82 & 11.87 & -0.10 & 0.44 & -4.16 & 3.63 \\
\hline
\end{tabular}

"Stayers" are observations in which industry/occupation combination did not change since last observation.

"Leavers" are observations in which industry/occupation combination did change since last observation.

Rows for occupation are major groupings from ISCO88. Rows for industry are major groupings from NACE1.1.

$\Delta$ means change between years. 
Table D.6: Descriptive statistics on reference groups and overlap with industry/occupation and reference group

\begin{tabular}{lcrrrrrrrr}
\hline & Mean & $1^{\text {st }}$ pct. & $25^{\text {th }}$ pct. & Median & $75^{\text {th }}$ pct. & $99^{\text {th }}$ pct. & SD & Min & Max \\
\hline Germany & & & & & & & & & \\
Size of reference group & 701.8 & 233.0 & 394.0 & 619.0 & 903.0 & 1264.0 & 429.9 & 1.0 & 2246.0 \\
Same indust. \& occup. & 0.064 & 0.001 & 0.003 & 0.008 & 0.038 & 0.240 & 0.127 & 0.000 & 1.000 \\
Same occupation & 0.103 & 0.010 & 0.022 & 0.055 & 0.129 & 0.280 & 0.127 & 0.000 & 1.000 \\
Same industry & 0.081 & 0.006 & 0.014 & 0.032 & 0.074 & 0.244 & 0.124 & 0.000 & 1.000 \\
\hline UK & & & & & & & & & \\
Size of reference group & 847.7 & 185.0 & 325.0 & 580.0 & 1261.0 & 1986.0 & 657.5 & 7.0 & 2524.0 \\
Same indust. \& occup. & 0.034 & 0.001 & 0.002 & 0.006 & 0.026 & 0.084 & 0.079 & 0.000 & 0.802 \\
Same occupation & 0.079 & 0.007 & 0.016 & 0.051 & 0.108 & 0.200 & 0.091 & 0.000 & 0.802 \\
Same industry & 0.058 & 0.007 & 0.015 & 0.035 & 0.069 & 0.118 & 0.078 & 0.000 & 0.802 \\
\hline
\end{tabular}

Note: "pct." refers to percentile. 
Robustness tables 


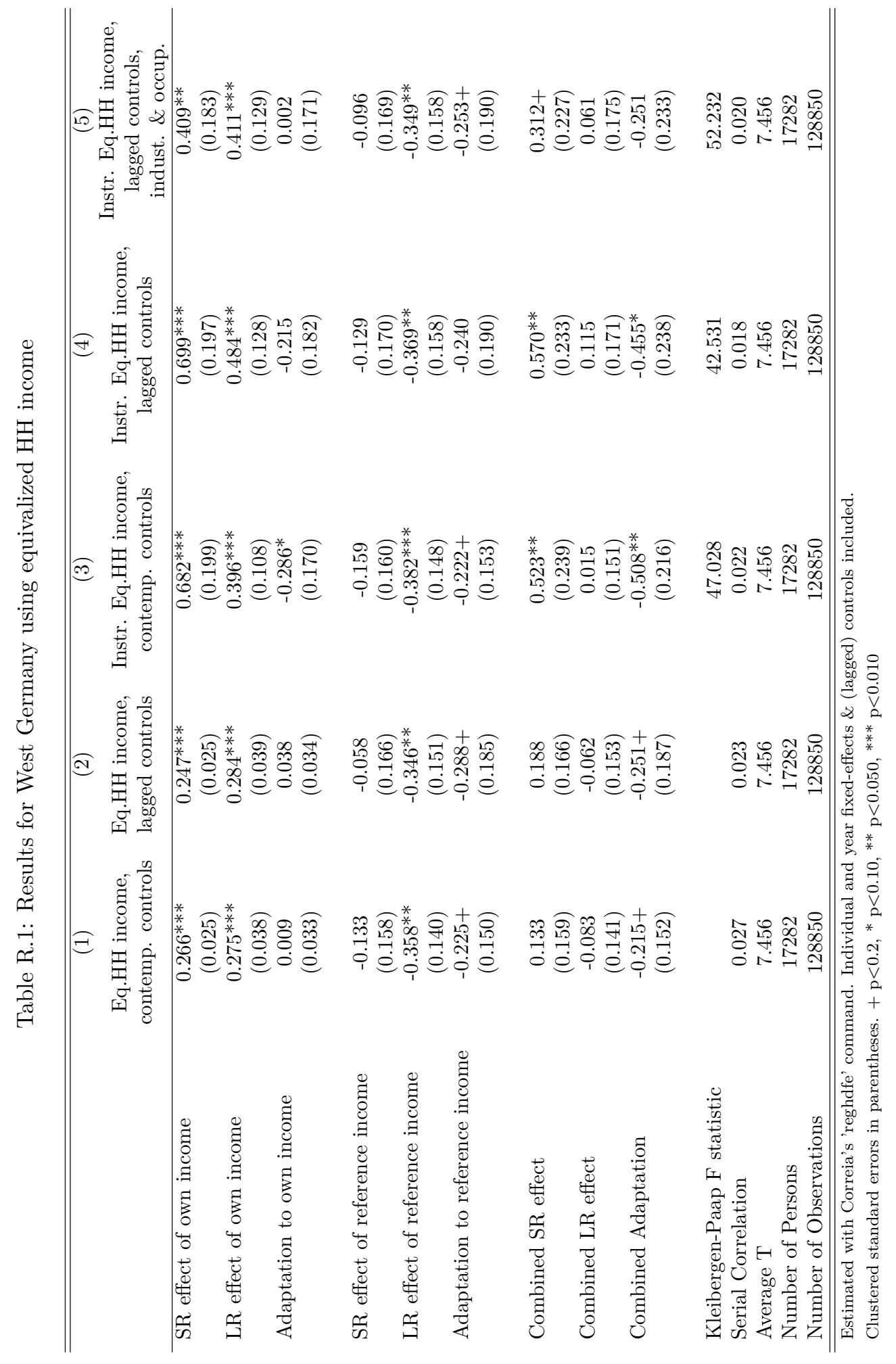




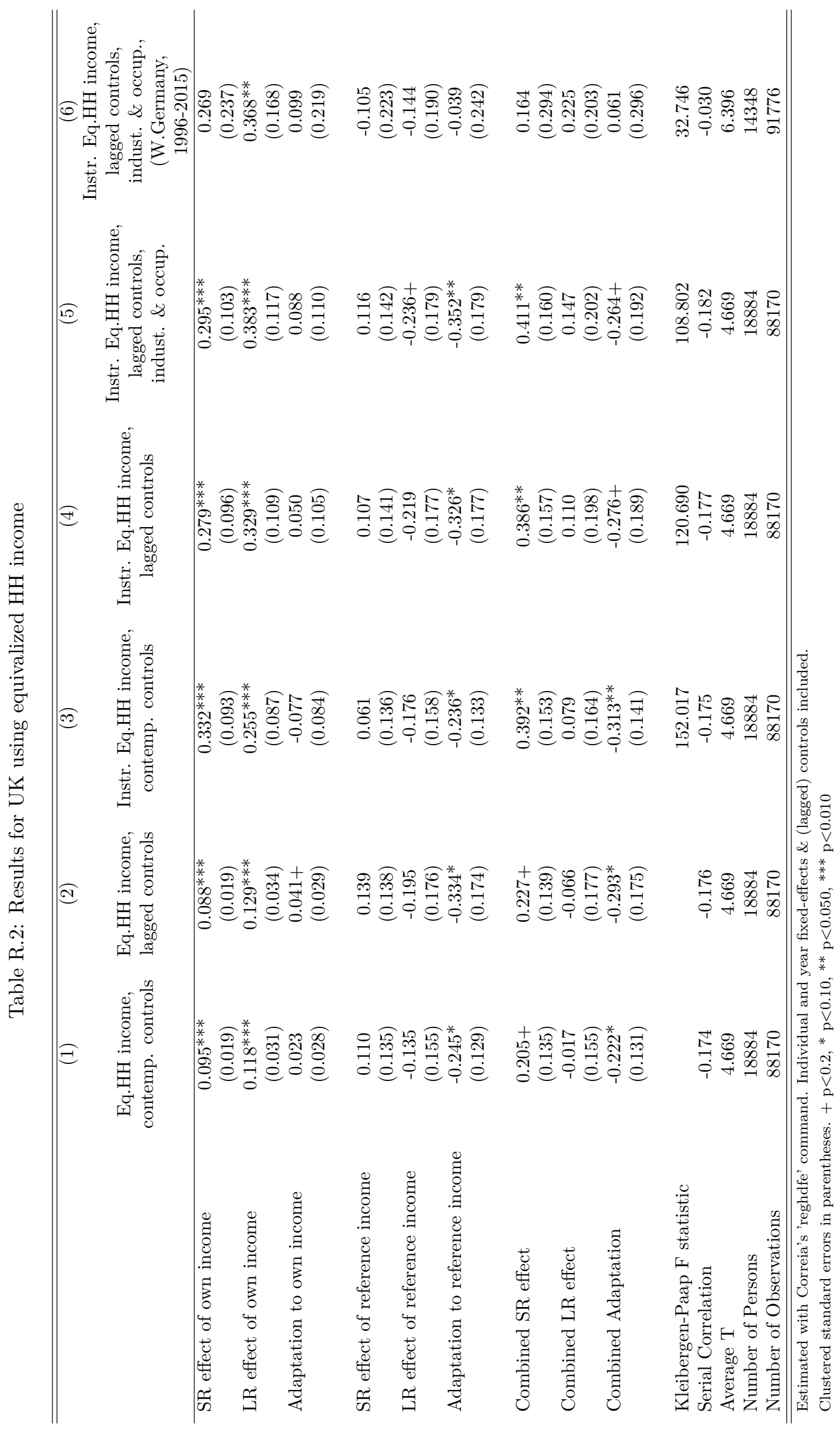


Table R.3: Main results, using non-eq. reference income

\begin{tabular}{|c|c|c|c|c|}
\hline & $\begin{array}{c}\text { (1) } \\
\text { W.Germany, } \\
\text { instr. HH income, } \\
\text { lagged controls }\end{array}$ & $\begin{array}{c}(2) \\
\text { W.Germany, } \\
\text { instr. HH income, } \\
\text { lagged controls, } \\
\text { indust. \& occup. }\end{array}$ & $\begin{array}{c}(3) \\
\text { UK, instr. HH income, } \\
\text { lagged controls }\end{array}$ & $\begin{array}{c}(4) \\
\text { UK, instr. HH income, } \\
\text { lagged controls, } \\
\text { indust. \& occup. }\end{array}$ \\
\hline SR effect of own income & $\begin{array}{c}0.714^{* * *} \\
(0.199)\end{array}$ & $\begin{array}{c}0.424^{* *} \\
(0.185)\end{array}$ & $\begin{array}{c}0.286^{* * *} \\
(0.095)\end{array}$ & $\begin{array}{c}0.303^{* * *} \\
(0.102)\end{array}$ \\
\hline LR effect of own income & $\begin{array}{c}0.473^{* * *} \\
(0.130)\end{array}$ & $\begin{array}{c}0.401^{* * *} * \\
(0.131)\end{array}$ & $\begin{array}{c}0.329^{* * *} \\
(0.107)\end{array}$ & $\begin{array}{c}0.383^{* * *} \\
(0.115)\end{array}$ \\
\hline Adaptation to own income & $\begin{array}{c}-0.242+ \\
(0.183)\end{array}$ & $\begin{array}{l}-0.023 \\
(0.171)\end{array}$ & $\begin{array}{c}0.043 \\
(0.103)\end{array}$ & $\begin{array}{c}0.080 \\
(0.108)\end{array}$ \\
\hline SR effect of reference income & $\begin{array}{c}0.202 \\
(0.169)\end{array}$ & $\begin{array}{l}0.251+ \\
(0.168)\end{array}$ & $\begin{array}{c}0.123 \\
(0.131)\end{array}$ & $\begin{array}{c}0.146 \\
(0.132)\end{array}$ \\
\hline LR effect of reference income & $\begin{array}{l}-0.138 \\
(0.113)\end{array}$ & $\begin{array}{l}-0.123 \\
(0.112)\end{array}$ & $\begin{array}{r}-0.246+ \\
(0.161)\end{array}$ & $\begin{array}{c}-0.268^{*} \\
(0.162)\end{array}$ \\
\hline Adaptation to reference income & $\begin{array}{c}-0.340^{* *} \\
(0.168)\end{array}$ & $\begin{array}{c}-0.374^{* *} \\
(0.168)\end{array}$ & $\begin{array}{c}-0.369^{* *} \\
(0.163)\end{array}$ & $\begin{array}{c}-0.414^{* *} \\
(0.164)\end{array}$ \\
\hline Combined SR effect & $\begin{array}{c}0.916^{* * *} \\
(0.229)\end{array}$ & $\begin{array}{c}0.674^{* * *} \\
(0.222)\end{array}$ & $\begin{array}{c}0.409^{* * *} \\
(0.147)\end{array}$ & $\begin{array}{c}0.449^{* * *} \\
(0.150)\end{array}$ \\
\hline Combined LR effect & $\begin{array}{c}0.335^{* *} \\
(0.143)\end{array}$ & $\begin{array}{l}0.278^{*} \\
(0.147)\end{array}$ & $\begin{array}{c}0.083 \\
(0.190)\end{array}$ & $\begin{array}{c}0.115 \\
(0.194)\end{array}$ \\
\hline Combined Adaptation & $\begin{array}{c}-0.582^{* * *} \\
(0.224)\end{array}$ & $\begin{array}{c}-0.397^{*} \\
(0.218)\end{array}$ & $\begin{array}{c}-0.326^{*} \\
(0.184)\end{array}$ & $\begin{array}{c}-0.334^{*} \\
(0.187)\end{array}$ \\
\hline Kleibergen-Paap F statistic & 42.042 & 51.956 & 120.634 & 109.105 \\
\hline Serial Correlation & 0.018 & 0.019 & -0.177 & -0.182 \\
\hline Average $\mathrm{T}$ & 7.456 & 7.456 & 4.669 & 4.669 \\
\hline Number of Persons & 17282 & 17282 & 18884 & 18884 \\
\hline Number of Observations & 128850 & 128850 & 88170 & 88170 \\
\hline
\end{tabular}

Estimated with Correia's 'reghdfe' command. Individual and year fixed-effects \& (lagged) controls included.

Clustered standard errors in parentheses. $+\mathrm{p}<0.2,{ }^{*} \mathrm{p}<0.10,{ }^{* *} \mathrm{p}<0.050,{ }^{* * *} \mathrm{p}<0.010$ 


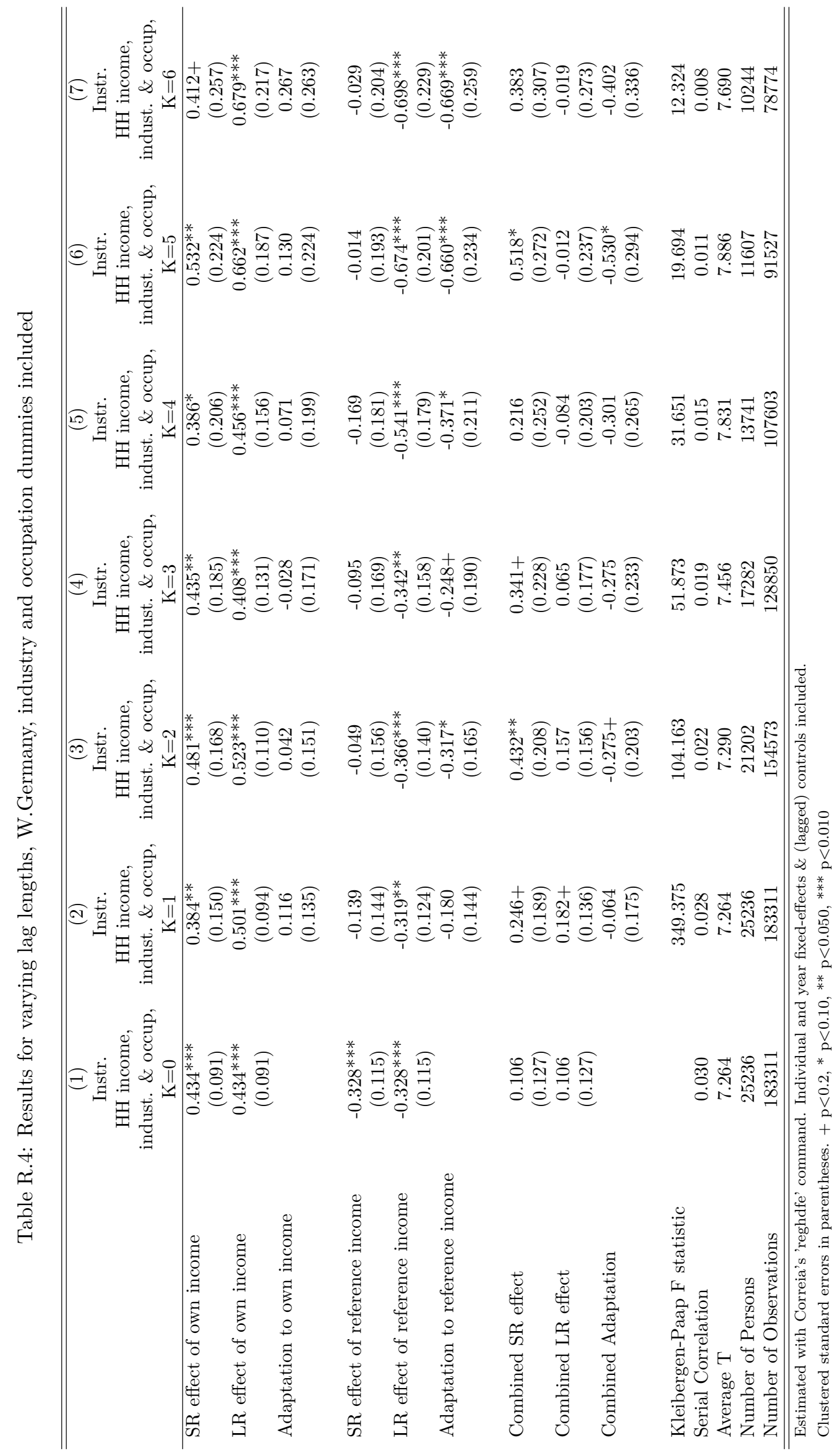




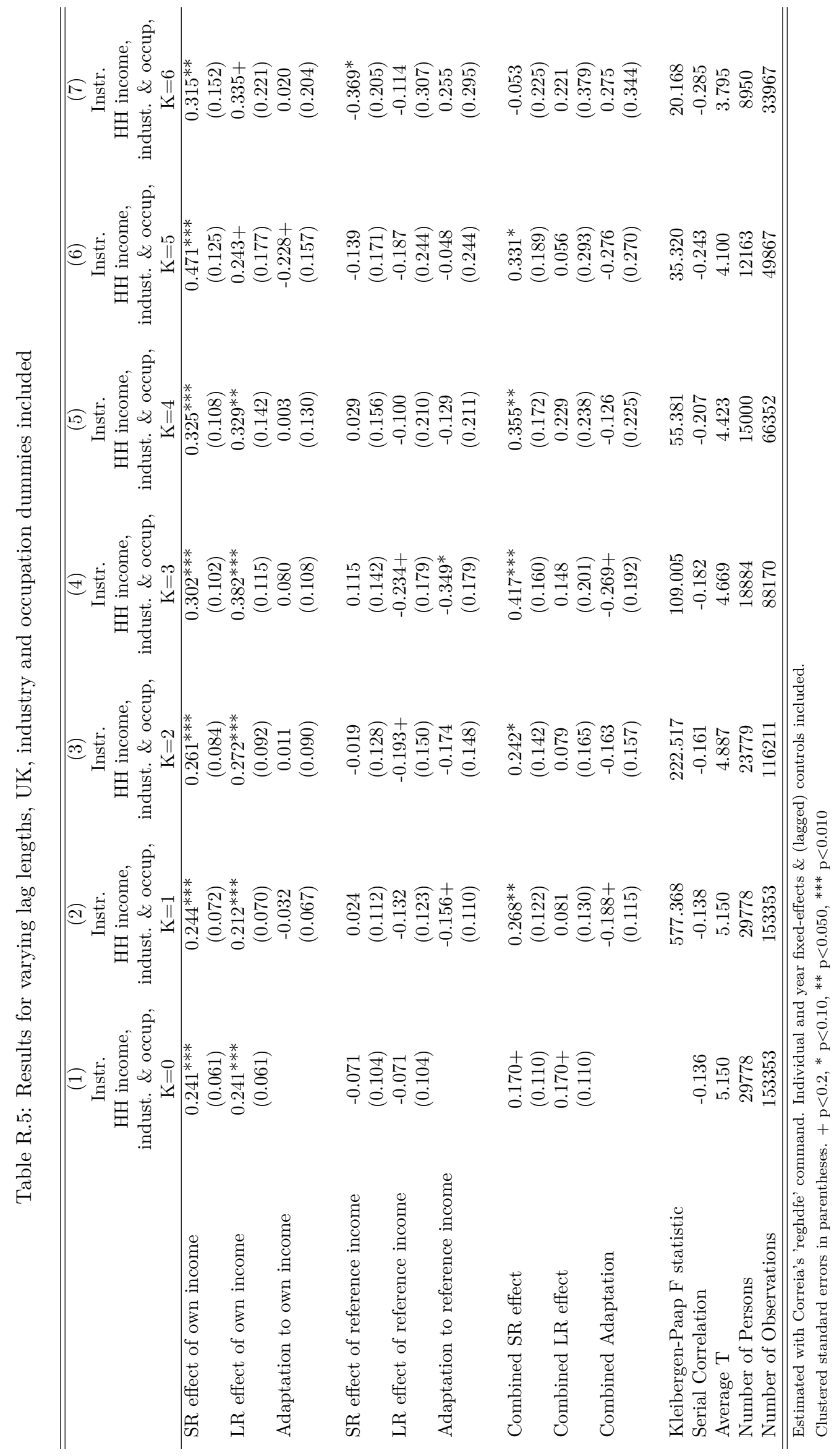




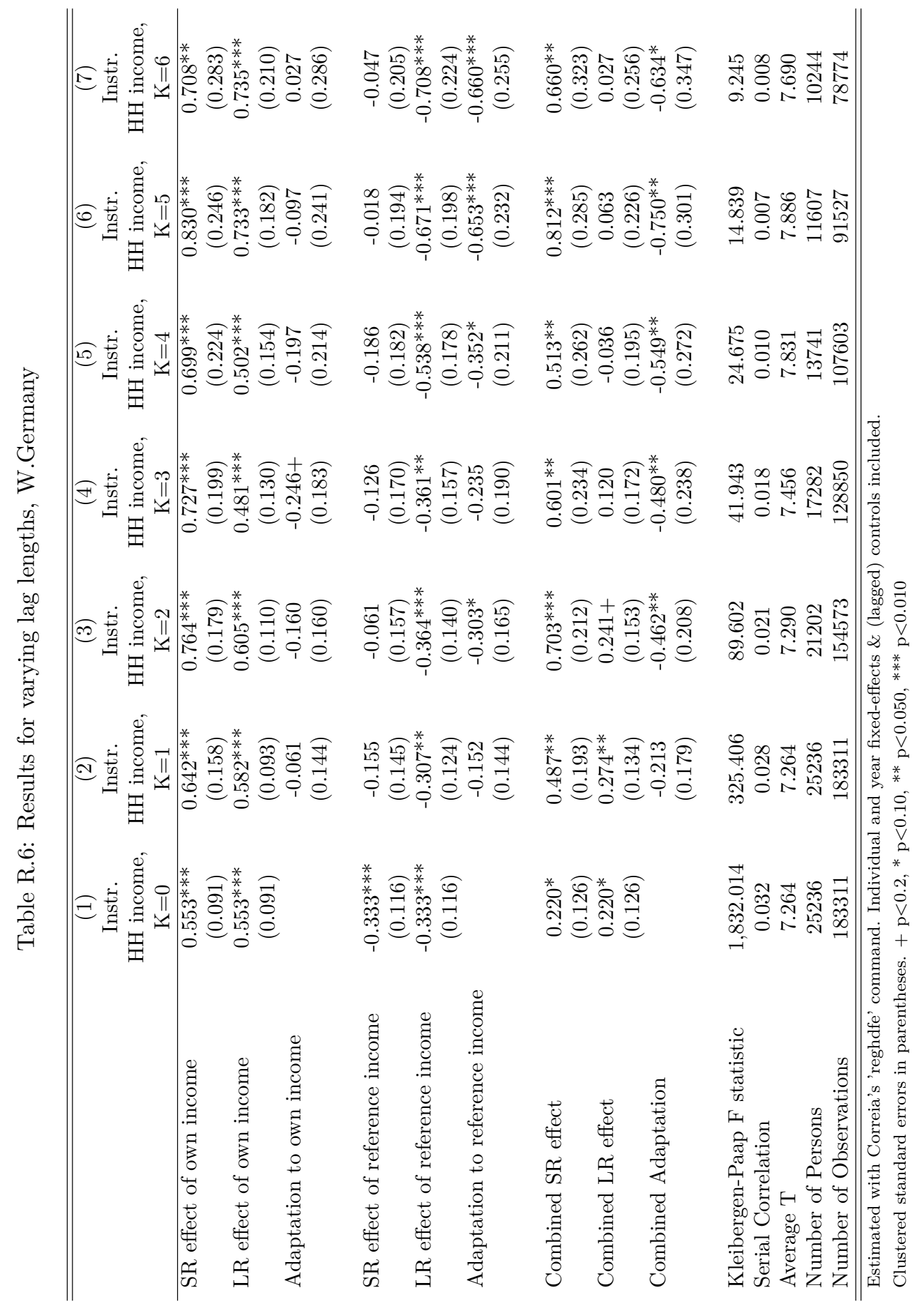




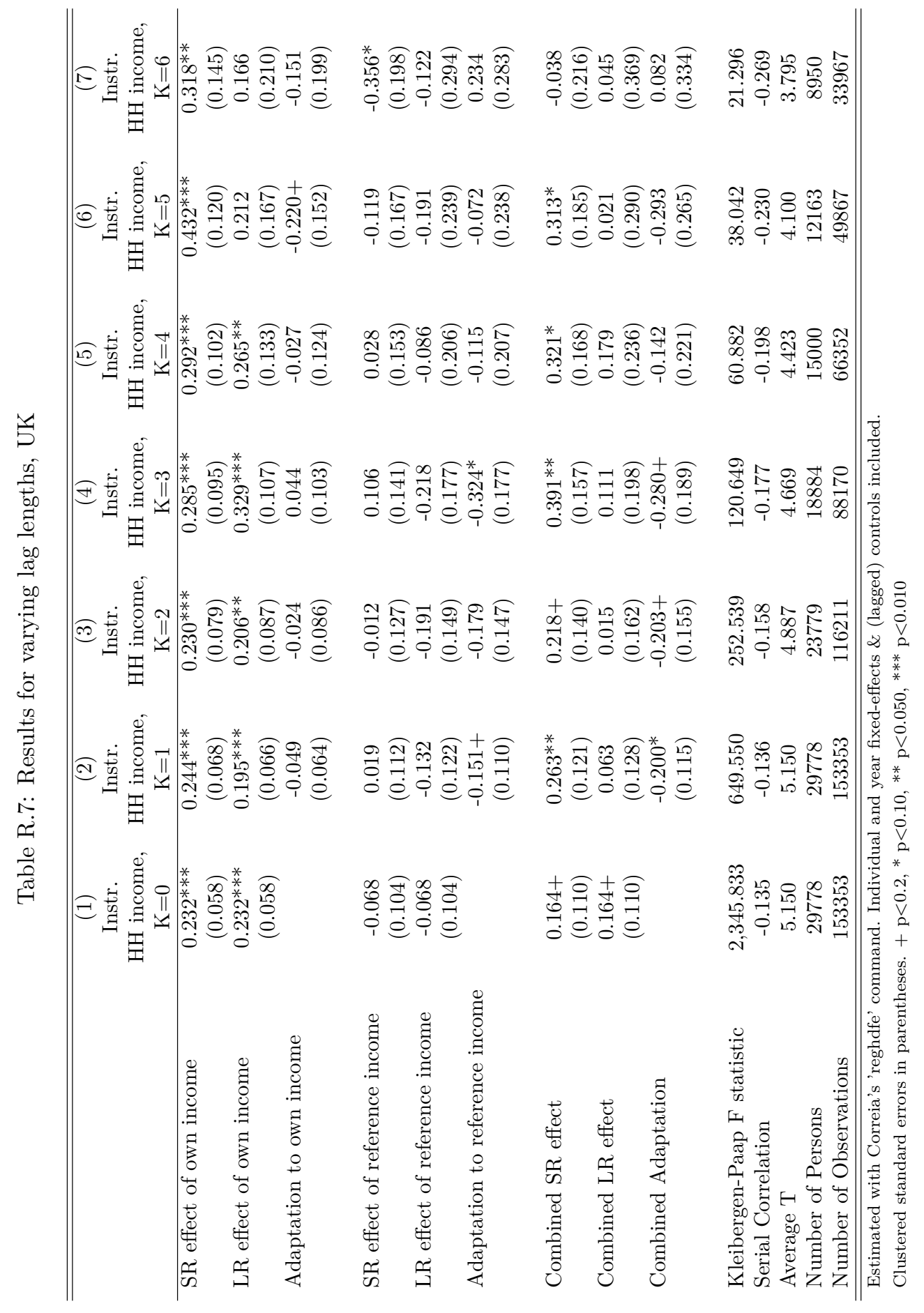


Table R.8: Check anticipation

\begin{tabular}{|c|c|c|c|c|}
\hline & $\begin{array}{c}(1) \\
\text { W.Germany, } \\
\text { Instr. HH income, } \\
\text { lagged controls }\end{array}$ & $\begin{array}{c}(2) \\
\text { W.Germany, } \\
\text { Instr. HH income, } \\
\text { lagged controls, } \\
\text { indust. \& occup. }\end{array}$ & $\begin{array}{c}(3) \\
\text { UK, } \\
\text { Instr. HH income, } \\
\text { lagged controls }\end{array}$ & $\begin{array}{c}(4) \\
\text { UK, } \\
\text { Instr. HH income, } \\
\text { lagged controls, } \\
\text { indust. \& occup. }\end{array}$ \\
\hline Anticipation of own income & $\begin{array}{c}0.212 \\
(0.213)\end{array}$ & $\begin{array}{c}0.206 \\
(0.196)\end{array}$ & $\begin{array}{c}0.059 \\
(0.110)\end{array}$ & $\begin{array}{c}0.005 \\
(0.116)\end{array}$ \\
\hline Contemp. effect of own income & $\begin{array}{l}0.494^{*} \\
(0.287)\end{array}$ & $\begin{array}{c}0.249 \\
(0.253)\end{array}$ & $\begin{array}{c}0.338^{* * *} \\
(0.128)\end{array}$ & $\begin{array}{c}0.362^{* * *} \\
(0.136)\end{array}$ \\
\hline SR effect of own income & $\begin{array}{c}0.706^{* * *} \\
(0.207)\end{array}$ & $\begin{array}{c}0.455^{* *} \\
(0.197)\end{array}$ & $\begin{array}{c}0.397^{* * *} \\
(0.132)\end{array}$ & $\begin{array}{c}0.367^{* * *} \\
(0.141)\end{array}$ \\
\hline LR effect of own income & $\begin{array}{c}0.471^{* * *} \\
(0.153)\end{array}$ & $\begin{array}{c}0.397 * * * \\
(0.154)\end{array}$ & $\begin{array}{c}0.417^{* * *} * \\
(0.143)\end{array}$ & $\begin{array}{c}0.471^{* * *} \\
(0.156)\end{array}$ \\
\hline Adaptation to own income & $\begin{array}{l}-0.235 \\
(0.192)\end{array}$ & $\begin{array}{l}-0.058 \\
(0.180)\end{array}$ & $\begin{array}{c}0.020 \\
(0.123)\end{array}$ & $\begin{array}{c}0.105 \\
(0.130)\end{array}$ \\
\hline Anticipation of reference income & $\begin{array}{l}0.325^{*} \\
(0.176)\end{array}$ & $\begin{array}{l}0.285+ \\
(0.176)\end{array}$ & $\begin{array}{c}0.153 \\
(0.162)\end{array}$ & $\begin{array}{c}0.171 \\
(0.165)\end{array}$ \\
\hline Contemp. effect of reference income & $\begin{array}{r}-0.307+ \\
(0.176)\end{array}$ & $\begin{array}{r}-0.264+ \\
(0.203)\end{array}$ & $\begin{array}{l}-0.088 \\
(0.171)\end{array}$ & $\begin{array}{c}-0.092 \\
(0.176)\end{array}$ \\
\hline SR effect of reference income & $\begin{array}{c}0.018 \\
(0.196)\end{array}$ & $\begin{array}{c}0.021 \\
(0.196)\end{array}$ & $\begin{array}{c}0.065 \\
(0.198)\end{array}$ & $\begin{array}{c}0.079 \\
(0.205)\end{array}$ \\
\hline LR effect of reference income & $\begin{array}{c}-0.363^{* *} \\
(0.179)\end{array}$ & $\begin{array}{c}-0.362^{* *} \\
(0.180)\end{array}$ & $\begin{array}{l}-0.156 \\
(0.219)\end{array}$ & $\begin{array}{l}-0.185 \\
(0.224)\end{array}$ \\
\hline Adaptation to reference income & $\begin{array}{c}-0.381^{*} \\
(0.208)\end{array}$ & $\begin{array}{c}-0.382^{*} \\
(0.209)\end{array}$ & $\begin{array}{c}-0.220 \\
(0.202)\end{array}$ & $\begin{array}{c}-0.264 \\
(0.207)\end{array}$ \\
\hline Combined Anticipation & $\begin{array}{c}0.537^{* *} \\
(0.250)\end{array}$ & $\begin{array}{c}0.491^{* *} \\
(0.241)\end{array}$ & $\begin{array}{c}0.212 \\
(0.179)\end{array}$ & $\begin{array}{c}0.176 \\
(0.184)\end{array}$ \\
\hline Combined SR effect & $\begin{array}{c}0.724^{* * *} \\
(0.259)\end{array}$ & $\begin{array}{l}0.476^{*} \\
(0.257)\end{array}$ & $\begin{array}{c}0.461^{* *} \\
(0.223)\end{array}$ & $\begin{array}{l}0.446^{*} \\
(0.230)\end{array}$ \\
\hline Combined LR effect & $\begin{array}{c}0.108 \\
(0.195)\end{array}$ & $\begin{array}{c}0.035 \\
(0.202)\end{array}$ & $\begin{array}{c}0.261 \\
(0.251)\end{array}$ & $\begin{array}{c}0.286 \\
(0.258)\end{array}$ \\
\hline Combined Adaptation & $\begin{array}{c}-0.616^{* *} \\
(0.256)\end{array}$ & $\begin{array}{c}-0.441^{*} \\
(0.251)\end{array}$ & $\begin{array}{c}-0.201 \\
(0.215)\end{array}$ & $\begin{array}{c}-0.159 \\
(0.221)\end{array}$ \\
\hline Kleibergen-Paap F statistic & 24.768 & 32.222 & 60.005 & 54.699 \\
\hline Serial Correlation & 0.018 & 0.017 & -0.216 & -0.223 \\
\hline Average T & 7.653 & 7.653 & 4.285 & 4.285 \\
\hline Number of Persons & 14227 & 14227 & 14931 & 14931 \\
\hline Number of Observations & 108882 & 108882 & 63975 & 63975 \\
\hline
\end{tabular}

Estimated with Correia's 'reghdfe' command. Individual and year fixed-effects \& (lagged) controls included.

Clustered standard errors in parentheses. $+\mathrm{p}<0.2,{ }^{*} \mathrm{p}<0.10,{ }^{* *} \mathrm{p}<0.050,{ }^{* * *} \mathrm{p}<0.010$ 
Table R.9: Main results, excluding observations with industry/occupation switches

\begin{tabular}{|c|c|c|c|c|}
\hline & $\begin{array}{c}\text { (1) } \\
\text { W.Germany, } \\
\text { instr. HH income, } \\
\text { lagged controls }\end{array}$ & $\begin{array}{c}(2) \\
\text { W.Germany, } \\
\text { instr. HH income, } \\
\text { lagged controls, } \\
\text { indust. \& occup. }\end{array}$ & $\begin{array}{c}(3) \\
\text { UK, } \\
\text { instr. HH income, } \\
\text { lagged controls }\end{array}$ & $\begin{array}{c}(4) \\
\text { UK, } \\
\text { instr. HH income, } \\
\text { lagged controls, } \\
\text { indust. \& occup. }\end{array}$ \\
\hline SR effect of own income & $\begin{array}{l}0.381^{*} \\
(0.217)\end{array}$ & $\begin{array}{l}0.348+ \\
(0.219)\end{array}$ & $\begin{array}{c}0.271^{* *} \\
(0.133)\end{array}$ & $\begin{array}{c}0.332^{* *} \\
(0.136)\end{array}$ \\
\hline LR effect of own income & $\begin{array}{c}0.528^{* * *} \\
(0.144)\end{array}$ & $\begin{array}{c}0.503^{* * *} \\
(0.145)\end{array}$ & $\begin{array}{c}0.325^{* *} \\
(0.143)\end{array}$ & $\begin{array}{c}0.455^{* * *} * \\
(0.153)\end{array}$ \\
\hline Adaptation to own income & $\begin{array}{c}0.147 \\
(0.201)\end{array}$ & $\begin{array}{c}0.155 \\
(0.201)\end{array}$ & $\begin{array}{c}0.053 \\
(0.139)\end{array}$ & $\begin{array}{c}0.123 \\
(0.143)\end{array}$ \\
\hline SR effect of reference income & $\begin{array}{c}0.002 \\
(0.190)\end{array}$ & $\begin{array}{l}-0.010 \\
(0.190)\end{array}$ & $\begin{array}{c}0.109 \\
(0.189)\end{array}$ & $\begin{array}{c}0.120 \\
(0.191)\end{array}$ \\
\hline LR effect of reference income & $\begin{array}{c}-0.191 \\
(0.170)\end{array}$ & $\begin{array}{c}-0.174 \\
(0.171)\end{array}$ & $\begin{array}{l}-0.269 \\
(0.238)\end{array}$ & $\begin{array}{l}-0.236 \\
(0.240)\end{array}$ \\
\hline Adaptation to reference income & $\begin{array}{l}-0.193 \\
(0.213)\end{array}$ & $\begin{array}{l}-0.164 \\
(0.214)\end{array}$ & $\begin{array}{r}-0.379+ \\
(0.240)\end{array}$ & $\begin{array}{r}-0.356+ \\
(0.241)\end{array}$ \\
\hline Combined SR effect & $\begin{array}{l}0.383+ \\
(0.260)\end{array}$ & $\begin{array}{l}0.338+ \\
(0.263)\end{array}$ & $\begin{array}{l}0.381^{*} \\
(0.218)\end{array}$ & $\begin{array}{c}0.452^{* *} \\
(0.219)\end{array}$ \\
\hline Combined LR effect & $\begin{array}{c}0.337^{*} \\
(0.193)\end{array}$ & $\begin{array}{c}0.329^{*} \\
(0.199)\end{array}$ & $\begin{array}{c}0.055 \\
(0.268)\end{array}$ & $\begin{array}{c}0.219 \\
(0.271)\end{array}$ \\
\hline Combined Adaptation & $\begin{array}{l}-0.046 \\
(0.263)\end{array}$ & $\begin{array}{l}-0.009 \\
(0.265)\end{array}$ & $\begin{array}{l}-0.325 \\
(0.255)\end{array}$ & $\begin{array}{l}-0.233 \\
(0.257)\end{array}$ \\
\hline Kleibergen-Paap F statistic & 42.583 & 48.852 & 67.879 & 63.790 \\
\hline Serial Correlation & -0.001 & -0.003 & -0.263 & -0.269 \\
\hline Average $\mathrm{T}$ & 6.489 & 6.489 & 3.792 & 3.792 \\
\hline Number of Persons & 15006 & 15006 & 16222 & 16222 \\
\hline Number of Observations & 97381 & 97381 & 61508 & 61508 \\
\hline
\end{tabular}

Estimated with Correia's 'reghdfe' command. Individual and year fixed-effects \& (lagged) controls included.

Clustered standard errors in parentheses. $+\mathrm{p}<0.2,{ }^{*} \mathrm{p}<0.10,{ }^{* *} \mathrm{p}<0.050,{ }^{* * *} \mathrm{p}<0.010$ 
Table R.10: Main results, excluding respondent observations with second job

\begin{tabular}{|c|c|c|c|c|}
\hline & $\begin{array}{c}\text { (1) } \\
\text { W.Germany, } \\
\text { instr. HH income, } \\
\text { lagged controls }\end{array}$ & $\begin{array}{c}(2) \\
\text { W.Germany, } \\
\text { instr. HH income, } \\
\text { lagged controls, } \\
\text { indust. \& occup. }\end{array}$ & $\begin{array}{c}(3) \\
\text { UK, } \\
\text { instr. HH income, } \\
\text { lagged controls }\end{array}$ & $\begin{array}{c}(4) \\
\text { UK, } \\
\text { instr. HH income, } \\
\text { lagged controls, } \\
\text { indust. \& occup. }\end{array}$ \\
\hline SR effect of own income & $\begin{array}{c}0.699^{* * *} \\
(0.209)\end{array}$ & $\begin{array}{c}0.418^{* *} \\
(0.194)\end{array}$ & $\begin{array}{c}0.258^{* *} \\
(0.100)\end{array}$ & $\begin{array}{c}0.284^{* * *} \\
(0.108)\end{array}$ \\
\hline LR effect of own income & $\begin{array}{c}0.444^{* * *} \\
(0.133)\end{array}$ & $\begin{array}{c}0.382^{* * *} \\
(0.135)\end{array}$ & $\begin{array}{c}0.363^{* * *} \\
(0.115)\end{array}$ & $\begin{array}{c}0.406^{* * *} \\
(0.123)\end{array}$ \\
\hline Adaptation to own income & $\begin{array}{r}-0.255+ \\
(0.194)\end{array}$ & $\begin{array}{l}-0.036 \\
(0.181)\end{array}$ & $\begin{array}{c}0.105 \\
(0.108)\end{array}$ & $\begin{array}{c}0.121 \\
(0.114)\end{array}$ \\
\hline SR effect of reference income & $\begin{array}{l}-0.161 \\
(0.175)\end{array}$ & $\begin{array}{c}-0.134 \\
(0.175)\end{array}$ & $\begin{array}{c}0.061 \\
(0.147)\end{array}$ & $\begin{array}{c}0.058 \\
(0.149)\end{array}$ \\
\hline LR effect of reference income & $\begin{array}{c}-0.343^{* *} \\
(0.163)\end{array}$ & $\begin{array}{c}-0.332^{* *} \\
(0.164)\end{array}$ & $\begin{array}{l}-0.184 \\
(0.183)\end{array}$ & $\begin{array}{l}-0.198 \\
(0.186)\end{array}$ \\
\hline Adaptation to reference income & $\begin{array}{l}-0.182 \\
(0.197)\end{array}$ & $\begin{array}{l}-0.198 \\
(0.197)\end{array}$ & $\begin{array}{r}-0.244+ \\
(0.184)\end{array}$ & $\begin{array}{r}-0.256+ \\
(0.187)\end{array}$ \\
\hline Combined SR effect & $\begin{array}{c}0.538^{* *} \\
(0.244)\end{array}$ & $\begin{array}{c}0.285 \\
(0.236)\end{array}$ & $\begin{array}{c}0.319^{*} \\
(0.165)\end{array}$ & $\begin{array}{c}0.342^{* *} \\
(0.169)\end{array}$ \\
\hline Combined LR effect & $\begin{array}{c}0.101 \\
(0.179)\end{array}$ & $\begin{array}{c}0.050 \\
(0.185)\end{array}$ & $\begin{array}{c}0.180 \\
(0.207)\end{array}$ & $\begin{array}{c}0.207 \\
(0.212)\end{array}$ \\
\hline Combined Adaptation & $\begin{array}{c}-0.437^{*} \\
(0.249)\end{array}$ & $\begin{array}{l}-0.235 \\
(0.242)\end{array}$ & $\begin{array}{l}-0.140 \\
(0.197)\end{array}$ & $\begin{array}{l}-0.135 \\
(0.200)\end{array}$ \\
\hline Kleibergen-Paap F statistic & 36.159 & 45.745 & 113.373 & 101.357 \\
\hline Serial Correlation & 0.013 & 0.015 & -0.191 & -0.197 \\
\hline Average $\mathrm{T}$ & 7.258 & 7.258 & 4.525 & 4.525 \\
\hline Number of Persons & 16612 & 16612 & 18047 & 18047 \\
\hline Number of Observations & 120576 & 120576 & 81671 & 81671 \\
\hline
\end{tabular}

Estimated with Correia's 'reghdfe' command. Individual and year fixed-effects \& (lagged) controls included.

Clustered standard errors in parentheses. $+\mathrm{p}<0.2,{ }^{*} \mathrm{p}<0.10,{ }^{* *} \mathrm{p}<0.050,{ }^{* * *} \mathrm{p}<0.010$ 
Table R.11: Main results, excluding observations with industries/occupations $\leq 50$ observations

\begin{tabular}{|c|c|c|c|c|}
\hline & $\begin{array}{c}\text { (1) } \\
\text { W.Germany, } \\
\text { instr. HH income, } \\
\text { lagged controls }\end{array}$ & $\begin{array}{c}(2) \\
\text { W.Germany, } \\
\text { instr. HH income, } \\
\text { lagged controls, } \\
\text { indust. \& occup. }\end{array}$ & $\begin{array}{c}(3) \\
\text { UK, } \\
\text { instr. HH income, } \\
\text { lagged controls }\end{array}$ & $\begin{array}{c}(4) \\
\text { UK, } \\
\text { instr. HH income, } \\
\text { lagged controls, } \\
\text { indust. \& occup. }\end{array}$ \\
\hline SR effect of own income & $\begin{array}{c}0.681^{* * *} \\
(0.228)\end{array}$ & $\begin{array}{c}0.459^{* *} \\
(0.213)\end{array}$ & $\begin{array}{c}0.266^{* *} \\
(0.103)\end{array}$ & $\begin{array}{c}0.285^{* * *} \\
(0.110)\end{array}$ \\
\hline LR effect of own income & $\begin{array}{c}0.411^{* * *} * \\
(0.141)\end{array}$ & $\begin{array}{c}0.335^{* *} \\
(0.142)\end{array}$ & $\begin{array}{c}0.316^{* * *} \\
(0.122)\end{array}$ & $\begin{array}{c}0.410^{* * *} \\
(0.131)\end{array}$ \\
\hline Adaptation to own income & $\begin{array}{r}-0.270+ \\
(0.209)\end{array}$ & $\begin{array}{l}-0.124 \\
(0.196)\end{array}$ & $\begin{array}{c}0.050 \\
(0.118)\end{array}$ & $\begin{array}{c}0.124 \\
(0.123)\end{array}$ \\
\hline SR effect of reference income & $\begin{array}{l}-0.036 \\
(0.185)\end{array}$ & $\begin{array}{l}-0.039 \\
(0.185)\end{array}$ & $\begin{array}{c}0.153 \\
(0.159)\end{array}$ & $\begin{array}{c}0.179 \\
(0.161)\end{array}$ \\
\hline LR effect of reference income & $\begin{array}{c}-0.285^{*} \\
(0.172)\end{array}$ & $\begin{array}{c}-0.301^{*} \\
(0.173)\end{array}$ & $\begin{array}{l}-0.247 \\
(0.201)\end{array}$ & $\begin{array}{c}-0.272+ \\
(0.204)\end{array}$ \\
\hline Adaptation to reference income & $\begin{array}{c}-0.249 \\
(0.208)\end{array}$ & $\begin{array}{c}-0.262 \\
(0.209)\end{array}$ & $\begin{array}{c}-0.400^{* *} \\
(0.202)\end{array}$ & $\begin{array}{c}-0.451^{* *} \\
(0.205)\end{array}$ \\
\hline SR effect of joint income & $\begin{array}{c}0.645^{* *} \\
(0.262)\end{array}$ & $\begin{array}{c}0.420^{*} \\
(0.254)\end{array}$ & $\begin{array}{c}0.419^{* *} \\
(0.176)\end{array}$ & $\begin{array}{c}0.464^{* * *} \\
(0.179)\end{array}$ \\
\hline LR effect of joint income & $\begin{array}{c}0.127 \\
(0.189)\end{array}$ & $\begin{array}{c}0.034 \\
(0.193)\end{array}$ & $\begin{array}{c}0.069 \\
(0.225)\end{array}$ & $\begin{array}{c}0.137 \\
(0.229)\end{array}$ \\
\hline Adaptation to joint income & $\begin{array}{c}-0.519^{*} \\
(0.265)\end{array}$ & $\begin{array}{c}-0.386+ \\
(0.259)\end{array}$ & $\begin{array}{c}-0.350+ \\
(0.216)\end{array}$ & $\begin{array}{c}-0.326+ \\
(0.220)\end{array}$ \\
\hline Kleibergen-Paap F statistic & 33.608 & 42.677 & 102.876 & 92.887 \\
\hline Serial Correlation & 0.002 & 0.003 & -0.206 & -0.210 \\
\hline Average $\mathrm{T}$ & 6.942 & 6.942 & 4.343 & 4.343 \\
\hline Number of Persons & 16043 & 16043 & 17403 & 17403 \\
\hline Number of Observations & 111370 & 111370 & 75576 & 75576 \\
\hline
\end{tabular}

Estimated with Correia's 'reghdfe' command. Individual and year fixed-effects \& (lagged) controls included.

Clustered standard errors in parentheses. $+\mathrm{p}<0.2,{ }^{*} \mathrm{p}<0.10,{ }^{* *} \mathrm{p}<0.050,{ }^{* * *} \mathrm{p}<0.010$ 
Table R.12: Main results, sample restriced to those with own labour income

\begin{tabular}{|c|c|c|c|c|}
\hline & $\begin{array}{c}\text { (1) } \\
\text { W.Germany, } \\
\text { instr. HH income, } \\
\text { lagged controls }\end{array}$ & $\begin{array}{c}(2) \\
\text { W.Germany, } \\
\text { instr. HH income, } \\
\text { lagged controls, } \\
\text { indust. \& occup. }\end{array}$ & $\begin{array}{c}(3) \\
\text { UK, } \\
\text { instr. HH income, } \\
\text { lagged controls }\end{array}$ & $\begin{array}{c}(4) \\
\text { UK, } \\
\text { instr. HH income, } \\
\text { lagged controls, } \\
\text { indust. \& occup. }\end{array}$ \\
\hline SR effect of own income & $\begin{array}{c}0.569^{* *} \\
(0.224)\end{array}$ & $\begin{array}{l}0.288+ \\
(0.203)\end{array}$ & $\begin{array}{c}0.244^{* *} \\
(0.108)\end{array}$ & $\begin{array}{c}0.220^{* *} \\
(0.109)\end{array}$ \\
\hline LR effect of own income & $\begin{array}{c}0.391^{* * *} \\
(0.147)\end{array}$ & $\begin{array}{c}0.300^{* *} \\
(0.146)\end{array}$ & $\begin{array}{c}0.273^{* *} \\
(0.111)\end{array}$ & $\begin{array}{c}0.273^{* *} \\
(0.118)\end{array}$ \\
\hline Adaptation to own income & $\begin{array}{l}-0.178 \\
(0.200)\end{array}$ & $\begin{array}{c}0.011 \\
(0.184)\end{array}$ & $\begin{array}{c}0.029 \\
(0.110)\end{array}$ & $\begin{array}{c}0.053 \\
(0.112)\end{array}$ \\
\hline SR effect of reference income & $\begin{array}{l}-0.216 \\
(0.190)\end{array}$ & $\begin{array}{c}-0.182 \\
(0.189)\end{array}$ & $\begin{array}{c}0.022 \\
(0.149)\end{array}$ & $\begin{array}{c}0.040 \\
(0.150)\end{array}$ \\
\hline LR effect of reference income & $\begin{array}{c}-0.379^{* *} \\
(0.174)\end{array}$ & $\begin{array}{c}-0.344^{* *} \\
(0.173)\end{array}$ & $\begin{array}{l}-0.239 \\
(0.188)\end{array}$ & $\begin{array}{r}-0.280+ \\
(0.190)\end{array}$ \\
\hline Adaptation to reference income & $\begin{array}{c}-0.163 \\
(0.210)\end{array}$ & $\begin{array}{c}-0.163 \\
(0.210)\end{array}$ & $\begin{array}{c}-0.261+ \\
(0.187)\end{array}$ & $\begin{array}{c}-0.320^{*} \\
(0.188)\end{array}$ \\
\hline Combined SR effect & $\begin{array}{l}0.352+ \\
(0.259)\end{array}$ & $\begin{array}{c}0.107 \\
(0.249)\end{array}$ & $\begin{array}{c}0.266+ \\
(0.169)\end{array}$ & $\begin{array}{l}0.260+ \\
(0.170)\end{array}$ \\
\hline Combined LR effect & $\begin{array}{c}0.012 \\
(0.187)\end{array}$ & $\begin{array}{l}-0.044 \\
(0.192)\end{array}$ & $\begin{array}{c}0.034 \\
(0.208)\end{array}$ & $\begin{array}{l}-0.007 \\
(0.212)\end{array}$ \\
\hline Combined Adaptation & $\begin{array}{c}-0.341+ \\
(0.259)\end{array}$ & $\begin{array}{l}-0.151 \\
(0.252)\end{array}$ & $\begin{array}{c}-0.233 \\
(0.200)\end{array}$ & $\begin{array}{c}-0.267+ \\
(0.201)\end{array}$ \\
\hline Kleibergen-Paap F statistic & 35.289 & 46.075 & 113.270 & 103.420 \\
\hline Serial Correlation & 0.005 & 0.007 & -0.180 & -0.186 \\
\hline Average $\mathrm{T}$ & 7.141 & 7.141 & 4.631 & 4.631 \\
\hline Number of Persons & 15372 & 15372 & 17128 & 17128 \\
\hline Number of Observations & 109776 & 109776 & 79313 & 79313 \\
\hline
\end{tabular}

Estimated with Correia's 'reghdfe' command. Individual and year fixed-effects \& (lagged) controls included.

Clustered standard errors in parentheses. $+\mathrm{p}<0.2,{ }^{*} \mathrm{p}<0.10,{ }^{* *} \mathrm{p}<0.050,{ }^{* * *} \mathrm{p}<0.010$ 


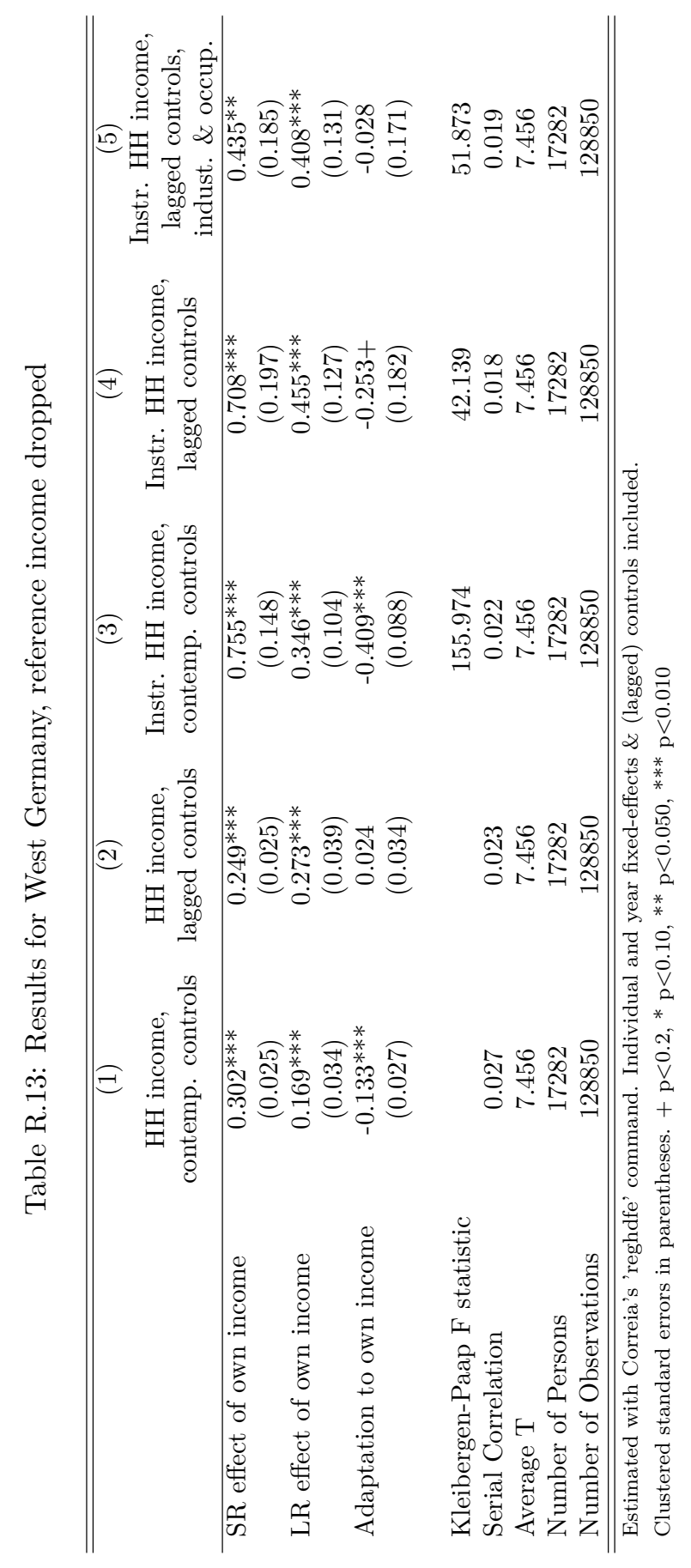




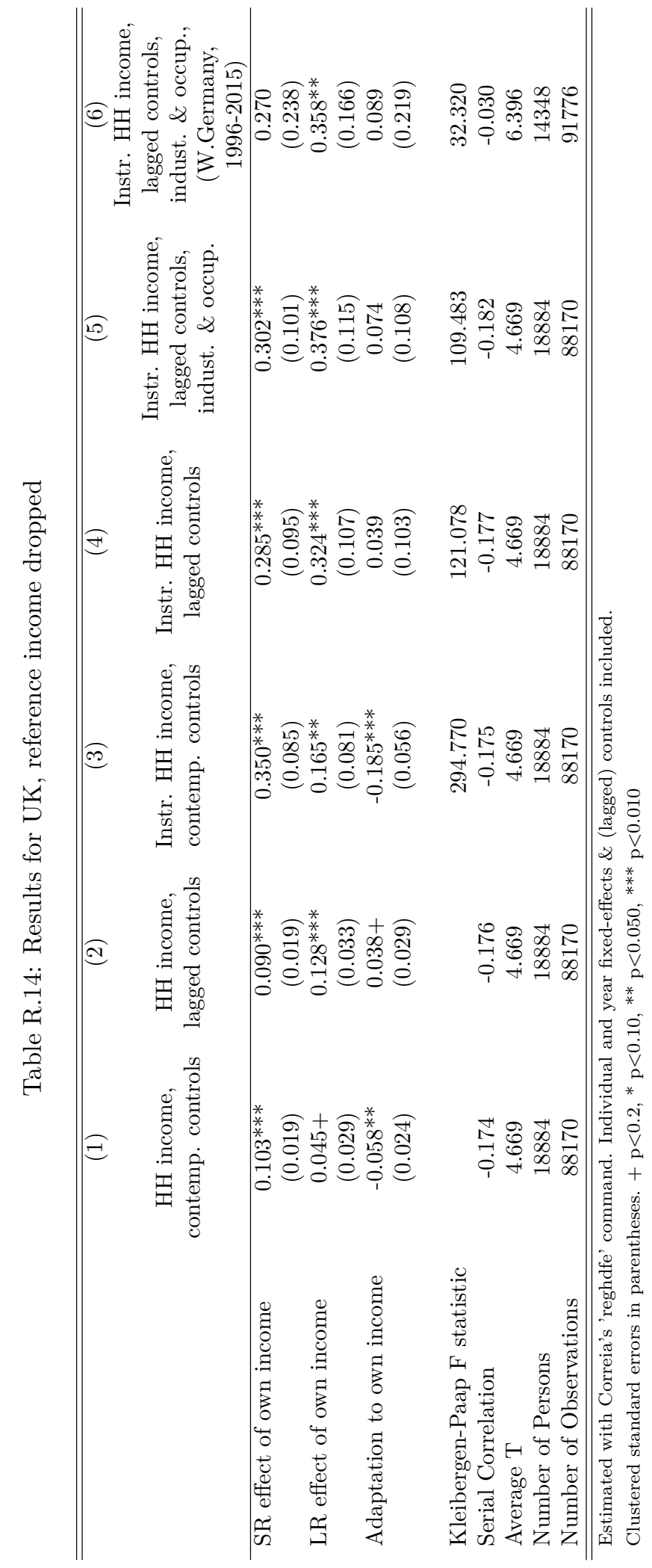


Table R.15: Regressions using observed income and controlling for industry and occupation dummies

\begin{tabular}{|c|c|c|c|c|}
\hline & $\begin{array}{c}(1) \\
\text { W.Germany, } \\
\text { HH income, } \\
\text { indust. \& occup. }\end{array}$ & $\begin{array}{c}(2) \\
\text { W.Germany, } \\
\text { HH income, } \\
\text { lagged controls, } \\
\text { indust. \& occup. }\end{array}$ & $\begin{array}{c}(3) \\
\text { UK, } \\
\text { HH income, } \\
\text { indust. \& occup. }\end{array}$ & $\begin{array}{c}\text { (4) } \\
\text { UK, } \\
\text { HH income, } \\
\text { lagged controls, } \\
\text { indust. \& occup. }\end{array}$ \\
\hline SR effect of own income & $\begin{array}{c}0.298^{* * *} \\
(0.025)\end{array}$ & $\begin{array}{c}0.245^{* * *} \\
(0.025)\end{array}$ & $\begin{array}{c}0.102^{* * *} \\
(0.019)\end{array}$ & $\begin{array}{c}0.089^{* * *} \\
(0.019)\end{array}$ \\
\hline LR effect of own income & $\begin{array}{c}0.168^{* * *} \\
(0.034)\end{array}$ & $\begin{array}{c}0.267^{* * *} * \\
(0.039)\end{array}$ & $\begin{array}{c}0.047+ \\
(0.029)\end{array}$ & $\begin{array}{c}0.128^{* * *} \\
(0.034)\end{array}$ \\
\hline Adaptation to own income & $\begin{array}{c}-0.129^{* * *} \\
(0.027)\end{array}$ & $\begin{array}{c}0.022 \\
(0.034)\end{array}$ & $\begin{array}{c}-0.055^{* *} \\
(0.024)\end{array}$ & $\begin{array}{l}0.038+ \\
(0.030)\end{array}$ \\
\hline SR effect of reference income & $\begin{array}{l}-0.118 \\
(0.158)\end{array}$ & $\begin{array}{l}-0.066 \\
(0.166)\end{array}$ & $\begin{array}{c}0.112 \\
(0.135)\end{array}$ & $\begin{array}{c}0.149 \\
(0.140)\end{array}$ \\
\hline LR effect of reference income & $\begin{array}{c}-0.313^{* *} \\
(0.140)\end{array}$ & $\begin{array}{c}-0.336^{* *} \\
(0.152)\end{array}$ & $\begin{array}{l}-0.098 \\
(0.155)\end{array}$ & $\begin{array}{l}-0.200 \\
(0.178)\end{array}$ \\
\hline Adaptation to reference income & $\begin{array}{c}-0.195+ \\
(0.150)\end{array}$ & $\begin{array}{c}-0.271+ \\
(0.186)\end{array}$ & $\begin{array}{c}-0.211+ \\
(0.129)\end{array}$ & $\begin{array}{c}-0.349^{* *} \\
(0.175)\end{array}$ \\
\hline SR effect of joint income & $\begin{array}{c}0.179 \\
(0.159)\end{array}$ & $\begin{array}{c}0.179 \\
(0.167)\end{array}$ & $\begin{array}{c}0.214+ \\
(0.136)\end{array}$ & $\begin{array}{c}0.239^{*} \\
(0.140)\end{array}$ \\
\hline LR effect of joint income & $\begin{array}{l}-0.145 \\
(0.141)\end{array}$ & $\begin{array}{c}-0.069 \\
(0.155)\end{array}$ & $\begin{array}{c}-0.052 \\
(0.155)\end{array}$ & $\begin{array}{c}-0.072 \\
(0.179)\end{array}$ \\
\hline Adaptation to joint income & $\begin{array}{c}-0.325^{* *} \\
(0.152)\end{array}$ & $\begin{array}{c}-0.248+ \\
(0.188)\end{array}$ & $\begin{array}{c}-0.266^{* *} \\
(0.131)\end{array}$ & $\begin{array}{c}-0.311^{*} \\
(0.177)\end{array}$ \\
\hline Serial Correlation & 0.025 & 0.021 & -0.176 & -0.181 \\
\hline Average $\mathrm{T}$ & 7.456 & 7.456 & 4.669 & 4.669 \\
\hline Number of Persons & 17282 & 17282 & 18884 & 18884 \\
\hline Number of Observations & 128850 & 128850 & 88170 & 88170 \\
\hline
\end{tabular}

Estimated with Correia's 'reghdfe' command. Individual and year fixed-effects \& (lagged) controls included.

Clustered standard errors in parentheses. $+\mathrm{p}<0.2,{ }^{*} \mathrm{p}<0.10,{ }^{* *} \mathrm{p}<0.050,{ }^{* * *} \mathrm{p}<0.010$ 
Table R.16: Main results, using interactions of industry and occupations

\begin{tabular}{|c|c|c|c|c|}
\hline & $\begin{array}{c}(1) \\
\text { W.Germany, } \\
\text { instr. HH income, } \\
\text { lagged controls }\end{array}$ & $\begin{array}{c}(2) \\
\text { W.Germany, } \\
\text { instr. HH income, } \\
\text { lagged controls, } \\
\text { indust. \& occup. }\end{array}$ & $\begin{array}{c}(3) \\
\text { UK, } \\
\text { instr. HH income, } \\
\text { lagged controls }\end{array}$ & $\begin{array}{c}(4) \\
\text { UK, } \\
\text { instr. HH income, } \\
\text { lagged controls, } \\
\text { indust. \& occup. }\end{array}$ \\
\hline SR effect of own income & $\begin{array}{c}0.693^{* * *} \\
(0.132)\end{array}$ & $\begin{array}{c}0.539^{* * *} \\
(0.127)\end{array}$ & $\begin{array}{c}0.254^{* * *} \\
(0.078)\end{array}$ & $\begin{array}{c}0.269^{* * *} \\
(0.083)\end{array}$ \\
\hline LR effect of own income & $\begin{array}{c}0.464^{* * *} \\
(0.105)\end{array}$ & $\begin{array}{c}0.421^{* * *} \\
(0.106)\end{array}$ & $\begin{array}{c}0.185^{* *} \\
(0.090)\end{array}$ & $\begin{array}{c}0.210^{* *} \\
(0.096)\end{array}$ \\
\hline Adaptation to own income & $\begin{array}{c}-0.228^{*} \\
(0.128)\end{array}$ & $\begin{array}{l}-0.117 \\
(0.125)\end{array}$ & $\begin{array}{l}-0.069 \\
(0.088)\end{array}$ & $\begin{array}{l}-0.059 \\
(0.091)\end{array}$ \\
\hline SR effect of reference income & $\begin{array}{c}-0.138 \\
(0.168)\end{array}$ & $\begin{array}{c}-0.124 \\
(0.168)\end{array}$ & $\begin{array}{c}0.096 \\
(0.140)\end{array}$ & $\begin{array}{c}0.104 \\
(0.142)\end{array}$ \\
\hline LR effect of reference income & $\begin{array}{c}-0.397^{* *} \\
(0.154)\end{array}$ & $\begin{array}{c}-0.382^{* *} \\
(0.155)\end{array}$ & $\begin{array}{l}-0.197 \\
(0.176)\end{array}$ & $\begin{array}{l}-0.204 \\
(0.179)\end{array}$ \\
\hline Adaptation to reference income & $\begin{array}{c}-0.259+ \\
(0.188)\end{array}$ & $\begin{array}{c}-0.258+ \\
(0.188)\end{array}$ & $\begin{array}{c}-0.293^{*} \\
(0.176)\end{array}$ & $\begin{array}{c}-0.308^{*} \\
(0.177)\end{array}$ \\
\hline Combined SR effect & $\begin{array}{c}0.554^{* * *} \\
(0.198)\end{array}$ & $\begin{array}{c}0.415^{* *} \\
(0.197)\end{array}$ & $\begin{array}{c}0.350^{* *} \\
(0.151)\end{array}$ & $\begin{array}{c}0.373^{* *} \\
(0.153)\end{array}$ \\
\hline Combined LR effect & $\begin{array}{c}0.067 \\
(0.165)\end{array}$ & $\begin{array}{c}0.039 \\
(0.169)\end{array}$ & $\begin{array}{l}-0.012 \\
(0.192)\end{array}$ & $\begin{array}{c}0.007 \\
(0.195)\end{array}$ \\
\hline Combined Adaptation & $\begin{array}{c}-0.488^{* *} \\
(0.212)\end{array}$ & $\begin{array}{c}-0.376^{*} \\
(0.212)\end{array}$ & $\begin{array}{c}-0.362^{* *} \\
(0.185)\end{array}$ & $\begin{array}{c}-0.367^{*} \\
(0.187)\end{array}$ \\
\hline Kleibergen-Paap F statistic & 136.948 & 151.517 & 167.525 & 158.156 \\
\hline Serial Correlation & 0.021 & 0.020 & -0.177 & -0.182 \\
\hline Average $\mathrm{T}$ & 7.455 & 7.455 & 4.669 & 4.669 \\
\hline Number of Persons & 17264 & 17264 & 18879 & 18879 \\
\hline Number of Observations & 128707 & 128707 & 88152 & 88152 \\
\hline
\end{tabular}

Estimated with Correia's 'reghdfe' command. Individual and year fixed-effects \& (lagged) controls included.

Clustered standard errors in parentheses. $+\mathrm{p}<0.2,{ }^{*} \mathrm{p}<0.10,{ }^{* *} \mathrm{p}<0.050,{ }^{* * *} \mathrm{p}<0.010$

Table R.17: Sensitivity to removal of controls, Germany

Own income

Reference income

\begin{tabular}{lllllll}
\hline Variable omitted & Short-run & Long-run & Adaptation & Short-run & Long-run & Adaptation \\
\hline Number of adults & $0.219^{* *}$ & $0.088+$ & $-0.131+$ & -0.150 & $-0.364^{* *}$ & -0.215 \\
Number of children & $0.408^{* *}$ & $0.346^{* * *}$ & -0.062 & -0.067 & $-0.288^{*}$ & -0.221 \\
Employment status & $0.565^{* * *}$ & $0.464^{* * *}$ & -0.100 & -0.117 & $-0.377^{* *}$ & $-0.260+$ \\
Partner employment status & $0.792^{* * *}$ & $0.460^{* * *}$ & $-0.332^{* *}$ & -0.134 & $-0.344^{* *}$ & -0.210 \\
Age & $0.435^{* *}$ & $0.408^{* * *}$ & -0.028 & -0.095 & $-0.342^{* *}$ & $-0.248+$ \\
Age-squared & $0.398^{* *}$ & $0.363^{* * *}$ & -0.035 & -0.209 & $-0.291^{*}$ & -0.082 \\
Marital status & $0.422^{* *}$ & $0.410^{* * *}$ & -0.012 & -0.101 & $-0.341^{* *}$ & -0.240 \\
Housing tenure & $0.453^{* *}$ & $0.424^{* * *}$ & -0.029 & -0.097 & $-0.343^{* *}$ & $-0.245+$ \\
Working hours & $0.440^{* *}$ & $0.406^{* * *}$ & -0.033 & -0.096 & $-0.339^{* *}$ & -0.243 \\
Ill health & $0.487^{* *}$ & $0.334^{* *}$ & -0.154 & -0.080 & $-0.400^{* *}$ & $-0.320+$ \\
Child birth & $0.364^{* *}$ & $0.387^{* * *}$ & 0.023 & -0.079 & $-0.333^{* *}$ & $-0.253+$ \\
Education & $0.426^{* *}$ & $0.396^{* * *}$ & -0.030 & 0.012 & $-0.234^{*}$ & $-0.247+$ \\
Wave & $0.411^{* *}$ & $0.391^{* * *}$ & -0.021 & $-0.407^{* * *}$ & $-0.617^{* * *}$ & $-0.210^{*}$ \\
Region & $0.434^{* *}$ & $0.407^{* * *}$ & -0.027 & -0.090 & $-0.340^{* *}$ & $-0.250+$ \\
Regional time trend & $0.435^{* *}$ & $0.407^{* * *}$ & -0.027 & -0.080 & $-0.325^{* *}$ & $-0.245+$ \\
\hline
\end{tabular}


Table R.18: Sensitivity to removal of controls, UK

\begin{tabular}{lllllll} 
& \multicolumn{3}{c}{ Own income } & \multicolumn{3}{c}{ Reference income } \\
\hline Variable omitted & Short-run & Long-run & Adaptation & Short-run & Long-run & Adaptation \\
\hline Number of adults & $0.131^{* *}$ & $0.132^{*}$ & 0.001 & 0.110 & -0.192 & $-0.302^{*}$ \\
Number of children & $0.289^{* * *}$ & $0.352^{* * *}$ & 0.063 & $0.200+$ & 0.006 & -0.194 \\
Employment status & $0.316^{* * *}$ & $0.408^{* * *}$ & 0.092 & 0.084 & $-0.282+$ & $-0.366^{* *}$ \\
Partner employment status & $0.377^{* * *}$ & $0.311^{* * *}$ & -0.066 & 0.080 & -0.223 & $-0.303^{*}$ \\
Age & $0.303^{* * *}$ & $0.383^{* * *}$ & 0.080 & 0.115 & $-0.233+$ & $-0.349^{*}$ \\
Age-squared & $0.285^{* * *}$ & $0.346^{* * *}$ & 0.060 & 0.091 & $-0.316^{*}$ & $-0.407^{* *}$ \\
Marital status & $0.257^{* *}$ & $0.353^{* * *}$ & 0.096 & 0.131 & $-0.238+$ & $-0.369^{* *}$ \\
Housing tenure & $0.309^{* * *}$ & $0.390^{* * *}$ & 0.082 & 0.114 & $-0.243+$ & $-0.357^{* *}$ \\
Working hours & $0.298^{* * *}$ & $0.374^{* * *}$ & 0.076 & 0.109 & $-0.255+$ & $-0.364^{* *}$ \\
Ill health & $0.364^{* * *}$ & $0.428^{* * *}$ & 0.064 & 0.128 & $-0.272+$ & $-0.399^{* *}$ \\
Child birth & $0.299^{* * *}$ & $0.381^{* * *}$ & 0.082 & 0.116 & $-0.240+$ & $-0.356^{* *}$ \\
Education & $0.301^{* * *}$ & $0.380^{* * *}$ & 0.079 & 0.072 & $-0.165+$ & $-0.236^{*}$ \\
Wave & $0.306^{* * *}$ & $0.343^{* * *}$ & 0.037 & 0.146 & $-0.642^{* * *}$ & $-0.788^{* * *}$ \\
Region & $0.305^{* * *}$ & $0.380^{* * *}$ & 0.075 & 0.122 & $-0.232+$ & $-0.355^{* *}$ \\
Regional time trend & $0.300^{* * *}$ & $0.378^{* * *}$ & 0.078 & 0.096 & -0.228 & $-0.325^{*}$ \\
\hline
\end{tabular}

